$\because$ THIRTY-SECOND ANNUAL PRIESTLEY LECTURES

\title{
Chloroplast Pigments
}

\author{
and
}

\section{Chromatographic Analysis}

by

Harold H. Strain

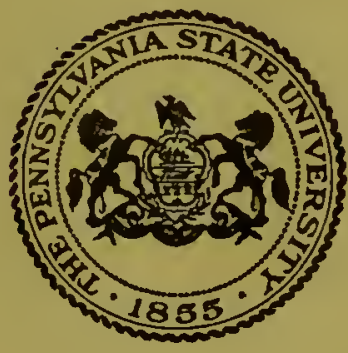

THE PENNSYLVANIA STATE UNIVERSITY

\section{Phi Lambda Upsilon}

and

Associated Departments

QK

899

S 86

UNIVERSITY PARK, PENNSYLVANIA 


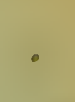


CHLOROPLAST PIGMENTS AND CHROMATOGRAPHIC ANALYSIS

$$
\text { by }
$$

Harold H. Strain

Senior Chemist

Argonne National Laboratory

Lemont, Illinois

Sponsored by

Phi Lambda Upsilon

and

Associated Departments
Agricultural and Biological Chemistry
Fuel Technology
Chemistry
Metallurgy
Chemical Engineering
Mineral Preparation
Ceramic Technology
Petroleum and Natural Gas

The Pennsylvania State University

University Park, Pennsylvania

March 24 to 28,1958 
Copyright 1958

by

Harold H. Strain

Printed in U. S. A。 
1927-PHYSICAL CHEMISTRY AND BIOCOLLOIDS

V. C. Cofman of the Experimental Station of the E. I. du Pont

de Nemours and Company.

1928--PHYSTCAL CHEMISTRY AND METALLOGRAPHY

Dr。 S。 L。 Hoyt of the Research Laboratory of the General Electric Company。

1929 $\rightarrow$ PHYSICAL CHEMISTRY AND MEDICINE

Dr。H。B。 Williams, Head of the Department of Physiology, College

of Physicians and Surgeons, Columbia University。

1930- PHYSICAL CHEMISTRY AND CERAMICS

Dr。 Louise Navias of the Research Laboratory of the General Blectric

Company。

1931 $\rightarrow$ PHYSICAL CHEMISTRY AND ELECTRICAL ENGINEERING

Dr。John W. Williams, Assistant Professor of Chemistry, University

of Wisconsin。

1932 $\infty$ PHYSTCAL CHEMISTRY AND BIOCHEMISTRY

Dr. Victor $\mathrm{K}$. LaMer, Associate Professor of Chemistry, Columbia

University。

1933-0PHYSICAL CHEMISTRY AND METALLURGY

Dr。Erio Ro Jette, Associate Professor of Chemistry, Columbia

University。

1934--PHYSICAL CHEMISTRY AND LIFE PROCESSES

Dr。 Ross A. Gortner, Professor of Agricultural Biochemistry,

University of Minnesota。

1935- $\rightarrow$ PHYSTCAL CHEMI STRY AND ELECTRO-METALLURGY

$\mathrm{Dr}$. Matthew A。 Hunter, Professor of Electro-chemistry and Head of

the Department of Physics and Electrical Engineering, Rensselaer

Polytechnic Institute。

1936 -PHYSICAL CHEMISTRY AND CHEMICAL ENGINEERING

Dr。 Warren $\mathrm{K}$ 。 Lewis, Professor of Chemical Engineering, Massachusetts

Institute of Technology。

1937- - PHYSICAL CHEMISTRY AND BIOCHEMISTRY

Dr。G。H。A。Clowes, Researoh Director, Eli Lilly and Company。

1938-0REACTIONS IN SOLID ALLOYS

Dr。 Robert F。 Mehl, Head of the Department of Metallurgy and

Director of Metals Research Laboratory, Carnegie Institute of

Technology。

1939 -PHYSICAL CHEMISTRY OF CELL MEMBRANES

Dr。 Kenneth S. Cole, Assooiate Professor of Physiology, Columbia

University。 
1940-PHYSICAL METALLURGY IN THE SERVICE OF INDUSTRY

Dr。 Oscar E。 Harder, Assistant Director, Battelle Memorial Institute, Columbus, Ohio。

1941 $\rightarrow$ THE PHYSICAL AND CHEMICAL BASIS OF NERVE ACTION

Dr. Detlev $W_{0}$ Bronk, Chairman of Department of Physiology and

Biophysics, Cornell University Medical College, New York。

1942--SYNTHESES FROM ALIPHATIC HYDROCARBONS

Dr。 H. B. Hass, Professor of Organic Chemistry and Head of Department of Chemistry, Purdue University。

1943-RESEARCHES IN ELECTROCHEMISTRY

Dr。 Duncan A. MacInnes, Member of the Rockefeller Institute for Medical Research。

1944-ORECENT DEVELOPMENTS IN ORGANIC CHEMISTRY

Dr。 Herman A. Bruson, Resinous Products and Chemical Company。

1945--CHEMICALS AND FOOD PRODUCTION

P. H. Groggins of the War Food Administration.

1946--VI RUSES

Dr。 Max A. Lauffer, Associate Research Professor Physics, The

University of Pittsburgh.

1947--PHYSICAL CHEMISTRY AND TECHNOLOGY OF FUELS

Dr。Alfred W. Gauger, Professor of Fuel Technology and Director,

Mineral Industries Experiment Station, The Pennsylvania State

University。

1948--THE DEVELOPMENT OF THEORETICAL ELECTROCHEMISTRY

Dr。 Raymond Mo Fuoss, Sterling Professor of Chemistry, Yale University。

1949-ACIDS, BASES, AND NON-AQUEOUS SYSTEMS

Dr。 Ludwig F。 Audrieth, Professor of Inorganic Chemistry, The

University of Illinois.

1950--PETROLEUM AND ITS PRODUCTS

Dr. William J. Sweeney, Vice President Standard Oil Development

Company。

1951--A SYMPOSIUM ON DEVELOPMENTS IN APPLIED CHEMISTRY

Dr. Grover C. Chandlee, Professor Emeritus of the Department of Chemistry, The Pennsylvania State University。

Dr。 Pauline Berry Mack, Di rector of the Ellen Ho Richards Institute, The Pennsylvania State University。

Dr。 Herbert.E. Longenecker, Dean of the Graduate School, University of Pittsburgh。

Dr. Woldemar A. Weyl, Head of the Department of Mineral Technology, The Pennsylvania State University。 
Dr. Merrell R. Fenske, Director of the Petroleum Refining Laboratory,

The Pennsylvania State University。

1952--RADIOACTIVE ATOMS AND ISOTOPIC TRACERS

Dr. Joseph W. Kennedy, Chairman, Department of Chemistry, Washington University。

1953-INNOVATIONS IN ELECTROANALYTICAL CHEMTSTRY

Dr。 James J。 Lingane, Professor of Chemistry, Harvard University。

1954--PROBLEMS IN THEORETICAL ORGANIC CHEMISTRY

Dro Fritz G. Arndt, Professor of Chemistry, The New University of Istanbul, Istanbul, Turkey.

1955--BIOLOGICAL POLYMERS

Dr。 Paul Doty, Associate Professor of Chemistry, Harvard University.

1956-0FAST CHEMICAL REACTIONS

Dr. George B. Kistiakowsky, Abbott and James Lawrence Professor of Chemistry, Harvard University.

1957-CHEMISTRY IN THE METALLURGY OF IRON AND STEBL

Dr。 John Chipman, Professor of Metallurgy, Massachusetts Institute

of Technology.

Copies of these previous lectures have been printed in expanded form. They may be ordered from Phi Lambda Upsilon, Department of Chemistry, The Pennsylvania State University, University Park, Pennsylvania。 

Joseph Priestley, theologian, philosopher, and soientist, was born in England on April 13, 1733. He was ordained as a Presbyterian minister, but later rejected Calvanism and adopted Unitarian views. He studied ohemistry and electricity at Warrington Academy. He was given an honorary LL。D。 by Edinburgh University in $17 \alpha_{4}$ and became a Fellow of the Royal Society in 1766. In 1774 his chemical experiments produced "dephlugisticated air", which Lavoisier named oxygen. Priestley's openly expressed sympathy with the aims of the French Revolution led, in 1791, to the wrecking of his home and the destruction of his library and scientific apparatus. In 1794 he emigrated to America and settled in Northumberland, Pennsylvania, where he built a home on the banks of the Susquehanna River. Here he continued his writing and chemical experimentation until his death in 1804.

In 1919, the alumni of the Chemistry Department of The Pennsylvania State University purchased the Priestley residence at Northumberland。 Near the house, a museum was built to preserve auch relics of Joseph Priestley as could be obtained, and then the property was deeded to the University to assure permanent maintenance of this memorial. Since the Priestley home is about seventy miles from State College, it was felt that the establishment of a less remote memorial would be desirable。 Dr。 Wheeler Po Davey, Research Professor of Chemistry and Physics, suggested the establishment of a series of lectures marking the anniversary of Priestley"s birth. In 1955 the University deeded the Priestley residence to the Borough of Northumberland which maintains the home as a public museum。

In April, 1927, the Priestley Lectures were inaugurated at The Pennsylvania State University under the sponsorship of Dr。 Davey and other members of the faculty of the Department of Chemistry。 In 1931, Mu chapter of Phi Lambda Upsilon, honorary chemical society, assumed the financial responsibility for the lecture series under co-sponsorship with Associated Departments.

The original concept for the Priestley Lecture Series was threefold in nature: (1) to establish a living memorial for Joseph Priestley; (2) to honor a succession of contemporary American Scientists: (3) to demonstrate that tineoretical chemistry was a vital functional part of modern applied chemistry.

An invitation to become a Priestley Lecturer indicates that the recipient is a recognized authority in a rather broad field, is an accomplished lecturer, and has the ability to present his material so that it is intelligible and stimulating to the college junior as well as interesting and informative to specialists in narrower segments of the same field. Men who have all these qualifications are indeed members of a very select company。

In dedioating this series of lectures to the memory of Joseph Priestley, Mu chapter of Phi Lambda Upsilon acknowledges with humble gratitude the services of the Priestley Lecturers, past and future, who make this memorial possible。 



\section{ACKNOWLEDGMENTS}

The studies of the chloroplast pigments of various organisms were carried out under the auspices of the Carnegie Institution of Washington at the Department of Plant Biology located at Stanford, California. They were pursued during one sumer at the Marine Laboratory of the University of Hawail. The extension and application of the chromatographic methods to inorganic separatory problems were the result of work performed under the auspices of the U. So Atomic Energy Commission at the Argonne National Laboratory, Lemont, Illinois 。

Leaves from many species of cycads were provided by the greeno houses of the University of Chicago.

A large number of interested colleagues aided in the culture, collection, and identification of various species, in the development of analytical techniques, and in the disoussion and correlation of the results. In this brief acknowledgment, the nature of these contribus tions can only be indicated. The significance of this assistance is revealed by the investigations themselves and by their usefulness in other fields such as analysis, photosynthesis, physiology, and taxonomy。 
Dr. Isabella A. Abbott aided in the collection and identification of Hawailan species of various algae.

Dr。 L。 R。 Blinks provided algal species from the Hopkins Marine Station。 Drs. JoC.Clausen, D。 D。 Keck, and $W_{0} M$. Hiesey made numerous collections in the Sierra Nevada Mountains. They assisted in the identification of various speoies and in the presentation of the observations.

Dr. M. S。 Doty collected Dichotomosiphon from Lake Michigan。

Dr。 F。 Drouet identified certain blue-green algae。

Dr。Lois Eubank Egerod identified Hawaiian species of green algae and contributed helpful advice in the classification of these organisms.

Drs.S。A。Gordon, J。Van Overbe日k, and H。E. Warmke collected algal species at Puerto Rico.

Dr。H.W. Graham examined collections of dinoflagellates。

Dr。 R。 Wo Hiatt arranged for collections by dredging at Hawaii。

Drs. Wo Mo Manning and Go Hardin collaborated in the first pigment studies with algae and provided much of the incentive for continuation of the investigations。

Mr。H.Wo Milner cultured several green and blue-green algae。

Dr. L。 Jo Muliins arranged for the collection of algae at Naples。

Miss Marie $C_{0}$ Neal identified many of the plant species collected in the Hawaiian Islands。

Dr。G。F。 Papenfuss enoouraged the correlation of pigment investigations with taxonomic studies。

Dr。 
Dr. G. M. Smith identified the marine and freshwater algae collected on the Pacific Coast. He supplied cultures of Chlamydomonas and Protosiphon, and he provided indispensable encouragement and advice.

Dr. L. G. Williams collected algae at North Carolina.

Dr. Ro D. Wood identified the one available species of Chara.

At the Argonne National Laboratory,

Dr. W. M. Manning encouraged the development and application of differential migration methods of analysis. Mr. $H_{0}$ Diamond, Mr. J. Engelke, Dr. G. H. Evans, Dr. G. W. Murphy, Mr. T。R。 Sato, Mr. P. A. Sellers, Mr. J. C. Sullivan, and Dr. S. E. Wood investigated various aspects of these differential migration methods. 

TABLE OF CONTENTS

I. Significance of Chloroplast Pigments and of Methods for Their Separation ..............................

II. Chromatographic Methods and the Chloroplast Pigments of Higher Plants and Green Algae ......................

III. Pigments of Algae and Chromatography of Altered Chloroplast Pigments ...............................

IV. Chloroplast Pigments and the Modifications of Chromatography $\ldots \ldots \ldots \ldots \ldots \ldots \ldots \ldots \ldots \ldots \ldots \ldots \ldots \ldots \ldots \ldots \ldots \ldots$

V. Electrochromatography and Analogous Differential Migration Methods of Analysis ........................ 107

\section{APPENDICES:}

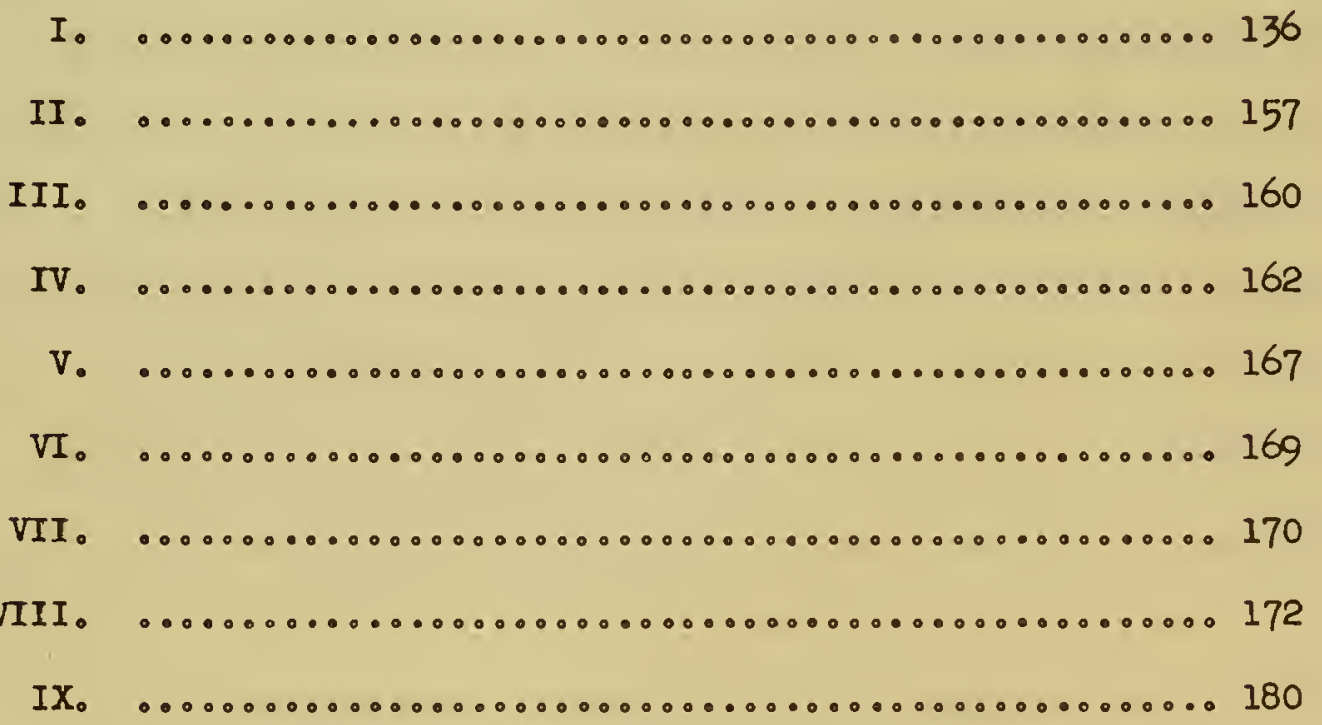





\section{SIGNIFICANCE OF CHLOROPLAST PIGMENTS AND OF METHODS}

\section{FOR THEIR SEPARATION}

\section{PHOTOSYNTHESIS REVEALED BY ANALYSIS}

Priestley's Contributions

These annual Priestley lectures, sponsored jointly by the Pennsylvania State University and by the Mu Chapter of Phi Lambda Upsilon provide a dynamic memorial to an outstanding chemist in America. They also provide a unique opportunity for the presentation of scientific accomplishments in specialized fields. They permit the elaboration of many aspects of these accomplishments that are frequently unsuited for the specialized publications of this day.

It is not surprising that many of the preceding lecturers in this series have traced the beginnings of their science to the work of Joseph Priestley and his contemporaries. The discovery of dephlogisticated air by Priestley and by Scheele in 1774 marked a key point in chemical progress. The recognition of dephlogisticated air as a chemical element, named oxygen by Lavoisier in 1776, helped clarify the nature of air, the nature of combustion and oxidation, the characteristics of respiration, and the features of photosynthesis (the assimilation of carbon dioxide or fixed air by green plants with the concomitant production of dephlogisticated air).

Priestley is famous not only for the basic nature of his scientific experiments but also for his defense of an erroneous concept. His keen observations on the properties of gases and on the nature of gaseous exchange stand in sharp contrast to his stout support of the phlogiston theory. Nonconformist as a minister, Priestley ironically championed the phlogiston theory in the face of increasing contrary evidence, much 
of which he provided by his own discovery of oxygen. But in the absence of adequate concepts concerning heat, work and energy, Priestley recognized that combustion, respiration and photosynthesis presented many baffling aspects in addition to the gaseous exchange processes that are involved $1,2,3$.

With conflicting views on religion, on scientific observations, and on scientific interpretation, Priestley was also intensely concerned with the stirring political changes that were taking place in Franoe and in the American Colonies. At the time of his discovery of oxygen, he probably could not foresee that these incongruent interests would drive him to emigrate to the United States just 20 years later. Nor could he know, even by the time of his death in 1804, that science was destined to rank with religion and government in its effect upon human affairs.

\section{Complexity of Oxygen Revealed by Analysis}

With the development and application of analytical methods, Priestley's dephlogisticated air was found to be our most abundent chemical element. It comprises about 89 per cent of the waters of the earth, about half of the rocks and soils, and about one fourth of the atmosphere by weight. It has become the standard to wnich the chemical atomic weights of all the other elements are referred. As a standard reference for these chemical atomic weights, oxygen was given the atomic weight of 16 exactly. But after a century of intensive chemical investigations, the value of the atomic weight assigned to oxygen was found to be in error. This error, like the erroneous concept of phlogiston, was based upon limited experimentation and upon concepts that appeared reasonable in the light of the available information. The error in the presumed 
atomic weight of oxygen was due to the fact that orygen as it occurs in nature, either free or combined, is a mixture. It is a mixture of isotopes that differ in atomic weight and that are not readily detectable or separable by chemical methods.

With the development of the mass spectroscope during 1918-1920, oxygen was found to be a mixture of three isotopes $0^{16}, 0^{17}$, and $0^{18}$, the $0^{16}$ comprising about 99.759 per cent of the mixture. Natural oxygen is, therefore, just a little heavier than the $0^{16}$ isotope, which is the reference standard of the physicists. For this reason, the atomic weights employed by the chemist are a little heavier than the atomic weights employed particularly by the nuclear physicists and nuclear chemists. Specifically these chemical atomic weights are heavier than the physical isotopic weights by a factor of $1.000272 \pm 0.000005$ or 272 units in $1,000,000$ or about 3 in 10,000 .

This difference between the basic physical and chemical atomic weights arose primarily because of the limitations of the analytical techniques that were available to the chemist. It is but one of many illustrations showing that analysis is an indispensable step in the resolution of mixtures and in the description of the components 4,5 . Analysis and the Interpretation of Photosynthesis

From the academic standpoint of correlation, interpretation, and instruction, the role of analysis in the physical, chemical and biological sciences is frequently overlooked. But from the technical standpoint of investigation and discovery, analysis often plays a critical role. It defines and establishes the progress that has been made. It brings to light new observations and new materials that continually 
provide the grist for the mill of scientific progress ${ }^{5}$.

At Priestley's time, the controversies about the chemical nature of combustion, respiration, fermentation and photosynthesis resulted largely from the lack of methods for the separation of gaseous mixtures. For example, the physiologists, the observant physicians of that day, soon recognized that animals consumed dephlogisticated air leaving spent air or phlogisticated air, our nitrogen, and fixed air ${ }^{3}$. Fixed air, obtainable from carbonates and from fermentation, was only gradually recognized as a product of combustion and an oxide of carbon ${ }^{l}$.

The early difficulties in the elucidation of gaseous reactions may be ascribed not only to the lack of analytical techniques for the separation and identification of gases but also to the deficiency of methods for the establishment of their chemical composition. Even today chemists and graduate students do not have a ready answer to the question, "How may one determine the chemical composition of carbon dioxide?"

Gradual progress in the chemical analysis of gaseous mixtures led, eventually, to a sound chemical understanding of gaseous exchange in combustion, respiration, fermentation, and photosynthesis. Through analysis by quantitative chemical methods, combustion (particularly of organic substances) and respiration were characterized as processes involving the consumption of oxygen. Combustion was oxidation accompanied by the liberation of heat or energy. Respiration was controlled, biochemical oxidation accompanied by the production of work and heat. As the carbon compounds of plant material have an average composition roughly equivalent to carbohydrate, the over-all processes of respiration may be written as a chemical equation, namely, 


$$
\begin{gathered}
-5- \\
\left(\mathrm{CH}_{2}=\mathrm{O}\right)_{\mathrm{x}}+\mathrm{xO}_{2} \rightarrow \mathrm{xCO}_{2}+\mathrm{xH}_{2} \mathrm{O}+\text { (Heat)。 }
\end{gathered}
$$

With respect to the gaseous chemical exchange, photosynthesis by green plants was the reverse of combustion and respiration. It was the absorption and utilization or assimilation of carbon dioxide and the liberation of oxygen. But this assimilation of carbon dioxide with the production of organic matter and oxygen differed greatly from the spontaneous combustion and respiration, because it occurred only in the green parts of plants and only in the presence of sunlight $1,2,3$. Once the gaseous exchange phenomena had been elucidated as chemical processes, special efforts were made to elucidate the mechanism of combustion, respiration, fermentation, and photosynthesis as a series of successive chemical reactions. These efforts led to two important lines of investigation. One course of investigation had as its objective the discovery of the chemical steps through which the exchange of gases leads to the formation and degradation of the carbon compounds of organic matter. The other line of investigation, beginning after the concept of phlogiston had deteriorated, had as its objective the use of the concept of energy or work to interpret the reactions.

The attempts to elucidate the chemical steps of combustion and respiration gradually led to the discovery of many internediate reactions involving oxidation. In respiration, many of these steps are dependent upon the enzymatic regulatory systems of the living cells. In some of these steps, oxidation reactions are linked with equivalent reduction reactions so that reduced substances and oxidized substances are produced simultaneously。 Similar, intermolecular, oxidation-reduction or dismutation reactions were found to be an integral part of most 
fermentation processes, particularly those that occur in the absence of air, as for example, alcoholic fermentation, in which a part of the sugar molecule is reduced to alcohol and another part is oxidized to carbon dioxide. In all these processes, virtually all the intermediate steps are spontaneous; biologically controlled, exothermic reactions.

With respect to the gaseous exchange process, photosynthesis proved to be the reverse of respiration, because it results in the assimilation of carbon dioxide and the evolution of oxygen. With respect to the nutrition of plants, photosynthesis is also the reverse of respiration, for it restores the cellular material and the energy that are depleted by respiration. But with respect to mechanism, photosynthesis incorporates a single powerful driving force that is absent in respiration. This driving force is sunlight, which, as has been noted above, is effective only in the green parts of plants $1,2,3$.

\section{CHLOROPLAST PIGMENTS AND PHOTOSYNTHESIS}

\section{Function of the Chloroplast Pigments}

When photosynthesis was found to result from the energy of absorbed sunlight, many attempts were made to elucidate the energy absorption mechanism。 The principles of the new field of photochemistry indicated that the green pigment of plants (chlorophyll - the green of leaves) must be an active photochemical intermediate, because to be effective in photosynthesis, sunlight must be absorbed, and only colored substances absorb this visible light。

With the development of the microscope, the green pigment of plants was seen to be localized in microscopic bodies or plastids within the plant cells. These green plastids were called chloroplasts, and 
the pigments which they contain were called chloroplast pigments.

From these observations, chloroplast pigments are the primary absorbers of light by plants. The chloroplasts are the transformers of absorbed radiant energy into chemical energy. The raw materials are the carbon dioxide of the atmosphere and the water of the plant. The final products are organic matter, that is supplied to the plant cells, and gaseous oxygen. As green plants provide the organic food for viro tually all the other living things, chloroplast pigments are an indispensable link in the chain of unique organizational forces that characterize living organisms ${ }^{6}$. From a chemical standpoint, the over-all process of photosynthesis could, therefore, be written

$$
\begin{aligned}
& \text { Sunlight }+(\text { Pigments })+x \mathrm{CO}_{2}+\mathrm{xH}_{2} \mathrm{O} \longrightarrow \\
& (\text { Pigments })+\left(\mathrm{CH}_{2}=\mathrm{O}\right)_{x}+\mathrm{xO}_{2} \text {. }
\end{aligned}
$$

Properties of the Chloroplast Pigments

Because of their basic role in Nature, chloroplast pigments have been the subject of many intensive investigations. For the interpretation of their photosynthetic reactions, the pigments were extracted from plants, and many attempts were made to isolate them in a state of high purity $7,8,9$. This line of investigation led not only to the discovery of a number of chloroplast pigments but also to the development of several selective separatory methods that were destined to serve for the separation and purification of all kinds of chemical substances. These analytical techniques have now become indispensable tools for most investigations concerned with cherical compounds and their reactions 5 .

Chloroplast pigments proved to be remarkably sensitive and labile substances. They were destroyed by many chemical reagents and by many 
reactive solvents. They were preferentially soluble in fats, and, therefore, their extraction from plant material required the use of fat solvents. With fresh plant material, it was necessary to employ solvents that also removed the water of the plant tissue as, for example, methanol, ethanol, or acetone. With freshly dried plant material, water-immiscible solvents, such as carbon disulfide, benzene, ether and petroleum ether could also be employed as extractants.

Multiplicity of the Chloroplast Pigments

For a long time, there was thought to be but a single pigment in photosynthetically active plants; namely, the green of leaves or chlorophyll. But as new separatory methods were applied to the extracts of various plants, several green pigments and many yellow ones were found. Both in plant extracts and in the chloroplasts themselves, the green pigments obscure the yellow ones. The green pigments are called chlorophyl1s 7,9. The yellow pigments are members of a large group of polyene pigments known as carotenoids. These chloroplast carotenoids are subdivided into two subgroups, the carotenes or polyene hydrocarbon carotenes or polyene hydrocarbon carotenoids, typified by the carotenes of carrot roots, and the xanthophylls or oxygen derivatives of the carotenes, typified by the xanthophylls or leaf yellow of autumn leaves 7,8 , $9,10,11,12$. Many pigments, representative of these three groups, have now been found in various plants, particularly in the algae9. Each kind of plant usually contains one or two chlorophylls, several xanthophylls and one or more carotenes 9.

A very large number of the carotenoids, especially the xanthophylls, occur in yellow specialized plant organs such as yellow flowers, fruits, 
and roots ${ }^{11}$, in yellow autumn leaves after the natural fading of the chlorophylls 10 , and in yellow etiolated leaves grown without chlorophyll in the dark. But in these yellow organs without chlorophyll there is no photosynthesis in the presence of sunlight。

In spite of the effectiveness of the separatory methods developed for the examination of the chloroplast pigments, no single separatory procedure has been found to serve for the separation of all these pigments obtained from a single plant. It has been necessary to combine several methods or modifications of the methods to effect oomplete separations。

ANALYTICAL METHODS FOR ISOLATION OF CHLOROPLAST PIGMENTS

Separation of Pigments by Partition between Immiscible Solvents

An effective method for the partial separation of the chloroplast pigments depends upon their distribution or partition between two immiso cible solvents 7,8 . As early as 1864 , Stokes shook an alcoholic extract of fresh leaves with carbon disulphide, which was immiscible with the aqueous alcohol, and observed that some of the green pigment was removed preferentially in the carbon disulfide layer. This pigment, ohlorophyll a, was spectrally different from the green pigment that remained in the alcohol, chlorophyll b. Upon continued extraction of the aqueous alcow hol with fresh batches of carbon disulfide, all the green was removed, and a yellow alcoholic solution remained. This yellow solution contained the alcohol-soluble xanthophylls, or oxy carotenoids, which could be fractionated further by continued batchwise extraction with carbon disulfide。 
In 1872 the partition of leaf pigments between benzene hydrocarbons and aqueous alcohol was reported independently by Kraus and by Konrad. And in 1873 Sorby re-examined the chloroplast pigments by partition between alcohol and carbon disulfide and found a series of yellow xanthophylls in addition to the chlorophylls. He regarded the separation of the chloroplast pigments by partition and their description by spectroscopic studies as different from the usual analytical investigations. He, therefore, proposed a new name for these studies of the pigments; namely, comparative vegetable chromatology 13 .

By 1877 Sachsse utilized aqueous alcohol and petroleum ether for the separation of the chloroplast pigments. And in 1913 willstltter and Stoll summarized the large scale partition and crystallization procedures that they had employed for the preparation of solid chlorophyll a and b, crystalline carotene and crystalline xanthophyll 7,8. Efficient as the partition procedure proved to be, it failed to separate the carotenes from the chlorophyll a. It also failed to separate the carotenes from one another. It required repeated application to effect a partial separation of the xanthophylls from one another. Unless special care was exercised some of the xanthophylls were lost in the aqueous layers that were discarded 10 .

Separations by Chemical Roactions Plus Partition between Immiscible

Solvents

Chemical alteration of the green pigments followed by partition of the alteration products between immiscible solvents has long facilitated the separation and isolation of the carotenes and xanthophylls $7,8,10$. In 1860, four years before Stokes' partial separation of the ohloroplast 
pigments by partition alone, Fromy had observed that strong hydrochloric acid and ether acting upon the residue from an alcohol extract of leaves yielded a yellow ether solution and a blue acid solution of the altered green pigments. This partition procedure with chemical reaction was soon modified through use of alkalies as the reagents for alteration of the chlorophyll. By saponification of the chlorophylls with caustic alkalies and partition of the products between diethyl ether and aqueous alcohol, the yellow carotenoids could be transferred to the ether while the green saponified chlorophyll remained in the aqueous layer。 In ano other modification, the green pigments were saponfied in alcohol, the xanthophylls and carotenes were transferred to petroleum ether, and then the xanthophylls were separated from the carotenes by extraction from the petroleum ether with aqueous methanol. Numerous modifications of these saponification plus partition methods have been adapted to the preparation and estimation of the xanthophyll mixture and the carotene mixture in extracts of leaves $7,8,9,10,11$. But with some of the algae, as the brown algae, the principal xanthophylls are also decomposed by alkalies along with the chlorophylls; hence saponification followed by partition is not a universally applicable procedure for the isolation of carotenes and xanthophylls 9 .

\section{Separations by Batchwise Selective Absorption}

Selective absorption of chlorophylls from extracts of leaves pero mitted the separation of the green pigments from the carotenoids ${ }^{8}$. Stokes observed in 1864 that the addition of sorptive aluminum hydrox ide to leaf extracts removed the green pigments and left the yellow ones. In the next year Fromy observed that both magnesium hydroxide 
and aluminum hydroxide carried down the chlorophyll in alcoholic extracts of leaves lesving only the yellow pigments in solution. And in 1868 Filhol found that animal charooal or bone black removed the green pigments preferentially from an alcoholic extract of leaves. Addition of charcoal in quantity insufficient to decolorize the extracts yielded a yellow solution containing a mixture of carotenold pigments。

\section{Separations by Chromatographic Adsorption Analysis}

In 1903 and 1906, the Russian botanist Mo Tswett described a particularly selective adsorption procedure that permitted extensive resolution and recovery of the chloroplast pigments. For these separations, Tswett employed an adsorption column, a glass tube constrioted at one end and filled with firmly packed, finely divided, surface-active adsorbents suoh as powdered inulin, powdered sugar or precipitated chalk. With the adsorption column attached to a suction flask, a little of a petroleum ether or carbon disulfide extract of dried leaves was filtered into the column, wherein the pigments were adsorbed as a narrow band near the top. These adsorbed pigments were then washed with fresh solvent, so that, owing to their selective adsorption, they were carried along at different rates and formed a series of colored zones as indicated in Figure I, l。 The weakly sorbed pigments, principally the carotenes, were washed through the column and collected separately in successive portions of the percolate. The zones of the more sorbed pigments were removed separately from the column, and the pigments were eluted from the sorbent with alcohol.

The washing of the narrow zone of adsorbed pigments with fresh solvent was called "die Entwicklung" or development of the chromatogram. 
Figure I, 1。 Successive steps in the formation of a chromatogram. Chloroplast pigments, of leaves, dissolved in petroleum ether, adsorbed in a colunn of powdered sugar (left) and washed with petroleum ether containing 0.5 per cent n-propanol (conter and right)。
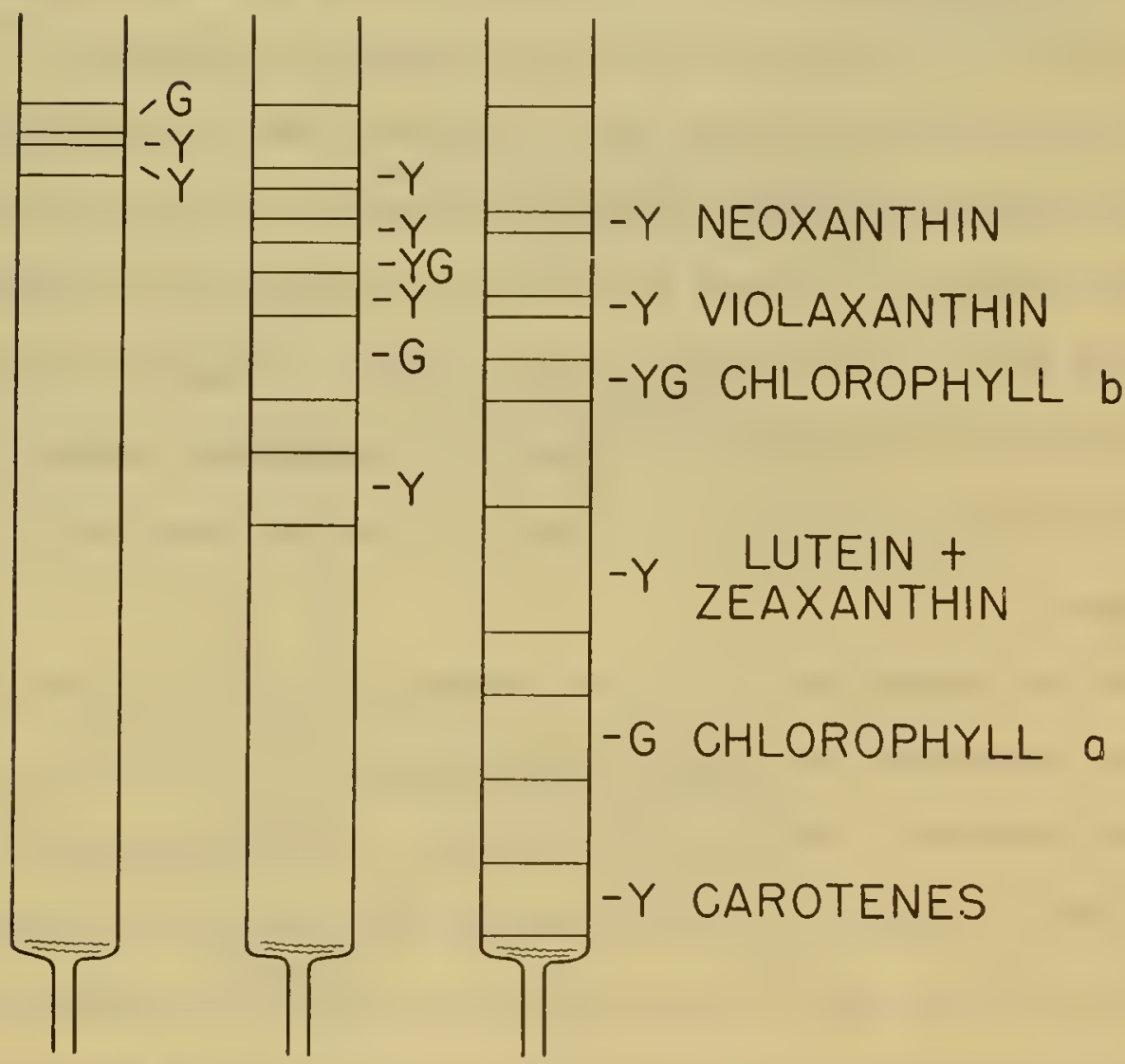
It represented an important modification of earlier columnar adsorption procedures in which only the solution of the mixture was filtered through the adsorption column. It made possible the extensive resolution of complex mixtures and the recovery of the separated components 5 . Tswett recognized that his separation procedure depended upon the selective adsorption of the pigments. As the separations revealed the presence of colored substances, he called his method "chromatographische Adsorptionsanalyse" or chromatographic adsorption analysis, now frequently condensed to chromatographic analysis or chromatography. Tswett also recognized that colorless substances as well as pigments were separated by the chromatographic adsorption procedure.

With his mild adsorbents Tswett separated two chlorophylls, three or four xanthophylls and the carotene mixture from leaf extracts. At the time, it was not realized that the leaf carotene was frequently a mixture of two or more isomeric pigments, alpha-carotene and beta-carotene, and that two xanthophylls, lutein and zeaxanthin, usually form a single zone when adsorbed under the mild conditions described by Tswett. (See Figure I, 1.)

For the separation of the leaf carotene, more active and more selective adsorbents were needed. These were found in the form of specially activated, finely powdered alumina, lime or magnesia15. With columns of specially activated magnesium oxide (Micron Brand Magnesium Oxide No. 264l) and with petroleum ether as solvent, the mixtures of carotenes in leaf extracts could be resolved without preliminary separation from the other leaf pigments ${ }^{10}$, as indicated in Figure I,2.

Mixtures of lutein and zeaxanthin, which were not separable in 
Figure I,2。 Carotenes separated by chromatographic adsorption of chloroplast pigments in a column of activated magnesia plus celite ( $1: 2$ by weight)。 Pigments adsorbed from petroleum ether and washed with petroloum ether con taining about 1 per cent acetone。

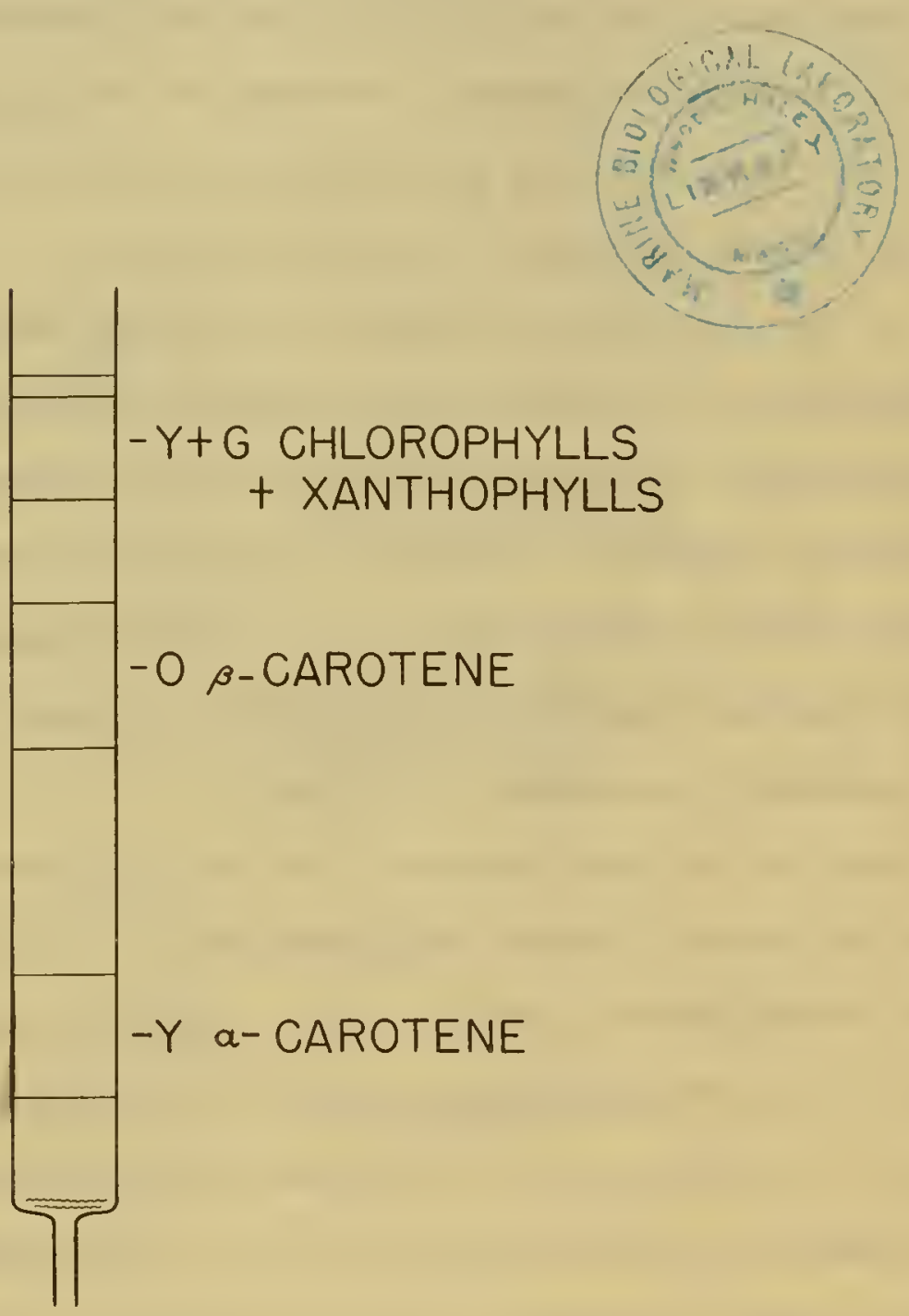


the sugar column (Figure $I, 1$ ), were readily resolved by use of magnesia columns provided chlorinated solvents or petroleum ether plus acetone were employed to accelerate the migration of the pigments through the strongly sorptive magnesia. With columns of magnesia the mixture of xanthophylls in leaf extracts could be resolved without preliminary separation from the other leaf pigments 10,16 as shown in Figure $I, 30$ Under these conditions, the neoxanthin and the zeaxanthin were frequently sorbed in different sequences as indicated in the figure. This variac tion in the sequence of the two zones is due, apparently, to various colorless sorbed substances in the plant extracts.

The filtration rate of magnesia columns and therefore the rate of separation of the pigments was increased by mixing the finely powdered adsorbent with a nonsorptive filter aid such as Celite, a heat-treated diatomaceous earth 10,15 . These mixtures served for separation of the carotenes and leaf xanthophylls, but the reactive magnesia destroyed the chlorophylls. The activated magnesia also slowly destroyed certain labile xanthophylls obtained from algae 16 。

Thus far, no single adsorbent has been found that will separate all the chloroplast pigments from one another by a single application of the chromatographic procedure. With columns of powdered sugar and with petroleum ether containing about 0.5 per cent ñpropanol as wash liquid, it has been possible to separate the chlorophylls and many of the carotenoids obtained from various kinds of photosynthetic plants. And with columns of magnesia it has been possible to make a more extensive resolution of these carotenoid pigments and to compare their chrom matographic behavior (by mixed adsorption) with carotenoids obtained from the yellow organs of nonphotosynthetic plant parts 9,16 . 
Figure I,3. Leaf xanthophylls separated by chromatographic adsorpo tion of chloroplast pigments in a column of activated magnesia plus Celite ( 182 by weight)。 Pigments ado sorbed from petroleum ether and washed with petroleum ether containing 25 per cent acetone. The sequence of the zeaxanthin and neoxanthin zones varied with the plant material due, apparently, to the presence of colorless, sorbed substances.

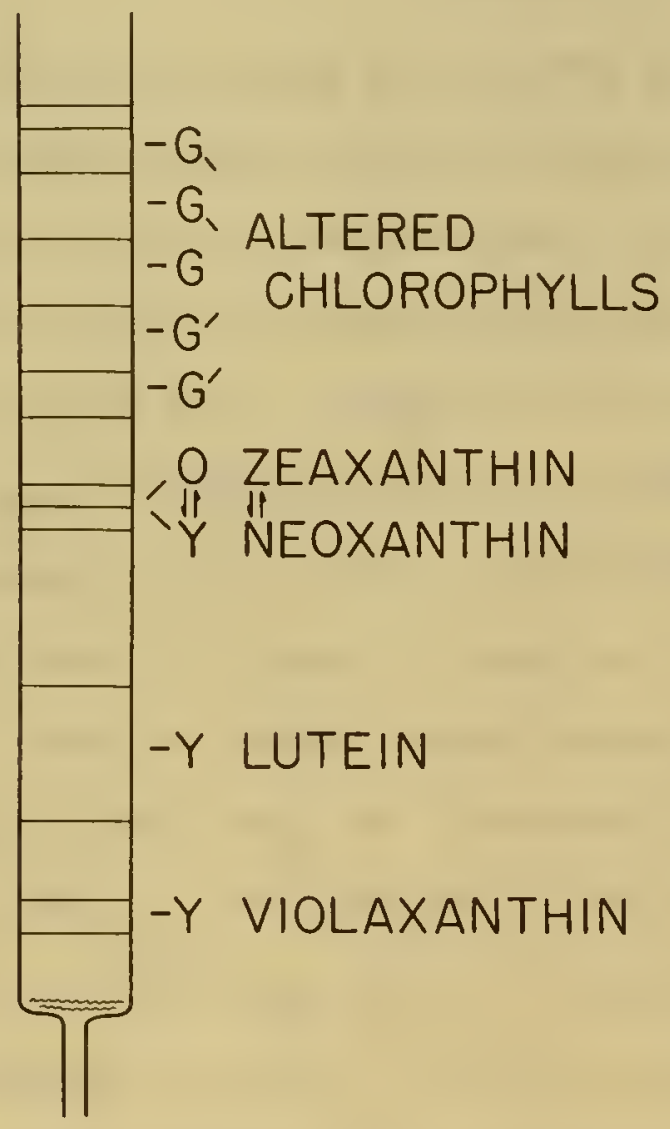


Soparations by Paper Chromatography

Another remarkably effective, extremely sensitive, and widely applioable separatory procedure, now called paper chromatography, was first demonstrated by separation of the chloroplast pigments. It had been known for many years thet mixtures of various substances were partially resolved when their solutions were drawn into filter paper by capillary action. This procedure, which provided partial resoluo tion of the mixture at the leading boundaries of the migrating solutes had been called capillary adsorption analysis and had been extensively investigated by Goppelsroeder 5 .

In 1939, Brown modified the capillary analysis procedure by introduoing the development or washing step of columnar chromtographyl7. In his demonstration, Brown adsorbed a little of a petroleum ether extract of dried leaves in the center of a sheet of filter paper. Then he added fresh solvent to the center of the spot so that as this wash liquid flowed outward it carried the pigments along at different rates and separated them from one another. In this separation by paper chromatography, the two green chlorophylls, two or three xanthophylls and the carotene mixture formed a series of concentric zones.

Since Brown's experiment, the paper chromatography of leaf pigments has been modified in many ways and reapplied to separation of the chloroplast pigments 18 . In one modification, the paper was moistened slightly with aqueous glycerine, so that the separation of the pigments depended upon their sorption at the petroleum etheraqueous glycerine interface, a liquid-liquid interface rather than the liquid-solid interface in dried paper and in powdered sugar 19 . 
Thus far, the separations of chloroplast pigments in paper have been similar to those obtained in columns of powdered cellulose. They are somewhat less effective than those obtained in columns of powdered sugar 20 . 


\section{REFERENCES}

1. H. A. Spoehr, Photosynthesis. The Chemical Catalog Co., Inc., New York, 1926.

2. E. I. Rabinowitch, Photosynthesis and related processes. Interscience Publishers, Inc., New York, 1945, 1956.

3. H. S. Reed, Jan Ingenhousz, plant physiologist. With a history of the discovery of photosynthesis. Chronica Botanica, 11, 285 (1945). Also as single copies, The Chronica Botanica Co., Waltham, Mass.

4. G. P. Barnard, Modern mass spectrometry. Institute of Physics, London, 1953.

5. H. H. Strain, Chromatographic adsorption analysis. Interscience Publishers Inc., New York, 1942.

6. H. H. Strain, In, Photosynthesis in plants. p. 133, Eds. J. Franck and W. E. Loomis, The Iowa State College Press, Ames, 1949.

7. R. Willstuter and A. Stoll, Untersuchungen Hber Chlorophyll, Methoden, Ergebnisse. Berlin, 1913.

8. L. So Palmer, Carotinoids and related pigments. The Chemical Catalog Co., Inc., New York, 1922.

9. H. H. Strain, In, Manual of phycology. p. 243. Ed., G. M. Smith. The Chronica Botanica Co., Waltham, Mass., 1951.

10. H. H. Strain, Leaf xanthophylls. Carnegie Institution of Washington, Publication No. 490, Washington, 1938.

11. P. Karrer and E. Jucker, Carotinoide. Verlag Birkhtuser, Basel, 1948.

12. V. H. Booth, Carotene, its determination in biological materials. W. Heffer \& Sons, Ltd., Cambridge, England, 1957. 
13. H. C. Sorby, Proc. Roy。Soc。, 21, 442 (1873).

14. M. Tswett, Ber。 deut, botan. Ges., 르, 384 (1906).

15. H。H。 Strain, J。Biol。Chem。, 105, 523 (1934)。

16. H.H. Strain, W. M. Manning, and G. Hardin, Biol. Bull., 86, 169 (1944)。

17. W. G. Brown, Nature, 143, 377 (1939)。

18. H。F。 Linskens, Ed., Papierchromatographie in der Botanik. Springer, Berlin, G8ttingen, Heidelberg, 1955.

19. H. H. Strain, J. Phys. Chem。, 57, 638 (1953)。

20. H. Ho Strain and T. $R_{0}$ Sato, In, A conference on radioactive isotopes in agriculture, Januery 12-14, 1956。 p。175. U.S。 Atomic Energy Commission Report Number TID-7512. 


\section{CHROMATOGRAPHIC METHODS AND THE CHLOROPLAST PIGMENTS}

\section{OF HIGHER PLANTS AND GREEN ALGAE}

\section{THE COURSE OF INVESTIGATION}

\section{Objectives}

When exploratory tests with chromatographic adsorption methods indicated that the chloroplast pigments of leaves could be separated in columns of powdered sugar $I, 5$ and in columns of magnesia $I, 10 ; I, 15$, a systematic investigation of the photosynthetic pigments of various kinds of plants was undertaken. The early studies in this series, carried out in collaboration with Drs. Winston M. Manning and Garret Hardin I, 16 , soon revealed that the chromatographic methods were effective with all kinds of fat-soluble chloroplast pigments from various species of plants.

At the beginning of these studies, it was believed that diverse plants adapted to a great variety of environmental conditions might yield a corresponding variety of chloroplast pigments. For a time, this presumption was supported, because several new chlorophylls and many new carotenoid pigments were discovered. But as the observations increased, it became clear that the individual chloroplast pigments are not distributed randomly through the plant kingdom. On the contrary, certain pigments and certain combinations of pigments occur only in plants that belong to taxonomically related groups. Conversely, the chloroplast pigments reflect relationships among the species of the major taxonomic olasses ${ }^{1,2}$.

This correlation between chloroplast pigments and plant classification has now been confirmed and extended by supplementary investigations of the pigments of many additional plants including species from 
different environments and from different parts of the world. Although a summary of these investigations has been brought to publication $I, 68 I, 9$, many observations upon which the summary was based have not been presented heretofore。

These studies of the chloroplast pigments from various plants were also pursued with the object of ascertaining the variability of the photosynthetic apparatus. In this way, it was hoped to gain clues to those pigments that play critical roles in the photosynthetic process itself。

Lability of the Chloroplast Pigments

An unanticipated outcome of these chromatographic studies was the observation that the natural pigments themselves are remarkably labile substances ${ }^{3-6}$. They undergo several kinds of alteration yielding other colored substances. The nature of these reactions, their extent, and the yield of the secondary products vary with the plant material, with its treatment, and with the conditions to which the extracts are exposed. Special care must be exercised in the extraction and separation of the pigments in order to prevent contamination of the natural pigments with these alteration products.

The principal secondary pigments that may contaminate the chloroplast pigments are described in part III. They include isomerization, oxidation and acid alteration products of the chlorophylls and carotenoids $3-6$.

\section{Presentation of Observations}

As the chloroplast pigments were separated by chromatography and as the chromatographic patterns serve for the description and definition 
of the pigments, the chromatograms typical of different kinds of plants are portrayed by simplified drawings. If the extraction and separatory procedures are followed, there is little difficulty in reproducing these chromatographic observations. It should be kept in mind, however, that these results were obtained only after many empirical trials. Deviations from the procedures, only a few of which can be indicated here, may lead to incomplete separation and to alteration and contamination of the natural pigments.

The identification of the pigments was based upon spectral absorption curves, color reactions with acids and readsorption with authentic preparations. Spectral absorption curves of the new pigments are reproduced as the so-called characteristio spectral adsorption curves, the shape of which is independent of the concentration of the pigments $I, 10 ; I, 16$.

For summarization of the observations and as an aid to readability, the plant species that wore studied have been tabulated according to their principal toxonomic classes. The tables of these species have been arranged in the form of appendices with cross references to the respective figures showing the ohromatograms of the pigments in columns of powdered sugar. The locations of the species, their natural habitats, and minor variations of the pigment systems are recorded in the tables.

PLANT MATERIAL AND ANALYTICAL METHODS

\section{Selection of Plant Material}

In the selection of plant material an attempt was made to examine species of special interest because of their taxonomic position ${ }^{1,2}$, 
their geographical location, or their adaptation to special environments. Some of the most interesting species were available only in remote parts of the earth and at partioular seasons. A few of these were collected by interested colleagues and shipped via air mail. A few species, particularly green, chysophycean, and blue-green algae, were cultured。 Some species, particularly some of the xanthophyceae of the genus Vaucheria, were found only after numerous collection trips in the vicinity of Stanford and at Hawaii.

For examination of the pigments, only mature, green tissues were seleoted. These tissues, as fronds and leaves, were handled carefully so that they were not damaged by storage, wilting or freezing before extraction of the pigments.

Algae collected in the field were examined for contamination by other species. They were washed thoroughly with water to remove extraneous organisms and then blotted with a towel. Unicellular algae grown in liquid culture media were collected in centrifuge tubes. Various species grown on agar gels were washed loose with water and then collected in centrifuge tubes. All these unicellular species were extracted in the centrifuge tubes.

In cultures of certain unicellular algae, some of the cells ap= peared to be yellower than others as if all were not growing at the same rate. These cultures yielded reduced quantities of the typical chloroplast pigments, and cultures of some organisms, Protosiphon and Ankistrodesmus, yielded new carotenoid pigments that were not present in the rapidly growing, deep green cultures. (See section on green algaө。) 
Extraction of the Pigments

For prevention of the hydrolytic and oxidative reactions of the pigments that may take place rapidly when plant material is crushed $3: I, 10$, coarse plant material, such as leaves, was chopped finely with a very sharp knife in a wooden bowl. The pigments were then extracted from this chopped material with an organic solvent.

Although scalding or blanching of the plant material may be utilized to destroy the oxidative enzymes and to facilitate subsequent pigment extraction, this preliminary heat treatment is undesirable because it accelerates the isomerization of the chlorophylls and of many carotenoids. Some of the isomerization reactions occur to a detectable extent even when the solutions have stood at room temperature for more than an hour or two 3,6 . It is desirable, therefore, to perform the extractions and the separations as rapidly as possible. Exposure of the solutions to bright light, such as sunlight, should also be avoided.

A solvent mixture composed of 2 volumes of absolute methanol and 1 volume of petroleum ether, (boiling point about $50^{\circ}$ ), has been found to yield very rapid extraction of the chloroplast pigments with a minimum of decomposition. About 5 grams of the chopped plant material, or about 1 to 5 grams of centrifuged algal cells were mixed with about $150 \mathrm{ml}$. of the solvent mixture. The resultant rapid extraction isolated the pigments from the plant material and reduced enzymatic changes。 The water in the fresh plant material diluted the methanol causing it to separate from the petroleum ether and thereby retarded allomerization of the chlorophyll. The petroleum ether dissolved the pigments and isolated them from the plant material and from the methanol. With all but the most impervious plant matorial, the extraction was complete in 5 to 15 minutes。 
Transference of the Pigments to Petroleum Ether

As soon as the pigments were dissolved from the plant material the solution was poured through a shallow pad of cotton supported in a funnel, and the filtrate was collected in a 1-1. separatory funnel. The plant material was washed with a little of the solvent mixture, and the pigments in the combined, filtered extracts were transferred to the petroleum ether by the addition of about 500 to $600 \mathrm{ml}$ of dilute (about 10 per cent) filtered, sodium chloride solution。 If , the pigments were not transferred completely to the petroleum ether, the separated aqueous methanol layer was re-extracted with more petroleum ether which was separated and added to the first extract. If some of the pigments crystallized, it was necessary to add more petroo leum ether or to start with a smaller quantity of the fresh plant material. The deep green petroleum ether solution was washed twice with a little dilute salt solution (or with water if emulsions did not form) whereupon it was ready for chromatographic examination. It was not necessary to dry the solution with anhydrous salts, and it was sometimes undesirable to do so owing to the sorption of the pigments.

Some pigments are not stable in the petroleum ether solutions。 It is inadvisable, therefore, to keep these solutions more than a few minutes before separation of the pigments by chromatography。

\section{Chromatography of the Pigments}

The chromatographic columns of powdered sugar were prepared in glass tubes about $3 \mathrm{~cm}$. in diameter and $30 \mathrm{~cm}$. long, tapered at the base and loosely plugged with cotton. Small portions of powdered sugar, "Confectioners Powdered Sugar" containing 3 per cent starch 
to prevent caking, were tightly pressed (not tamped) into these tubes with a plunger but slightly smaller than the diameter of the glass tube I, 5. These small portions, each about $2 \mathrm{~cm}$. deep, were packed in succession until the sugar column was about $25 \mathrm{~cm}$. deep. During this packing, the glass tube was supported on a cork ring or stopper on a wooden box.

It was not necessary to dry the sugar or to screen it before packing it into the chromatographic tubes. Sugar that had been exposed to the moist atmosphere for several summer months at Hawaii and at Chicago proved just as effective as that from freshly opened packages or that dried in desiccators. Powdered sugar dried in an oven at $100^{\circ}$ did not form as uniform columns as the unheated preparations unless it was carefully screened.

For the chromatographic separations, a sugar column was attached to a suction flask and a little of the deep green, petroleum ether solution of the pigments was drawn into the upper layers until it formed a green zone about 0.7 to $1.5 \mathrm{~cm}$. deep. This zone was then washed with petroleum ether containing about 0.5 per cent $n$-propanol. Under these conditions, the pigments separated rapidly from each other providing a succession of green and yellow zones analogous to those indicated already in Figure I, $I$.

As the petroleum ether plus propanol wash liquid penetrated tho powdered sugar, there was little change in the color of the zones of most of the sorbed pigments. But with violaxanthin and, particularly, with a minor xanthophyll of certain green algae that is adsorbed just above the violaxanthin, the initially yellow zones turned orange as the petroleum ether plus propanol moved through them. At this stage, 
the orange zonea could easily be mistaken for an orange xanthophyll, siphonaxanthin, of the siphonalean green algae. Upon continued washing with petroleum ether plus propanol, the orange zones gradually become light yellow。

Many varlations of the solvent and of the wash liquid were tested. As a rule unsaturated hydrocarbon solvents, such 28 benzene, were better solvents for the pigments than petroleum ether, but as wash liquids for formation of the chromatogram, these solvents provided less effective separations than petroleum ether plus n-propanol. In these hydrocarbon solvents, some of the pigments, such as chlorophyll c, appeared to be altered, and isomers of the chlorophylls were not readily separated. Substitution of other alcohols for the n-propanol in the wash petroleum ether yielded less effective separations. Methanol frequently separated from the petroleum ether as a distinct phase as the solution filtered through the column. Ethanol provided satisfactory separations only at the beginning of the washing. Iso-propanol did not effect as complete separation of the chlorophyll a from the lutein plus zeaxanthin as did $\underline{n-p r o p a n o l . ~ A ~ c o m p l e x ~ m i x t u r e ~ o f ~ v a r i o u s ~ m o n o h y-~}$ droxy and dihydroxy allphatic alcohols plus several ketones and amines, when substituted for the $\underline{n}$-propanol, produced equivalent separation of the pigment zones. Substitution of 4 per cent acetone for the $n$-propanol, produced a variation of the pigment sequence with the chlorophyll a zone above the lutein plus zeaxanthin。

Verious sorbents were also tested for the chromatographic separation of the pigments. Starch, regenerated starch, cellulose and Cellte did not yield as distinct zones with as little alteration of the pigments as did powdered sugar. Separations in paper were also less effective than those in colums of sugar, 20 . 
Mixtures of magnesia and Celite were effective for the separation of carotenes in plant extracts and for the separation of certain xanthophylls from the extracts. (See Figures $I, 2$ and $I, 30$ ) Columns of magnesia plus Celite were employed to confirm and to extend the separations effected in the sugar columns ${ }^{1}, 16$. They also served to remove traces of chlorophyll that contaminated the carotenoid pigments separated in the sugar columns.

\section{Properties of Pigments Separated in the Sugar Columns}

For the isolation of the pigments separated in the sugar columns, the individual colored zones were removed separately with a long spatula and packed into short filter tubes. The pigments were then eluted with methanol. With the green pigments, the residual petroleum ether in the eluates was removed quickly with vacuum, and the wave lengths of the absorption maxima were observed. The chlorophylls from various sources were then compared by sorption of the mixtures in fresh columns of powdered sugar.

The eluates containing the carotenoid pigments were diluted with a little petroleum ether, and the pigments were transferred to this solvent by the addition of dilute salt solution. Unless they were altered by magnesia, the pigments were then adsorbed in columns formed by pressing a 182 mixture of activated magnesia (Micron Brand Magnesium Oxide) and nonsorptive siliceous earth (Celite 545) into glass tubes about $3 \mathrm{~cm}$. in diameter and $20 \mathrm{~cm}$. tall. The carotenes were separated by washing the pigments with petroleum ether; the xanthophylls were separated by washing with petroleum ether plus 25 per cent acetone. (See Figures $I, 2$ and $I, 30$ ) 
The readsorption of the carotenoids, eluted from the sugar, in columns of magnesia facilitated the removal of traces of the green pigments that are strongly and irreversibly sorbed. It also made possible the separation of some xanthophylls such as lutein and zeaxanthin and the carotenes $\alpha$-carotene and $\beta$-carotene that are not soparated in columns of sugar.

The carotenoid pigments readsorbed in the magnesia columns were recovered by elution with petroleum ether containing ethanol. These eluted pigments were then transferred to petroleum ether and to ethanol for determination of the spectral absorption curves and to ethyl ether for determination of the color reaction with concentrated hydrochloric acid. They were compared with authentic preparations of various xanthophylls by adsorption of the mixtures in columns of powdered sugar and in columns of magnesia $I, 16$.

\section{PIGMENTS OF HIGHER PLANTS AND GREEN ALGAE}

\section{Chloroplast Pigments of Flowering Plants (Spermatophytes)}

The pigments of flowering plants were readily separable in a column of powdered sugar and yielded a series of zones like those shown in Figure II,lo The pigments were always a mixture of chlorophylls (chlorophylls a plus b), xanthophylls (neoxanthin, violaxanthin, and lutein plus zeaxanthin), and carotenes ( $\beta$-carotene plus or minus $\alpha$-carotene). The species that have been examined, their habitats, the locations of the specimens and notes on the pigments are presented in Appendix I.

Occasionally traces of other pigments were observed in addition to those indicated by Figure II, 10 The cycads (Cycadaceae), for 
Figure II, I。 Chloroplast pigments of flowering plants (Spermatophytes), nonflowering plants (Pteridophytes and Bryophytes), mosses and lichens (Musei and Hepaticae) and most green algae (Chlorophytes)。 (See Appendices $I_{2} I_{2} I_{I}$ and IVo)

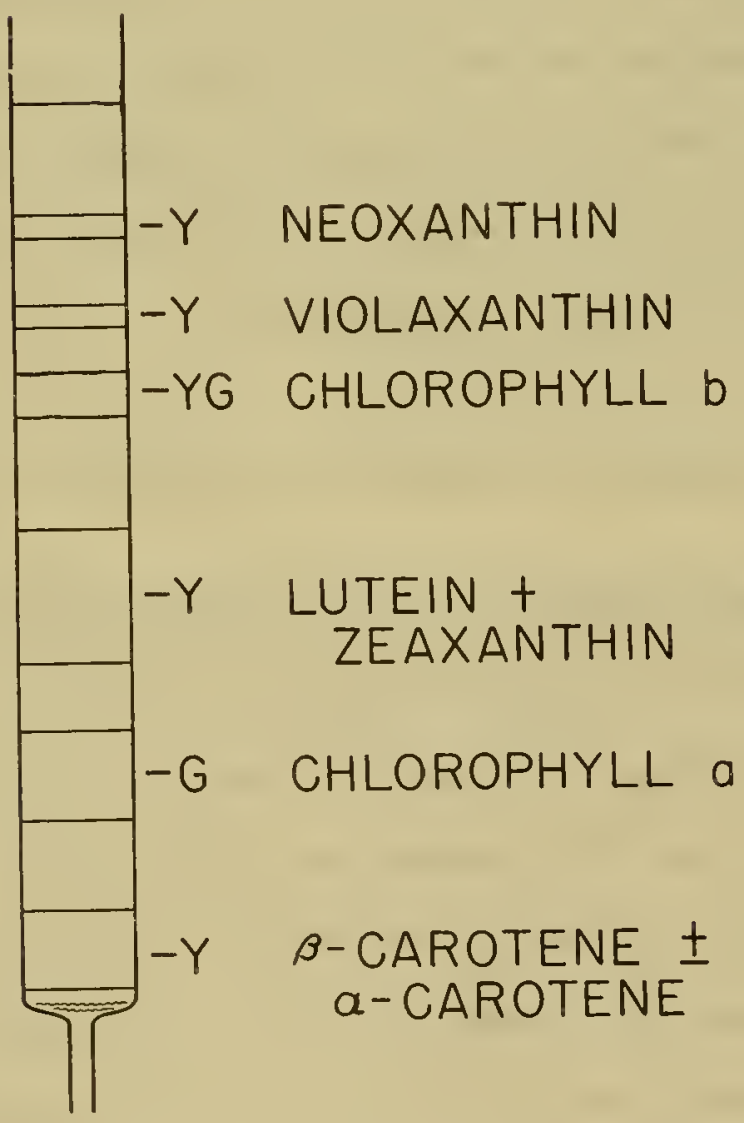


example, whether growing in a greenhouse at Chicago or outdoors elsewhere, yielded traces of taraxanthin. This xanthophyll formed a yellow zone just below and contiguous with the chlorophyll b zone. It was identified by absorption spectra and color reactions and by mixed adsorption with taraxanthin from dandelion flowers as has been described beforeI,16. For these chromatographic comparisons columns both of sugar and of magnesia were employed.

In some of the earlier experiments in which leaf xanthophylls were isolated on a relatively large scale, traces of two xanthophylls that resembled the flavoxanthin of buttercups were frequently observed ${ }^{1}, 10$. It is not certain whether these small quantities of pigments occur naturally or whether they arise from violaxanthin, which is known to yield two flavoxanthin-like pigments when exposed to various mild conditions such as the action of weak organic acids. These pigments were rarely observed in the sugar columns 4 .

Leaves of various species of flowering plants usually yielded the same principal pigments even when the plants were growing under vastly different conditions. Marine plants, as Phyllospadix (Najadaceae) and Halophila (Hydrocharitaceae), salt-marsh plants, as mangrove (Rhizophoraceae), Cotula coronopifolia (Compositae) and Salicornia ambigua (Chenopodiaceae), and various plants growing on the land at sea level or near timber line, in fertile meadows or in barren desserts always yielded these same green and yellow substances. Seed plants growing in the tropics, in the temperate zone, or in the glacial zone of the high Sierra Nevada Mountains also yielded these pigments。 Plants native to Europe, Asia, Africa and South America produced the same pigments when growing in Hawail or in California. 
Variations in the proportions of the leaf pigments were observed in Symgonium (Araceae) which contained much neoxanthin and little violaxanthin, in Solidago (Compositae) which contained much violaxanthin, and in Fremontia (Sterculariaceae) which contained an amount of zeaxanthin equal to or greater than the lutein.

There was no simple relation between the pigments of leaves and the pigments of flowers and fruits. When flowers were immature and green they usually contained the same pigments found in leaves and in other green tissues as green fruits and bark. But when they matured, the flowers usually lost the chloroplast pigments. Many flowers then developed red and blue waterosoluble pigments。 Some flowers, particularly the yellow ones, developed carotenold pigments that were present in the green tissue, as violaxanthin in pansy flowers. But some flowers developed unique carotenoid pigments that could not be detected in the greon tissues. Examples of these unique flower pigments are taraxanthin of the dandelion, Taraxacum (Compositae), and echscholtzxanthin of the California poppy, Eschscholtzia (Papaveraceae) ${ }^{7}$. In the green fruits of the tomato, the chloroplast pigments are superseded during ripening by the polyene hydrooarbon lycopene which does not occur in the leaves.

\section{Supplemental Pigments of Leaves}

Leaves of a few plants develop supplemental pigments when the growth is retarded as at the onset of winter $I, 8$. In many leaves there is extensive loss of the chloroplast pigments sometimes accompanied by the formation of fat-soluble, carotenoid pigments ${ }^{1}$ 10, An unusual caroteo noid called rhodoxanthin has long been known as a constituent of the winter foliage of certain conifers $I, 11$. 
The red winter follage of the ommental Cryptomeria japonica, var. elegans (Taxodiaceae) growing at Stanford contained large quantities of rhodoxanthin, which disappeared again in the spring as the leaves became green. This rhodoxanthin was isolated from the winter foliage of Cryptomeria by adsorption in columns of powdered sugar of Celite. In the sugar columns it formed a red zone between the lutein and the chlorophyll a. Its speotral absorption curves are reproduced in Figure $I I, 2$ 。

Although rhodoxanthin is very weakly sorbed in columns of sugar and of Celite, it is very strongly sorbed in columns of magnesia, even with petroleum ether plus 25 per cent acetone as the wash liquid. In the magnesia column, it is more sorbed that the strongly sorbed siphonaxanthin and zeaxanthin plus neoxanthin 5 .

Chloroplast Pigments of the Nonflowering Plants, Ferns, Horsetails, Club Mosses and Quillworts (Pteridophytes), of Mosses and Liverworts (Bryophytes), and of Stoneworts (Certain Chlorophytes)

Taxonorically, both the flowerless, spore-bearing plants and the flowering plants evolved from common ancestorsl,2. This phylogenetio relationship is supported by the nature of the chloroplast pigments。 For example, a number of ferns, horsetails and club mosses and a quillwort yielded the same chloroplast pigments found in the flowering plants。The species examined are tabulated in Appendix II。

Seteral mosses (Musci), liverworts (Hepaticae), a lichen (Lichenes) and a stonewort (Chrophyceae) also yielded the same chloroplast pigo ments found in leaves. The species of mosses and liverworts that were examined are tabulated in Appendix III. The lichen yielded pigments 
Figure II,2。 Characteristic spectral absorption curves of the xanthophyll, rhodoxanthin。

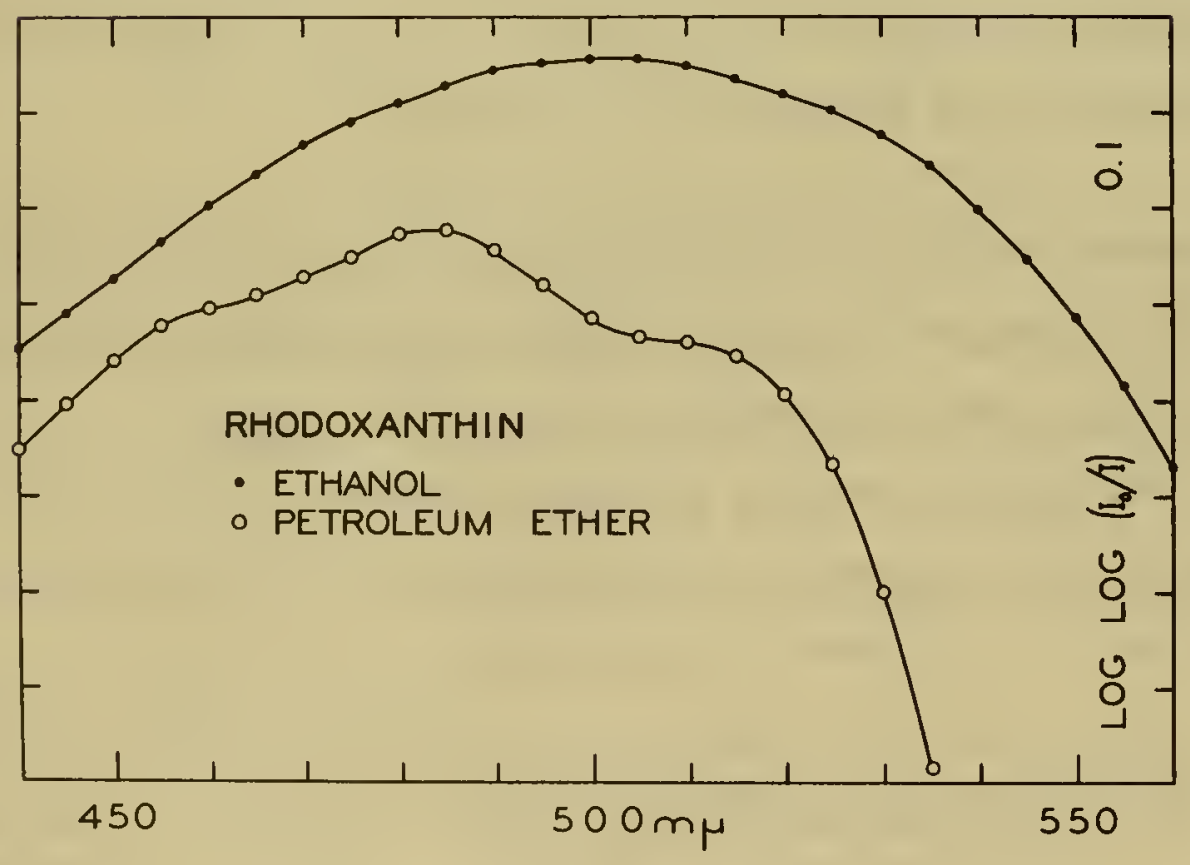


that are found in the green algae as well as in leaves and that came, undoubtedly, from the green algae within the thallus. Other species of lichens with blue-green algae within the thallus would be expected to yield the pigments characteristic of the blue-green organisms. The stonewort, which is classified as a green algal, yielded the pigments which are common to flowering plants, ferns, mosses and most green algae。 (See Appendix IV。)

\section{Chloroplast Pigments of Green Algae (Chlorophyta)}

The green algae have long been regarded as representative of ancestors common to their line and to the higher forms of green plants ${ }^{1,2}$. The occurrence of the principal leaf pigments in all green algae lends further support to this view。

With respect to pigments, the green algae have now been found to fall into two principal groups. The species of one group contained the same pigments found in leaves, often plus traces of a xanthophyll that was adsorbed between the neoxanthin and the violaxanthin in the sugar columns. The species of the second group contained the pigments characteristic of higher plants plus an additional xanthophyll, siphonaxanthin, and its ester, siphonein $I, 6: I, 9$, as indicated in Figure II, 3 .

The algae of the first group included one species of the one order Charales in the class Charophycea,, and they included many species in nine of the twelve orders in the class Chlorophyceae. These species are tabulated in Appendix IV。

The green algae containing siphonaxanthin and siphonein belonged to the order Siphonales of the class Chlorophycere. They included representatives of the five principal families show in Appendix V. 
Figure II,30 Chloroplast pigments of the siphonalean grean algao (Siphonales)。 (See Appendix Vo)

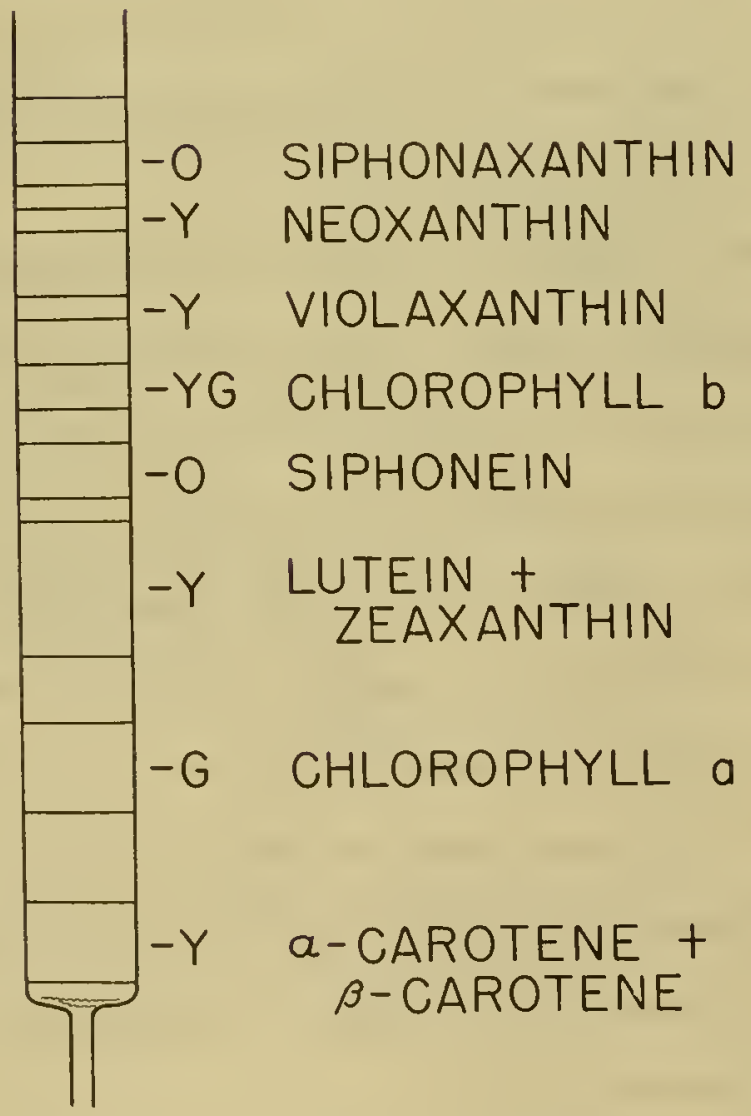


Properties of the Xanthophylls from the Green Algae

The minor xanthophyll observed between the neoxanthin and the violaxanthin from many of the green algae in Appendix IV was 1solated by adsorption in columns of powdered sugar. The eluted pigment was purified by adsorption in columns of magnesia followed by readsorption in columns of sugar. Its spectral absorption curves in petroleum ether and in ethanol, shown in Figure II,4, are similar to the curves for lutein I, 10. Dissolved in diethyl ether and treated with concentrated hydrochloric acid, this xanthophyll did not yield a blue color.

Siphonaxanthin and siphonein were isolated from various species of the siphonalean green algae. As shown by adsorption of mixtures of these preparations, the same pigments were obtained from all the species. The siphonein was converted into siphonaxanthin by saponification with alooholic potassium hydroxide. Spectral absorption curves of the two pigments are shown in Figure II,5.

Although siphonaxanthin resembles fucoxanthin of the diatoms and brown algae with respect to spectral absorption curves, as shown by Figure II,6, the two pigments differ greatly in other ways。 With hydrochloric acid and ether, fucoxanthin yields a deep blue color in the acid, siphonaxanthin does not. Fucoxanthin is decomposed by alkalies, siphonaxanthin is not. In columns of powdered sugar siphonaxanthin is sorbed above neoxanthin, whereas fucoxanthin is sorbed far below neoxanthin and betweon violaxanthin and tareoxanthin I, 16 . In columns of magnesia and with petroleum ether plus 25 per cent aceo tone, siphonaxanthin is also strongly adsorbed above neoxanthin and zearanthin.

Siphonein resembles fucoxanthin in sorbability as well as with respect to spectral absorption. It is sorbed with fucoxanthin in 
Figure II,4. Characteristio spectral absorption ourves of the greenalgal xanthophyll sorbed between neoxanthin and violaxanthin。

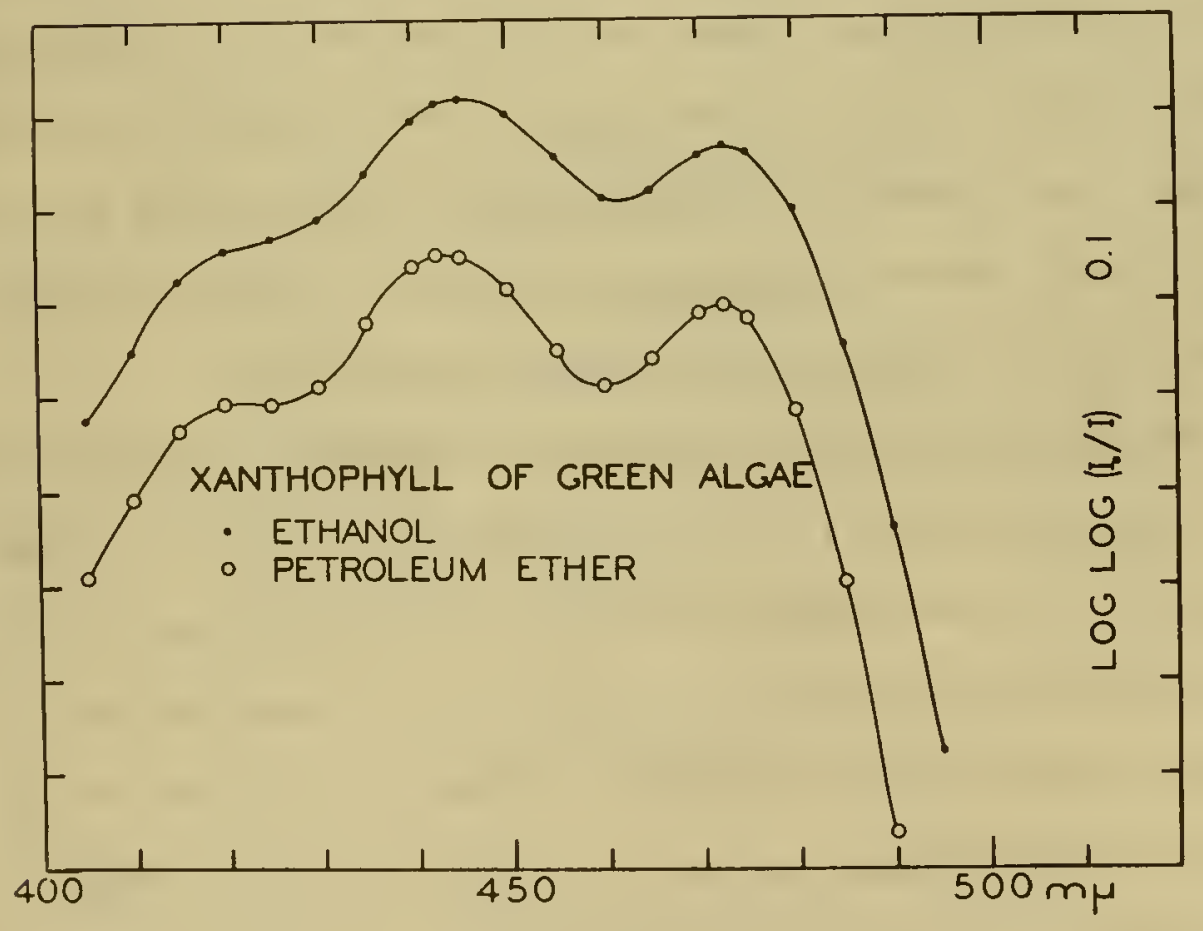


Figure II,5. Characteristic spectral absorption curves of siphonaxanthin and siphonein from siphonalean green algae. (See Figure II, 30)

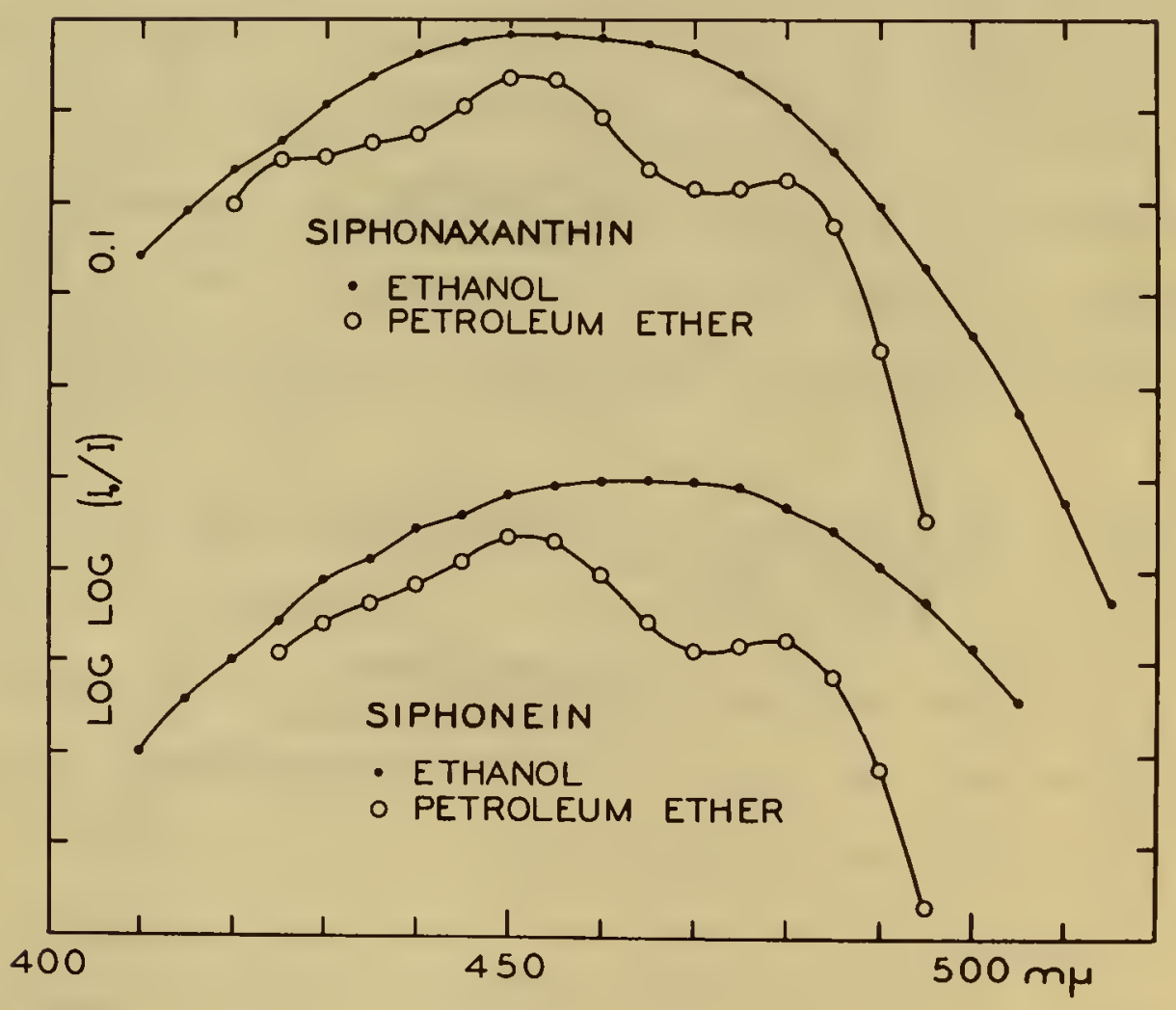


Figure II,6。 Characteristic spectral absorption curves of siphonaxanthin and fucoxanthin。

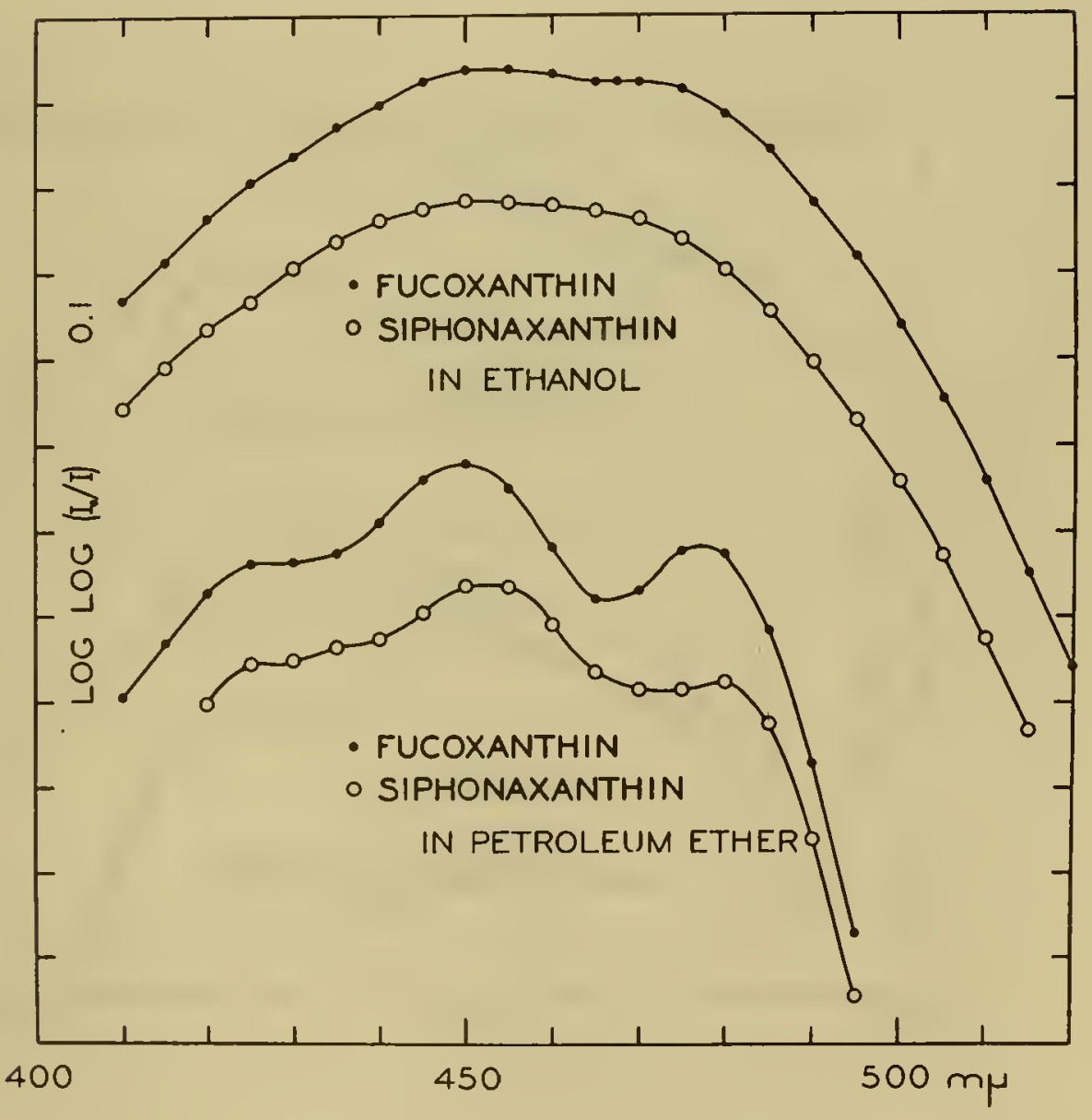


columns of sugar and in columns of magnesia, but it is converted to siphonaxanthin by alkalies whereas fucoxanthin is destroyed。

When nopropanol solutions of siphonaxanthin and siphonein are heated, the absorption in the green region of the spectrum decreases relative to that in the blue. This is due to the formation of spatially isomeric pigments (neo isomers $6 \xi I, 11$ ) that have been isolated by chromatographic adsorption. The characteristic spectra of these isomers compared to the parent pigments is shown in Figure II,7.

\section{Supplemental Carotenoid Pigments of Green Algae}

Some of the green algae have long been known to lose their green color and to become yellow when exposed to various unfavorable conditions such as dehydration, lack of nutrients and high salt concentration. This phenomenon has frequently been ascribed to the development of a secondary pigment, "haematochrome". In some species, as Dunaliella salina and Chlorella vulgaris, haematoohrome has proved to be Bocarotene $I, 9$.

Like so many green algae, Protosiphon botryoides (Chlorococcales) (Appendix IV) is also known to turn yellow to red when the cultures on agar are allowed to dry out. These red organisms have been found to yield two unusual carotenoid pigments that replace the green and yellow pigments of the green organisms. (See Figure II, I and Appendix IV。) In columns of powdered sugar these two pigments were weakly sorbed forming purple-orange zones. They were separated readily by washing the sugar columns with petroleum ether plus 2 per cent acetone. The spectral absorption curves are shown in Figure II,8. In columns of sugar and with petroleum ether plus 0.5 per cent $\underline{n}-$ propanol as wash 
Figure II,7. Characteristic spectral absorption ourves of neosiphonaxanthin and neosiphonein, isomers of siphonaxanthin and siphonein, in ethanol.

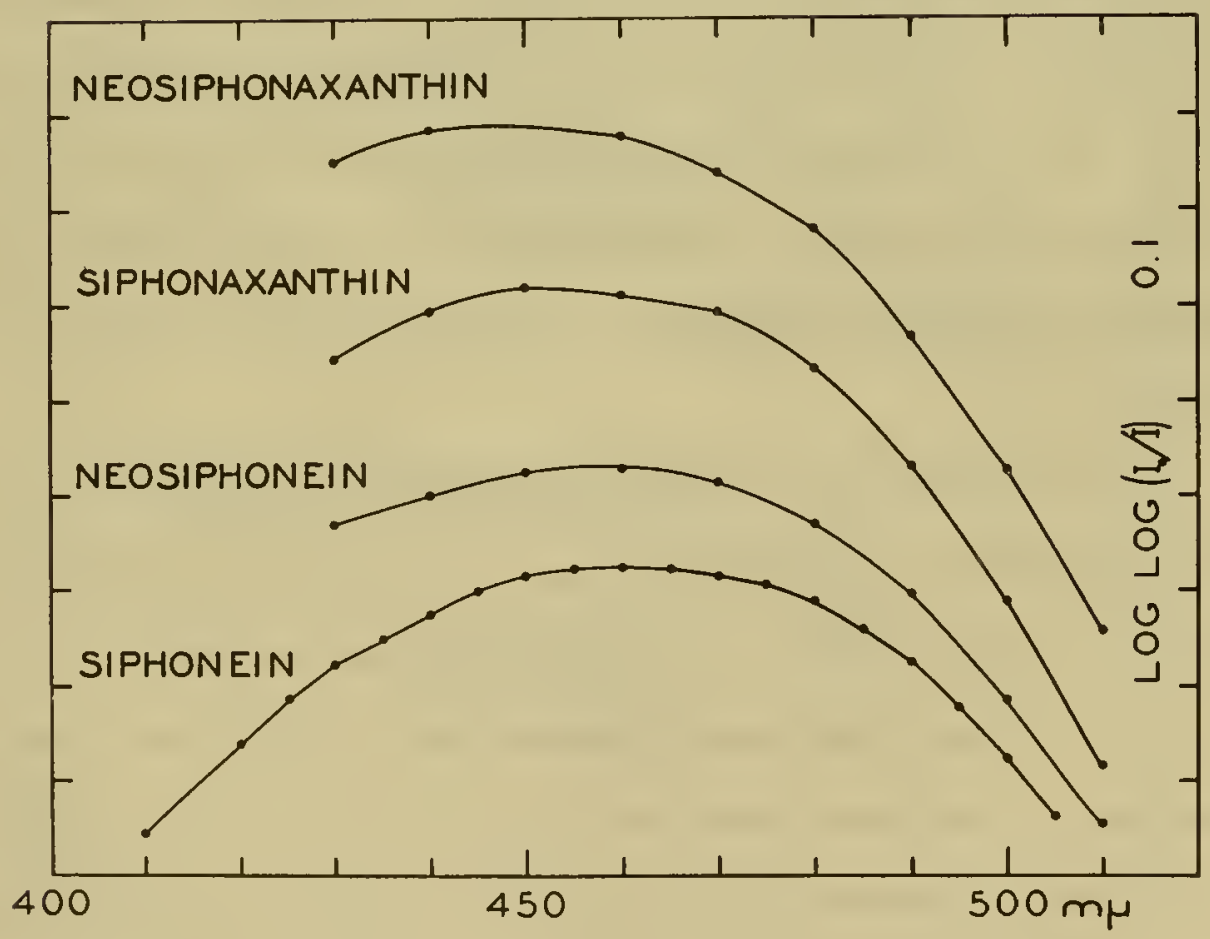


Figure II,8. Characteristic spectral absorption curves of the supplemental xanthophylls from the red forms of Protosiphon。

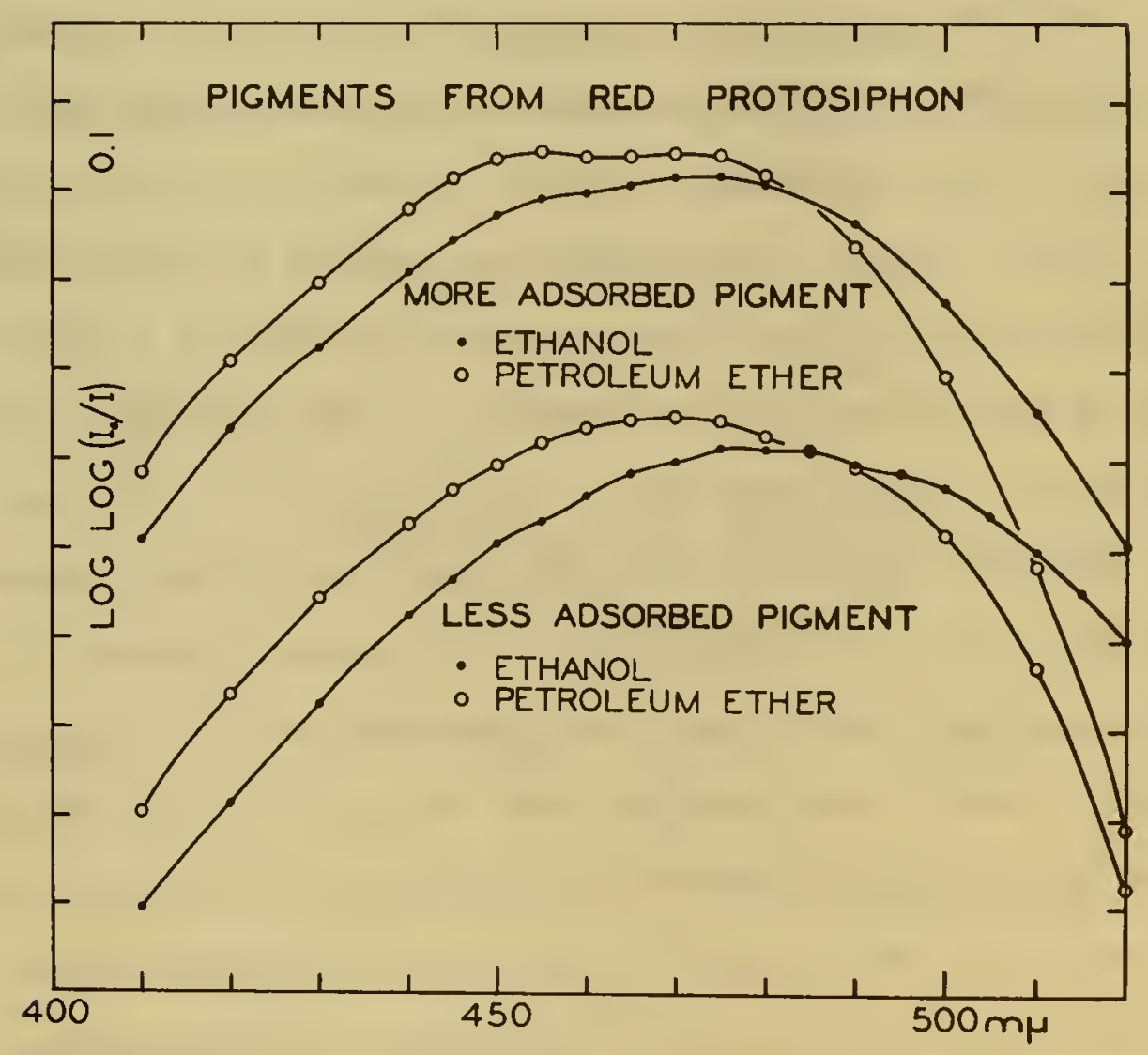


liquid, the more sorbed pigment formed a zone below lutein and well above cryptoxanthin. The less sorbed pigment formed a zone just below cryptoxanthin. In columns of magnesia and with petroleum ether plus 25 per cent acetone as the wash liquid, the Protosiphon pigment that was the more sorbed in sugar columns formed a red-orange zone below lutein. The less sorbed pigments formed a violet-red zone just above lutein. The sequence of the Protosiphon pigments in the magnesia column was, therefore, the inverse of the sequence in the sugar column. With respect to spectral absorption and sorbability, these pigments are xanthophylls that contain carbonyl $(C=0)$ groups $I, 10 ; I, 11$ 。

Cells of Ankistrodesmus falcatus (Chlorococcales) (Appendix IV) cultured under continuous illumination for several weeks often varied in color from yellow-green to green. Extracts of the cells from the old cultures yielded a pink-orange zone between the lutein and the chlorophyll a, a similar zone between the chlorophyll a and $a^{\prime}$ and another similar zone below ohlorophyll a'. The spectral curves of the pigment from the zone between the lutein and the chlorophyll a are reproduced in Figure II,9. The other, less sorbed pigments exhibited similar spectral properties. In columns of sugar and with petroleum ether plus 0.5 per cent $n$-propanol, the upper Ankistrodesmus pigment formed a zone contiguous with the zone of rhodoxanthin. The other Ankistrodesmus pigments formed zones much lower than rhodoxanthin in the column. With respect to the spectral absorption curves (Figures II, 8 and II,9) and the relative sorbability, the supplementary pigments from Protosiphon and from Ankistrodesmus are very much alike。 
Figure II,9. Characteristic spectral absorption curves of the supplemental xanthophyll from Ankistrodesmus.

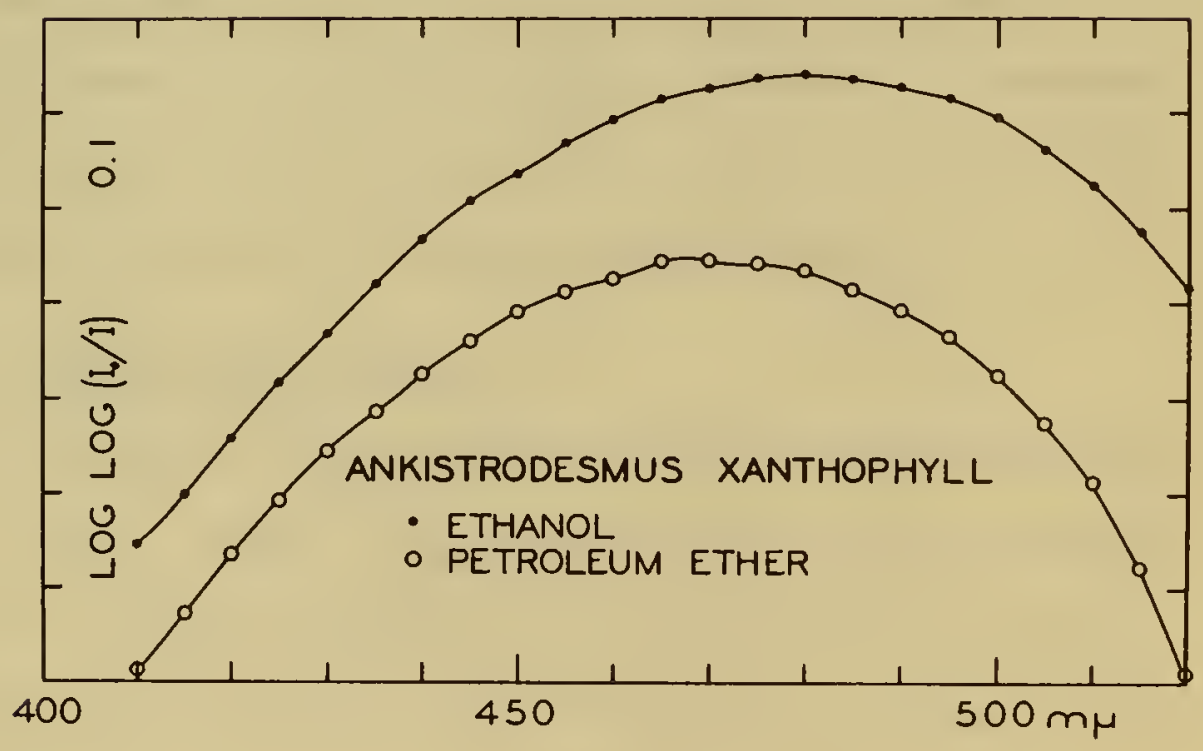




\section{REFERENCES}

1. G. M. Smith, Cryptogamic botany. 2nd, edition。 McGraw-Hill, New York, 1955.

2. G. M. Smith, Ed., Manual of phyoology. The Chronica Botanioa Co., Waltham, Mass.1951.

3. H. H. Strain, J. Agr。 Food Chem., 2, 1222 (1954)。

4. H. H. Strain, Arch。Biochem。Biophys., 48, 458 (1954)。

5. H. Ho Strain, Jo Am。Chem。Soc。, 70, 588 (1948)。

6. H. H. Strain and $W_{0} M_{0}$ Manning, J.Am, Chem. Soc。, 64, 1235 (1942)。

7. H. H. Strain, J。Biol。Chem, 123, 425 (1938)。 


\section{PIGMENTS OF ALGAE AND CHROMATOGRAPHY}

\section{OF ALTERED CHLOROPLAST PIGMENTS}

\section{ALGAL PIGMENTS}

\section{Complexity of the Algae}

From a taxonomic standpoint, the different kinds of algeo represent very remotely related organisms $I I, 1: I I, 2$. Apart from the green algae that resemble the higher plants, the species of the various algal classes might be expected to show variations of ohloroplast pigments commensurate with the great variations of their photosynthetic products, cellular composition and reproductive patterns.

The algal species that have now been examined represent an extensive cross section of the plant kingdom. There are, nevertheless, additional species that occupy interesting taxonoric positions but that were unavailable for the pigment investigations.

\section{Pigments of Euglens (Euglenophyta)}

Only two species of Euglena were avallable for the examination of their pigments. Euglena gracilis was grown in small quantitios in pure culture. Euglena polymorpha was found in unialgal condition in stagnant rain pools in a cow corral at Stanford. These motile organisms were skimmed off in quantity in the early morning when they concentrated at the surface of the dark puddles.

The pigments from Euglena polymorpha were separated in a column of powdered sugar as indicated in Figure III, l. They included chlorow phylls a and b, two unique xanthophylls, a nonsorbed carotenoid, and Bocarotene. In the early stages of the chromatographic separation, the principal xanthophyll was sometimes preoipitated, and for a time, 
Figure 1II,l. Chloroplast pigments of Euglena.

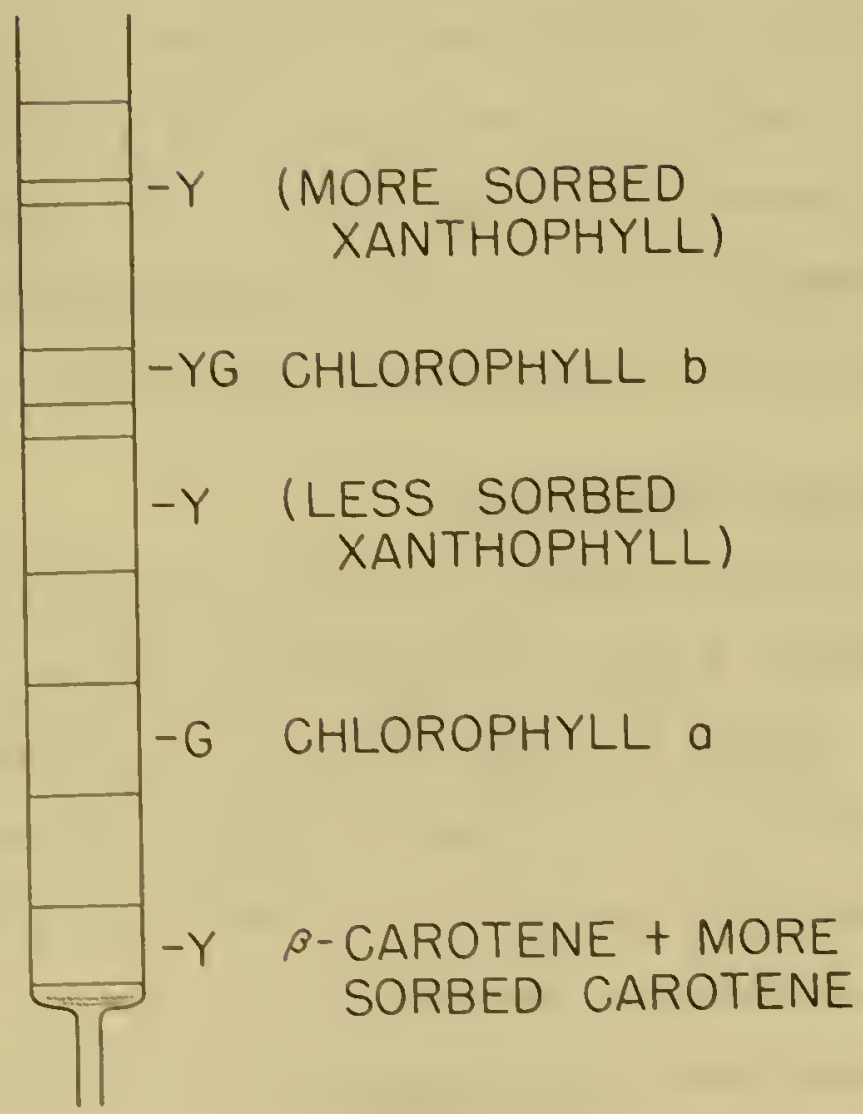


the ohlorophyll b zone appeared below the precipltated portion of this xanthophyll zone. Only after prolonged washing of the colum was all the principal ranthophyll carried below the chlorophyll b zone. Smaller quantities of a more sorbed xanthophyll formed a zone above the chlorophyll b. These two xanthophyll pigments separated in the same sequence when the Euglena extract was adrorbod in a column of magnesia and washed with petroloum ether oontaining 25 per cent acetone, Under these conditione, a third pigment appeared bolow the principal xanthophyll and above the nonsorbed $\beta$-carotene. This third oarotenoid pigment was not sorbed in the sugar oolumn and remained with the $\beta$-carotene. It was separated rapidly from the $\beta$-carotene by oorption of the carotene fraotion in a magnesia column. The adeorption spectra of this pigment and of the two unique zanthophylis are shown in Figure III,2。

The more adsorbed xanthophyll formed a zone far above lycopene and zeaxanthin in columns of magnesia when washed wh petroleum ether plus 25 per cent acotoneII, 5. The 1088 adsorbed xanthophyll mixed with lycopene and sorbed in a column of magnesia ylelded a single zone, but in columns of sugar, the xanthophyll was readily separable from the nonsorbed lycopene. In ether solutions, the Euglens carotenold pigments did not yield blue colors when treated with concentrated hydrochlorio acid。 They were not altered by saponification with potas8ium hydroxide in methanol. The carotene-11ke pigment was not extracted from petroleum ether with 90 per cent methanol, and therefore, it may be a carotene rather than a xanthophyl1。

Plgments of the "Golden" Algae (Chrysophyta) of the Class Xanthophycere or Heterokontze

The dozen species of the Heterokontae arallable for these studies were green or yellowagreen organisme (Appondix VI) that ylelded the 
Figure III,2. Characteristic spectral absorption curves of the unique xanthophylls and carotene from Euglena. (See Figure III, $I_{0}$ ) (Curves located arbitrarilyo)

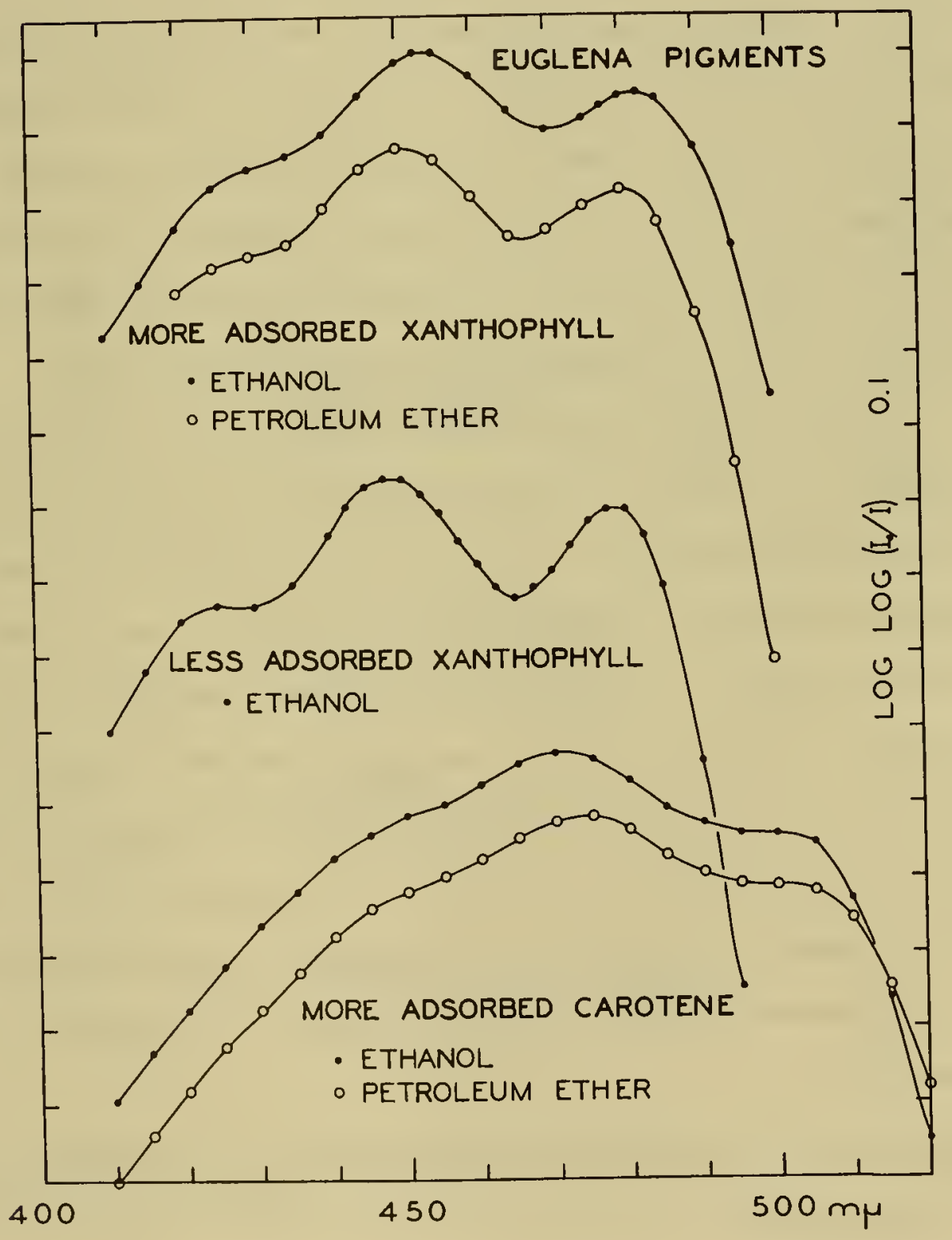


pigments shown in Figure III,3. Each species contained chlorophyll a, several xanthophylls which, from their relative sorbability, spectral properties and color reactions, appear to be hitherto undescribed carotenoids, and $\beta$-carotene. The xanthophylls have not been encountered in the autotrophic species of any other taxonomic class.

In the sugar column, a strongly sorbed Heterokontee xanthophyll remained near the top of the sorbent (Figure III,3). Two xanthophylls that separated slowly from each other and that represented most of the total xanthophyll fraction moved slowly through the column. These two xanthophylls were often preceded by traces of another xanthophyll that formed a light yellow zone.

The two principal xanthophylls that formed adjacent zones in the sugar column were not separated from each other if the initial zone of the plant extract contained much pigment or if the zones were not washed far along in the column. These two pigments were readily separated, but in the inverse sequence, when the mixture was eluted and readsorbed in a column of magnesia or when the plant extract itself was sorbed in a column of magnesia. In the magnesia column, however, the xanthophyll that had formed the zone second from the top in the sugar column was weakly sorbed and was easily washed through the sorbent. The xanthophyll forming the zone third from the top in the sugar column was moderately sorbed and remained in the upper regions of the magnesia column. The spectral absorption curves of the "strongly adsorbed" xanthophyll (most sorbed in the sugar column), of the xanthophyll "moderately adsorbed" in the magnesia column (third from the top in the sugar column), and of the xanthophyll "weakly sorbed" in the magnesia column (seoond from the top in the sugar column) are reproduced in Figures III, 4 
Figure III, 3. Chloroplast pigments of the Hetrokontre。 (See Appendix VI and Figure III,40)

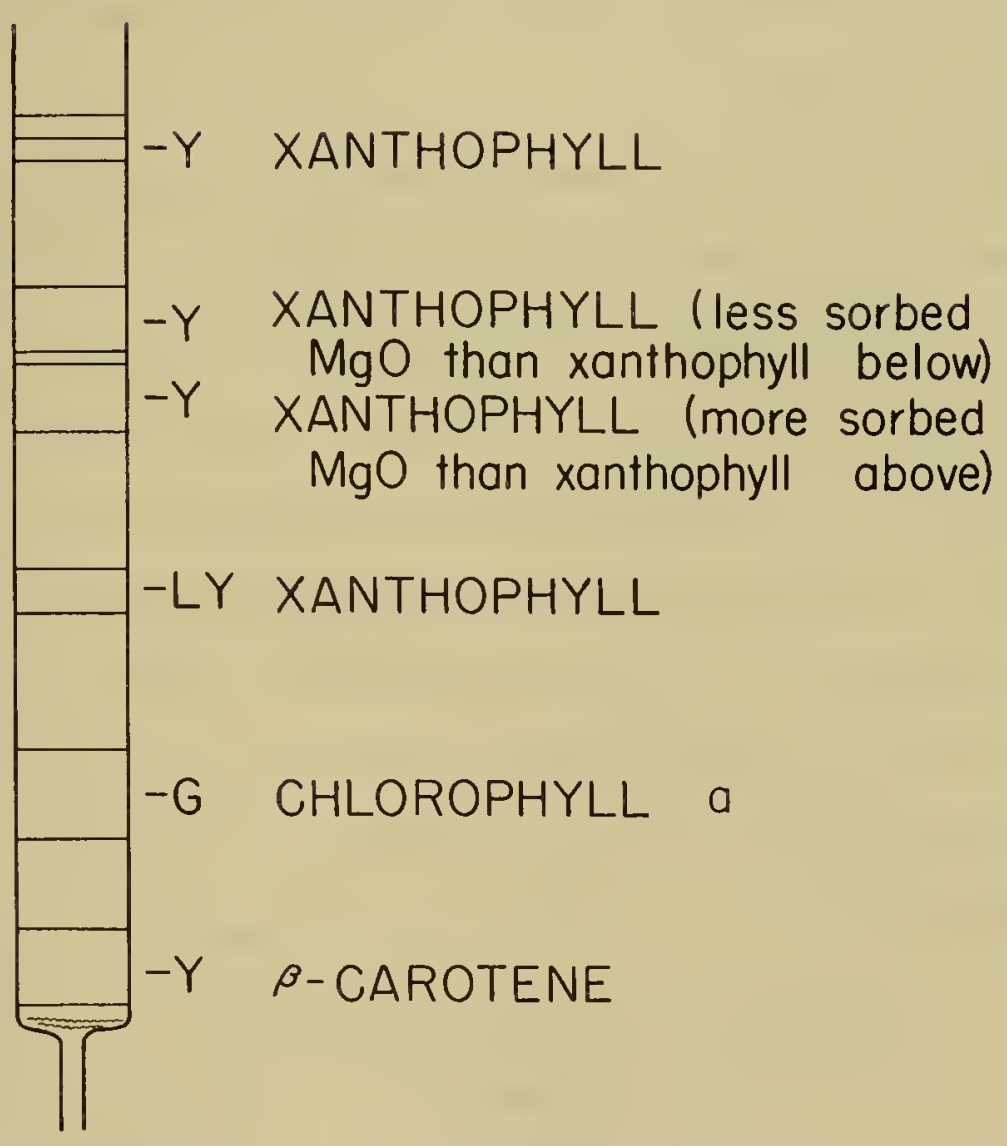


and III,5. Relative to other xenthophylls, the most adsorbed xanthophyll from the sugar column was very strongly sorbed being much more sorbed than neoxanthin in columns of sugar and of magnesia. A solution of this strongly sorbed xanthophyll in diethyl ether yielded a blue-green color in the acid layer when shaken with concentrated hydochloric acid. This blue color faded to yellow in a few minutes.

The moderately sorbed xanthophyll from the magnesia column (third in the sugar column) was slightly more sorbed than neoxanthin and zeaxanthin in magnesia with petroleum ether plus 25 per cent acetone as the wash liquid. This xanthophyll was much more sorbed than zeaxanthin in columns of powdered sugar. In sugar columns, it was slightly more sorbed than chlorophyll $\underline{b}$ and less sorbed than violaxanthin. In solution in ether, it reacted with concentrated hydrochloric acid yielding a light blue-green that faded to yellow in a few minutes。

The weakly sorbed xanthophyll from the magnesia column (second in the sugar column) was sorbed to the same degree as violaxanthin in columns of magnesia with petroleum ether plus 25 per cent acetone as the wash liquid. But this xanthophyll was less sorbed than violaxanthin in columns of sugar. Both the weakly sorbed and the moderately sorbed Heterokontae xanthophylls from the magnesia columns (second and third zones, Figure III,3) formed adjacent zones, in the inverse sequence, between violaxanthin and chlorophyll b in sugar columns。 The weakly sorbed xanthophyll from the magnesia columns did not yield more than a trace of blue when the ether solution was treated with concentrated hydrochloric acid.

The minor xanthophylls adsorbed just above and below the two major xanthophylls (Figure III,3) were strongly sorbed in columns of 
Figure III,40 Characteristic spectral absorption ourves of the unique xanthophylls from the Heterokontae. (See Figure III, 3 and Appendix VI。) ("Moderately adsorbed" and "weakly adsorbed $^{p 9}$ refer to magnesia columns, see Figure III, 3 and texto)

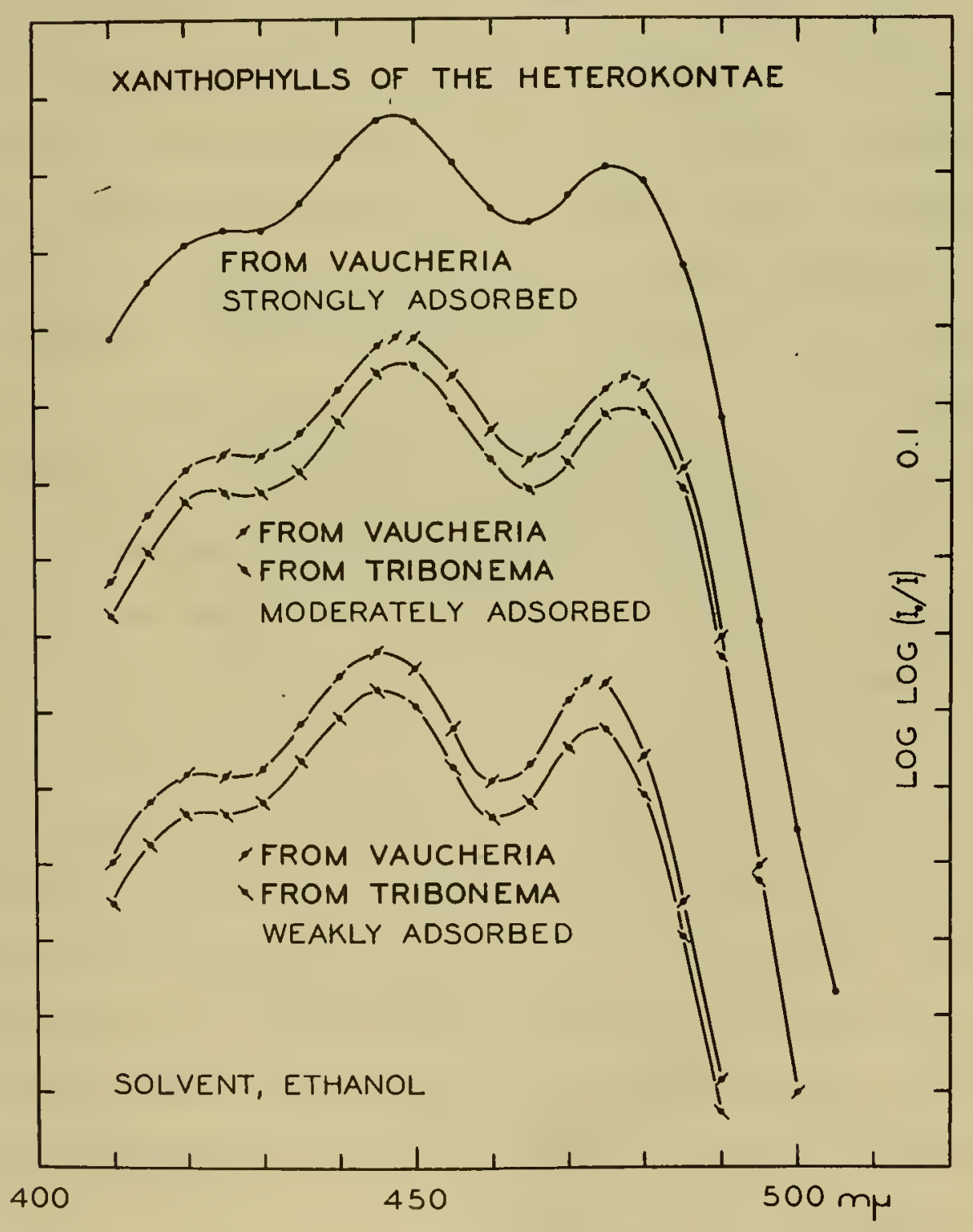


Figure III,50 Characteristic spectral absorption curves of the unique xanthophylis from the Heterokontae。 (See Figure III,3。) ("Moderately adsorbed" and "weakly adsorbed" refer to magnesia column, see Figure III, 3 and text。)
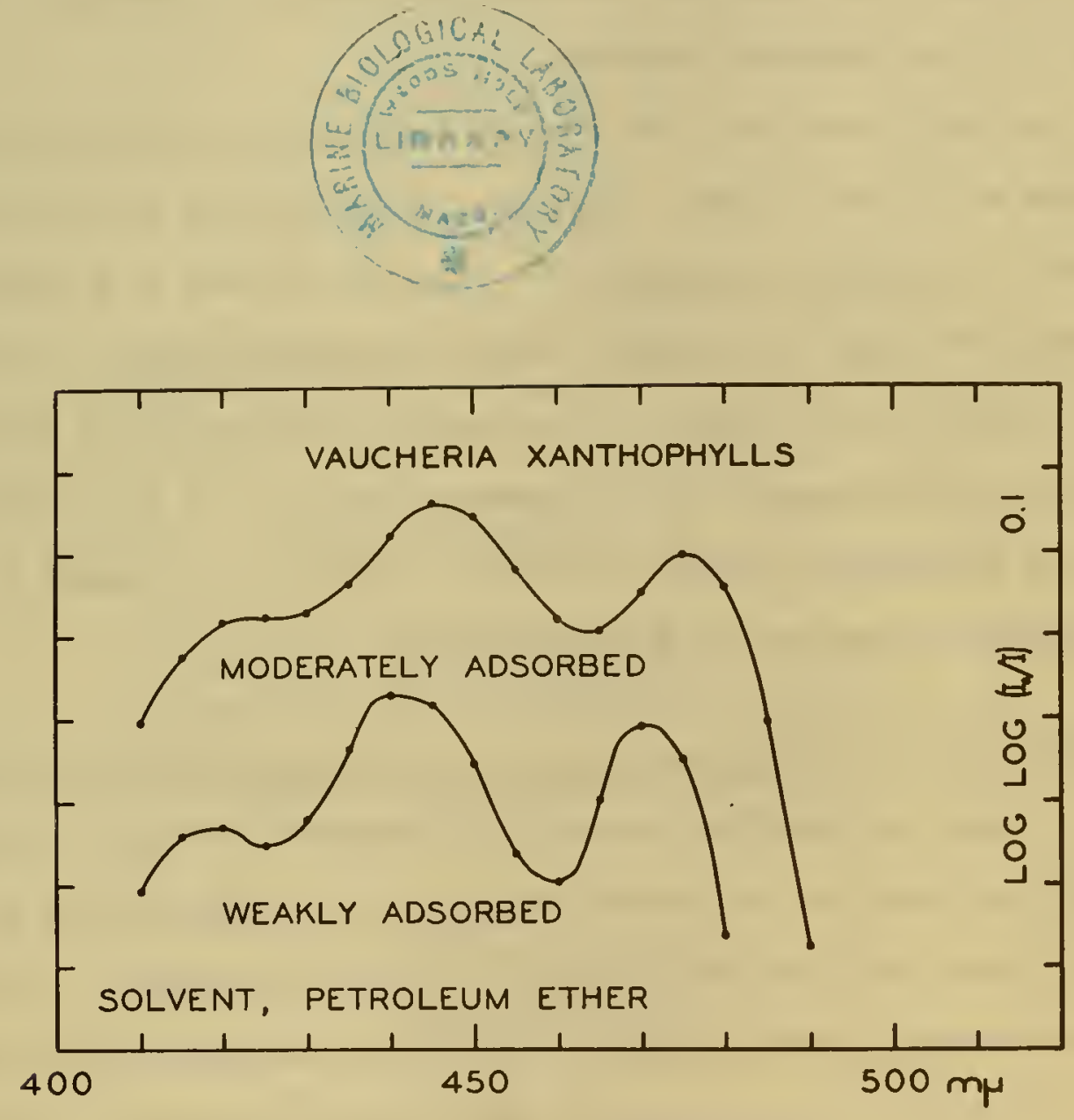
magnesia. They were not observed below the green zones when extracts of the organisms were sorbed in magnesia columns. They resembled the two principal xanthophylls。

Corresponding pigments from the several species of the Heterokontae were shown to be identical by mixed adsorption, by spectral properties and by color reactions with acid。

In 1943 traces of a chlorophyll (chlorophyll e), with adsorption maxima at 415 and $654 \mathrm{my}$ in methanol, were isolated from a natural growth of Tribonema bombycinum I, 6 . In 1948 the same or a similar chlorophyll was found in a natural stand of Vaucheria hamata. This chlorophyll has not been observed in the small quantities of the species that were cultured (Appendix VI)。 Whether or not it is a trace constituent of the Heterokontae algae, a secondary product, or a pigment from algal contamination has yet to be established.

Pigments of the Chrysophyta of the Class Bacillariophycea,, Diatoms

Several unidentified species of filamentous diatoms collected at Palo Alto Yacht Harbor, at Half Moon Bay and at Oahu yielded the pigo ments shown in Figure III, 6, namely, chlorophylls a and $\underline{c}$, fucoxanthin andits isomers, diadinoxanthin, diatoxanthin and $\beta$ ocarotene plus or minus $\alpha$-carotene. These are the same pigments previously isolated from pure cultures or from unialgal cultures of four species ${ }^{2}, 16$.

Comparison of the pigments of the Heterokontae (Figure III,3) with those of the Bacillariophyceae (Figure III,6) reveals that these two kinds of organisms differ with respect to the principal xanthophylls and the minor chlorophyll. This difference corresponds in magnitude to the pigment differences among the principal algal 
Figure III,6. Chloroplast pigments of diatons (Bacillariophyceae)。

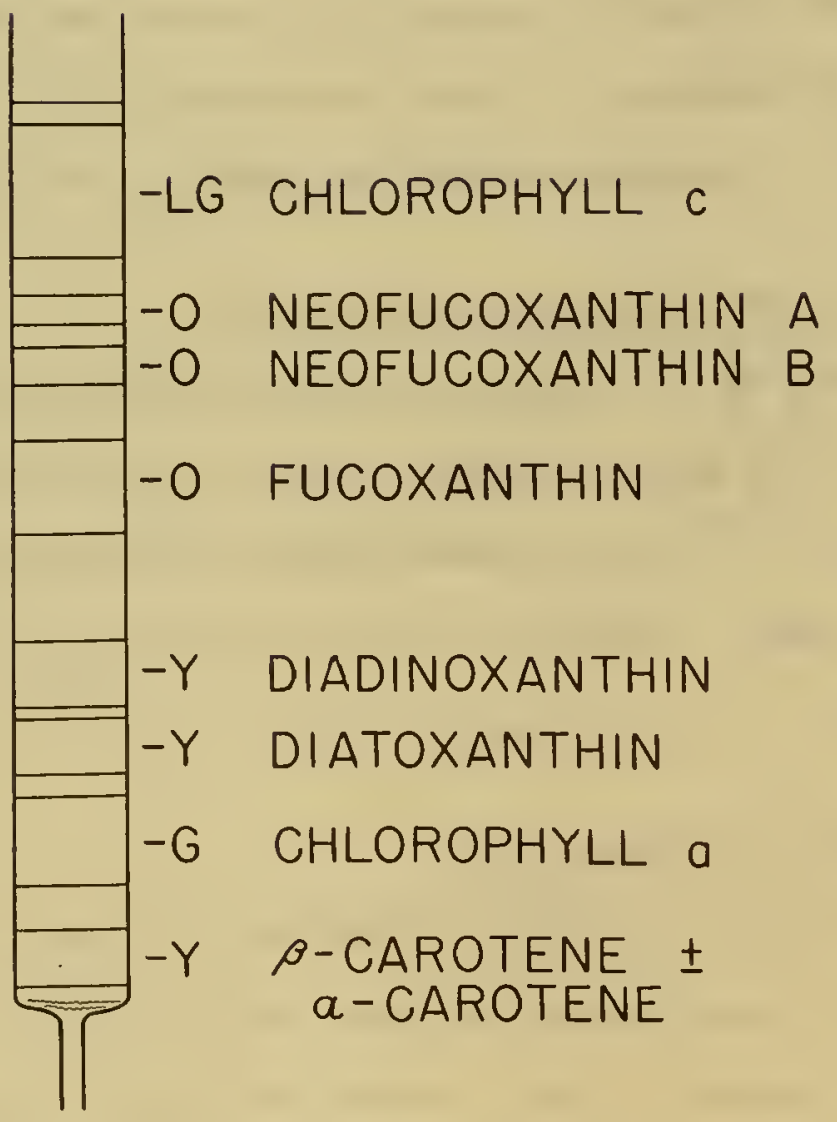


groups. It indicates that the Heterokontae and the Bacillariophyceae may belong to different classes.

Pigments of the Brown Alga (Phaeophyta)

The pigments separated from additional species of brown algae I, 16 are indicated by Figure III,70 The species examined and their locations are recorded in Appendix VII. Pigmentwise, these organisms, with ohlorophylls a and $\underline{c}$, fucoxanthin and its isomers, violaxanthin, and $\beta$-carotene plus or minus d-carotene, are similar to the diatoms.

With the algal extracts adsorbed in a column of powdered sugar, the violaxanthin was sorbed with and partially below the fucoxanthin. Readsorption of the mixture of these two xanthophylls in columns of magnesia yielded the violaxanthin zone far below the fucoxanthin zoneI, 16;II,6.

Pigments of the Dinoflagellates (Pyrrophyta)

The pigments of the dinoflagellates are illustrated by Figure III,8. Since these results were described in 1943, no additional species have become available I, 16. The pigments include chlorophylls a and $\underline{c}$, peridinin and its isomer, dinoxanthin and diadinoxanthin and their isomers, and $\beta$-carotene.

Pigments of Red Algae (Rhodophyta)

The fat-soluble chloroplast pigments of the red algae and their positions in the sugar columns are shown in Figure III,9. The variations of these pigments in many species are indicated in Appendix VIII。 The pigments include chlorophyll plus or minus chlorophyll d, lutein and/or zeaxanthin, and $\beta$-carotene plus or minus $\alpha$-carotene.

In the species of most groups, $\beta$-carotene was the principal carow tene and lutein the principal xanthophyll. In a few species of two 
Figure III,7. Chloroplast pigments of brown algae (Phaeophyta)。 (See Appendix VII。)

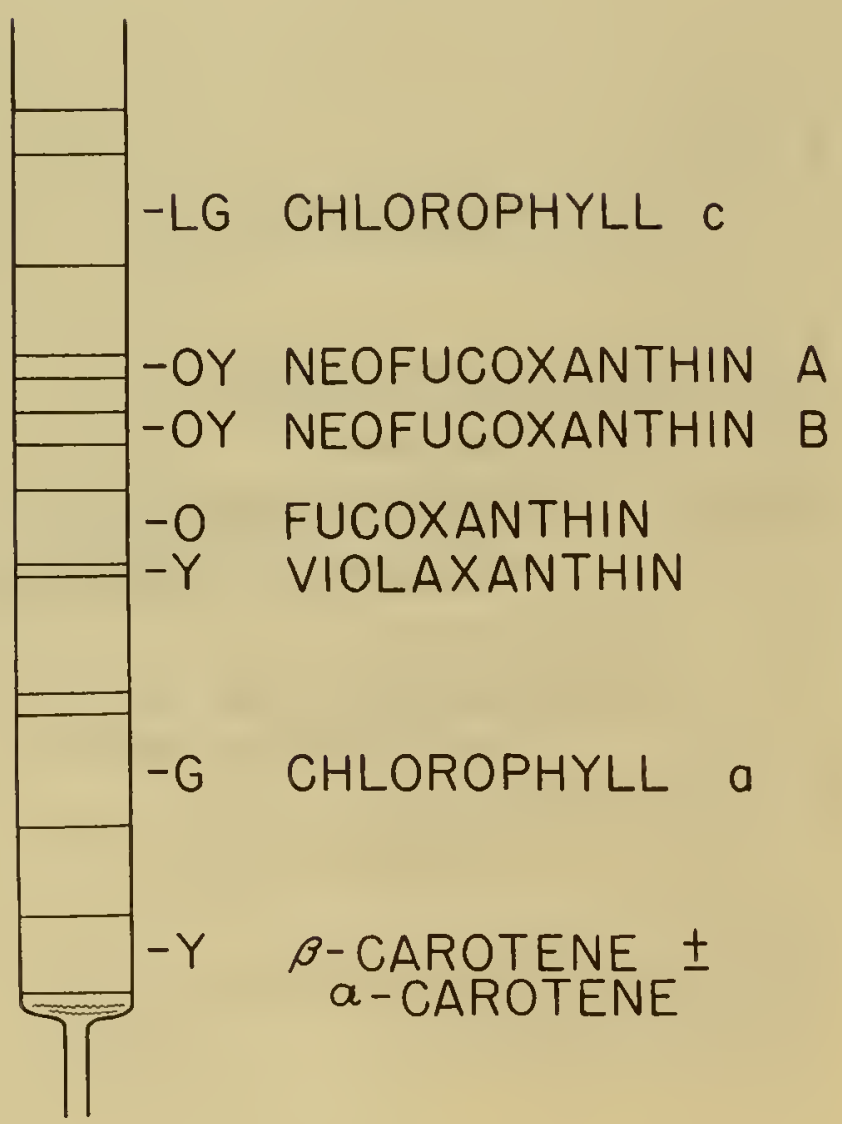


Figure III,8. Chloroplast pigments of dinoflagellates (Pyrrophyta)。

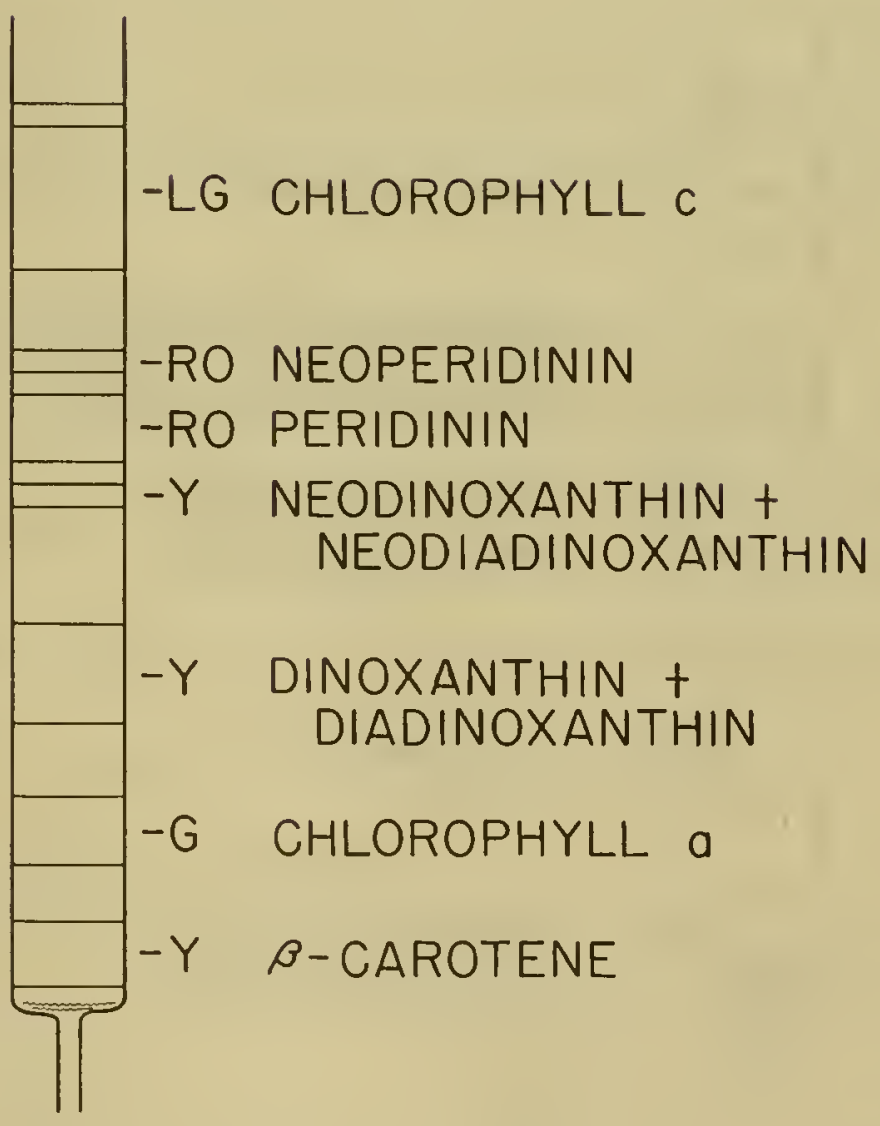


Figure III,9. Chloroplast pigments of red algae (Rhodophyta). (See Appendix VIII。)

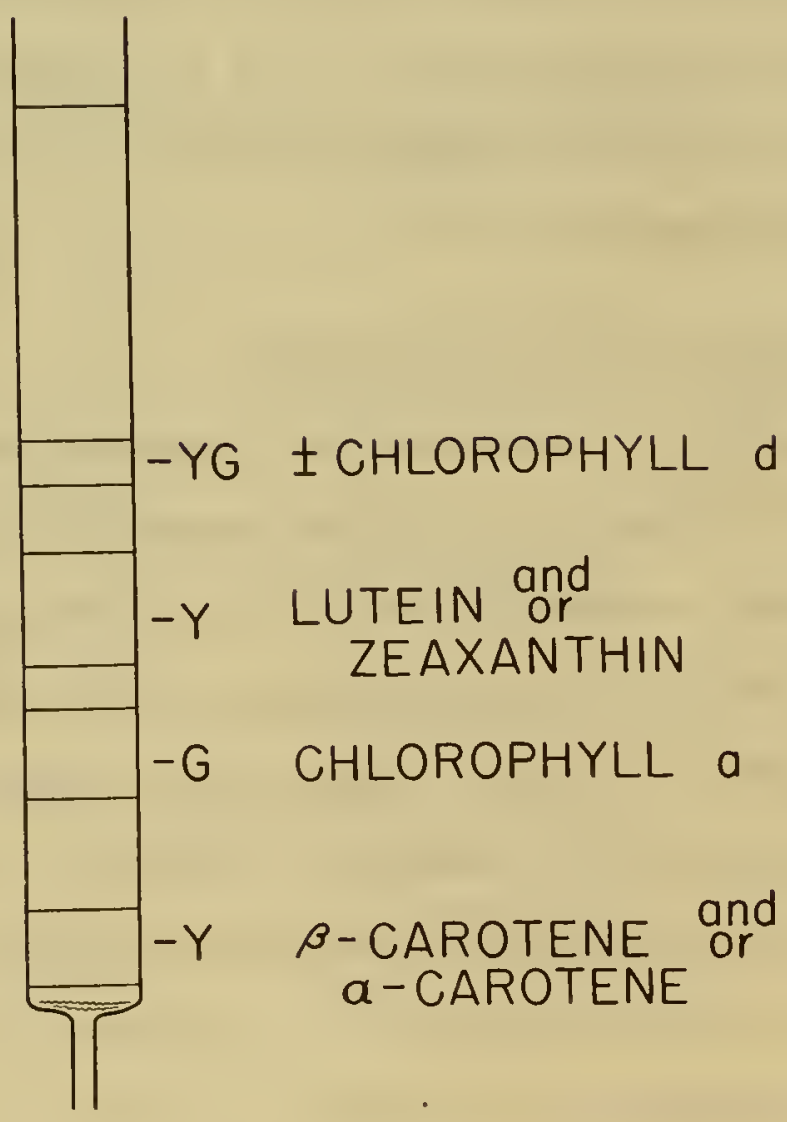


groups (Bangiacae and Rhodomelaceae) $\beta$-carotene was the principal carotene but zeaxanthin was the major xanthophyll. And in a few species of several groups (Ceramiaceae, Gigartinaoeae, Gracilariaoeae, Grateloupiaceae and Plocamiaceae) $\alpha$-carotene was the principal carotenoid hydrocarbon, lutein the predominant xanthophyll. Chlorophyll d was often absent or present only in traces. Only one plant, Rhodochorton Rothii, (Chantransiaceae) contained as much as 30 per cent of the total chlorophyll as chlorophyll d.

All the species examined contained r-phycoerythrin, a water-soluble, red, proteinaceous pigment that was not extractable with organic solvents. Even deep green species such as young plants of Halosaccion glandiforme were pink after extraction of the fat-soluble pigments with methanol and petroleum ether I, 6;I,9.

\section{Pigments of Blue-Green Algae (Cyanophyta)}

Several species of blue-green algae (Appendix IX) yielded the pigments indicated in Figure III, 10. These pigments included chlorphyll a, myxoxanthophyll, zeaxanthin plus or minus lutein, two similar pigments with the properties of myxoxanthin, and $\beta$-carotene. The proporo tions of the pigments in these organisms varied significantly with the age of the cultures and with the culture conditions. All the species contained the blue water-soluble c-phycocyanin which was not extracted with methanol and petroleum ether I,6;1,9. Spectral absorption curves of the unique xenthophylls are presented in Figure III, 11. 
Figure III,10. Chloroplast pigments of blue-green algae (Cyanophyta)。 (See Appendix IX)

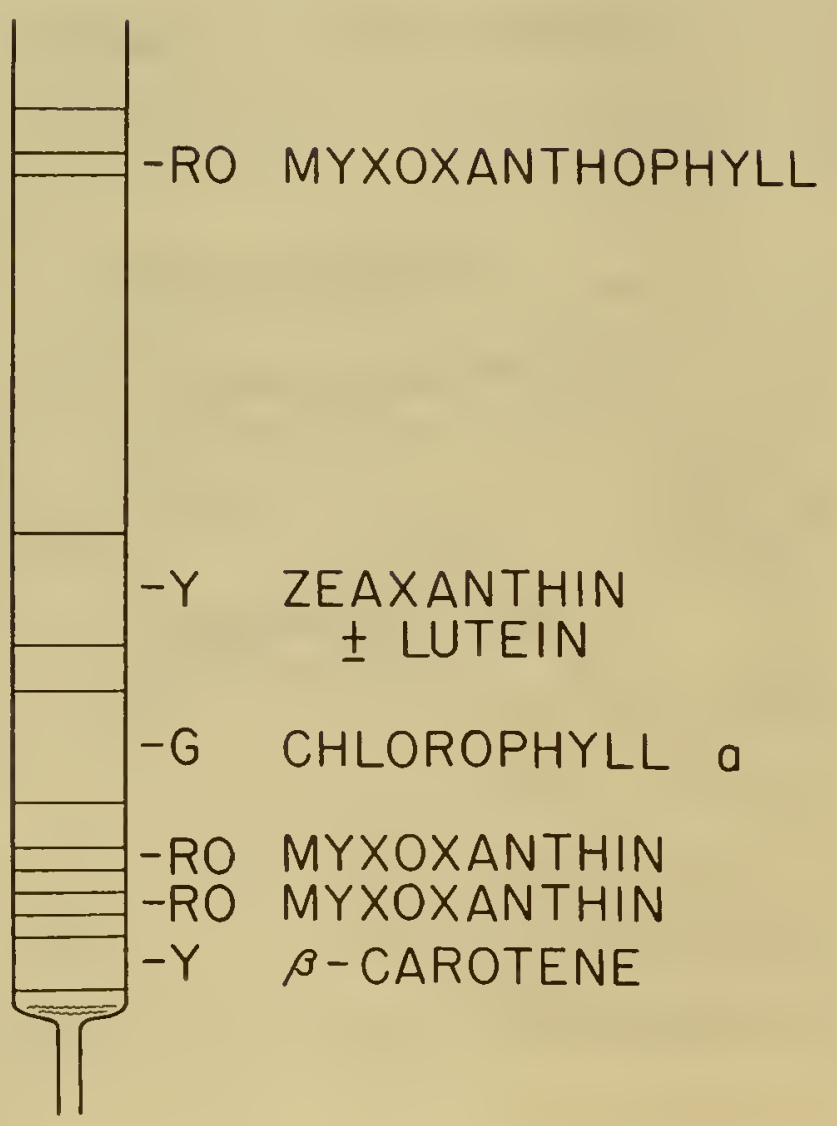


Figure III, 11. Characteristic spectral absorption curves of the unique xanthophylls of blue-green algae (Cyanophyta). (See Figure III,10.)

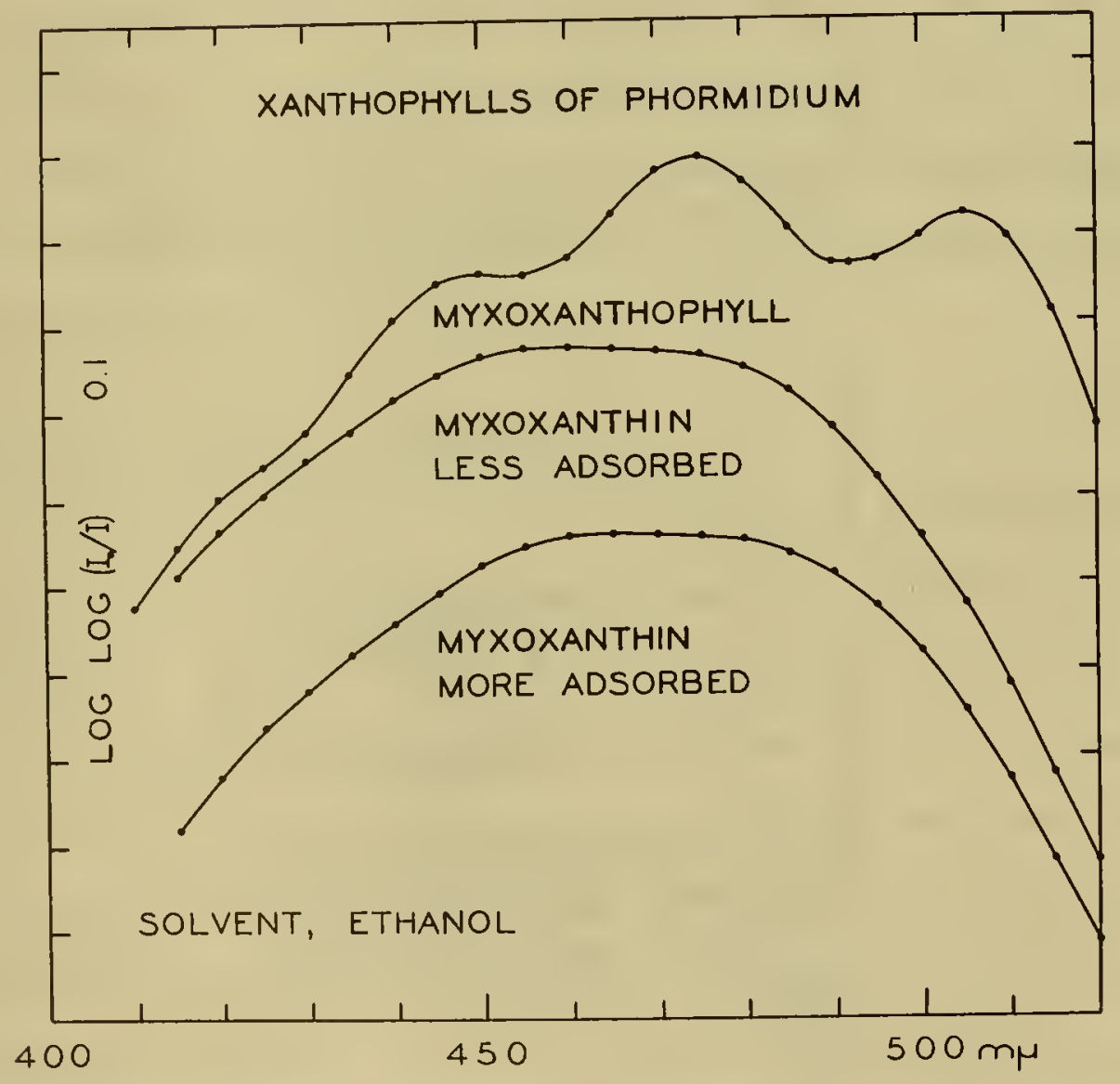




\section{ALTERATION PRODUCTS OF CHLOROPLAST PIGMENTS}

\section{Established Alteration Reactions}

Both the carotenoid pigments $I, 10: I I, 6$ and the chlorophylls 1,2 undergo isomerization reactions. These reations yield additional isomeric pigments that are easily separable in the chromatographic columns。

When plants are killed under conditions that do not inactivate enzymes, the chlorophylls often undergo rapid oxidation with the production of additional green pigments. The formation of these oxidation products, which is accelerated by enzymes and by autoxidation, varies from plant to plant and with the treatment of the plant tissue I, $10: I I, 3$.

The oxidation of the chlorophylls in methanol solutions, which has long been called allomerization of chlorophyl13, has been found to yield a mixture of several pigments. Some of these oxidation products are chromatographically identical with the enzymatic oxidation products of the chlorophylls.

Chromatographic studies have shown that the methanolysis products of the chlorophylls, long known as the methyl chlorophyllides 3 , are readily separable in the sugar columns. These pigments, formed by enzymatic methanolysis in the presence of dilute methanol, are more sorbed than the natural chlorophylls. The chlorophyllides, themselves, formed by hydrolysis of the chlorophylls, are also separable as very stongly sorbed zones in the sugar columns.

The pheophytins, which are formed when acid solutions remove the magnesium from the chlorophyll molecule, are weakly sorbed in columns 
of powdered sugar. They form yellow or gray colored zones that precede the green zones of the chlorophylls ${ }^{2}$.

Like the chlorophylls, the methyl chlorophyllides and the pheophytins yield additional pigments when the solutions are heated II, 3 . In columns of powdered sugar, these heat-formed substances are less sorbed that the parent pigments. They are reconverted to the parent compounds by heating their solutions? ${ }^{2}$. By analogy with the chlorophylls, they are isomers of the parent pigments.

Some of the xanthophylls, such as violaxanthin, are extremely sensitive to acid. An acid as weak as acetic acid in organio solvents soon converts these xanthophylls into several pigments that exhibit spectral absorption maxima at wave lengths shorter than those of the maxima of the parent pigments $I I, 4$.

\section{Isomerization of the Chlorophylls by Heating Leaves}

When leaves are scalded or blanched with boiling water for only 5 to 10 minutes, relatively large amounts of the chlorophyll isomers ar and b' are formed ${ }^{1}, 4$. Separation of the extracted pigments in a column of powdered sugar yielded a series of zones like that shown in Figure III, 12。

Isomerization of Chlorophylls a and b in Solution at Room Temperature

When petroleum ether solutions of the chloroplast pigments are permitted to stand at room temperature for only an hour or two, detectable quantities of ohlorophylls $\underline{a}^{\prime}$ and $\underline{b}^{\prime}$ are formed. These isomers separate readily in the sugar columns as already indicated in Figure III,12。 Solutions that have stood for longer periods contain much more of the $\underline{a}^{\prime}$ and $\underline{b}^{\prime}$ isomers, which increase to 10 to 20 per cent of the $a$ and $\underline{b}$. 
Figure III, 12. Chlorophylls $a^{\prime}$ and $b^{p}$ formed by scalding barley leaves with böiling water for 10 minutes.

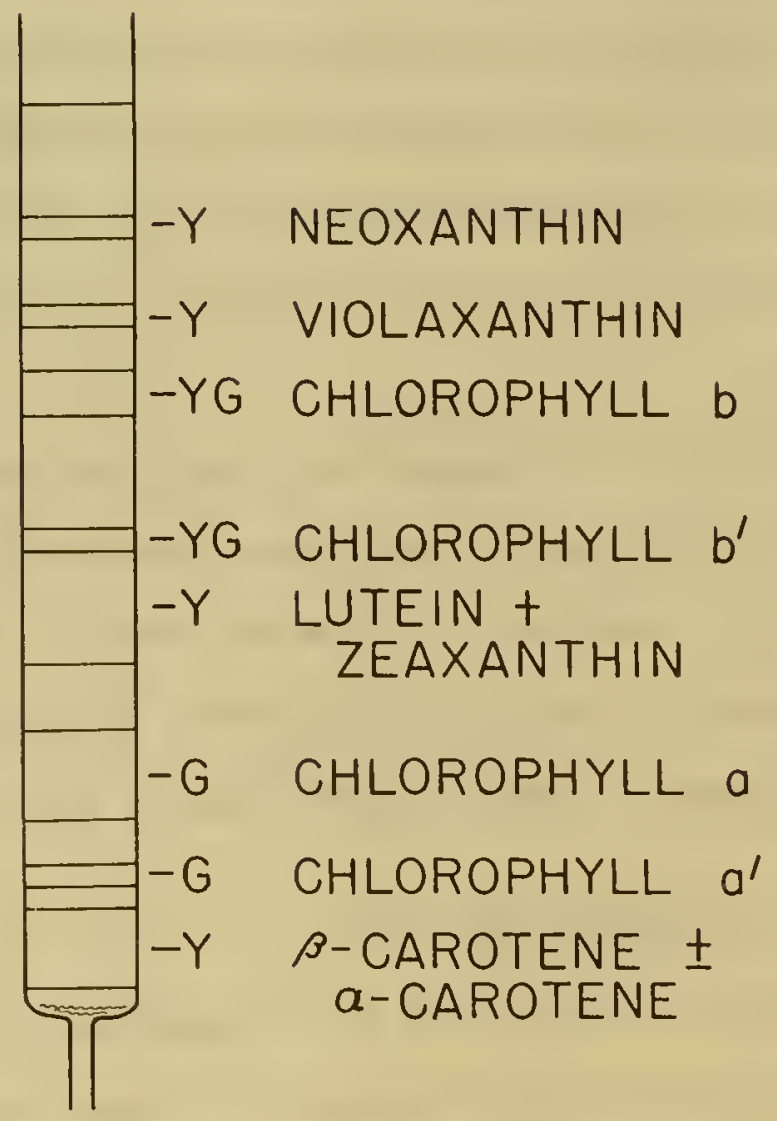


As a rule, large scale preparations of chlorophylls a and $\underline{b}$ contain the $a^{\prime}$ and $\underline{b}^{\prime}$ isomers. The presence of these isomers may be attributed to the relatively long time required for the isolation of the pigments and also to the fact that the preparation procedures usually employed do not separate the natural chlorophylls from their isomers $3: 1,7$.

Isomerization of Chlorophylls $\underline{a}$ and $\underline{b}$ by Heat and Alkalies

When $\underline{n-p r o p a n o l}$ or dioxane solutions of chlorophylls $\underline{a}$ and $\underline{b}$ are heated to $100^{\circ}$ for an hour, the pigments are converted to an equilibrium mixture with their respective isomers. If the isomers $a^{\prime}$ and $\underline{b}^{\prime}$ are separated by adsorption, recovered and heated again in solution, they are reconverted into the same equilibrium mixture obtained by heating $\underline{a}$ and $\underline{b}$ as illustrated by Figure III,13. And if the reformed $\underline{a}$ and $\underline{b}$ are separated, recovered and reheated, they again yield $\underline{a}^{\prime}$ and $\underline{b^{\prime}}$

The isomerization of chlorophylls $\underline{a}$ and $\underline{b}$ in $\underline{n}$-propanol yielding about 20 per cent of $\underline{a}^{\prime}$ and $\underline{b}^{\prime}$ occurs almost instantly at room temperature when traces of potassium hydroxide are added to the solution II, 3 . The $\underline{a}^{\prime}$ and $\underline{b}^{\prime}$ formed by alkalies and isolated by adsorption are reconverted to the mixture of isomers by retreatment with alkalies。

Isomerization of Chlorophyll d

When solutions of chlorophyll d are permitted to stand for a few hours at room temperature, small amounts of a less sorbed isomer, chlorophyll d', are formed. Upon longer standing or upon heating the solution, two additional, less sorbed isomers, isochlorophyll d and isochlorophyll de appear. All these isomers are separable in columns of powdered sugar with petroleum ether plus 0.5 per cent $\underline{n}$-propanol 
Figure III,13. Mixture of chlorophylls formed by heating a n-propanol solution of chlorophylls $\underline{a}^{8}$ and $\underline{b}^{\circ}$ at $100^{\circ}$ for 1 hour。

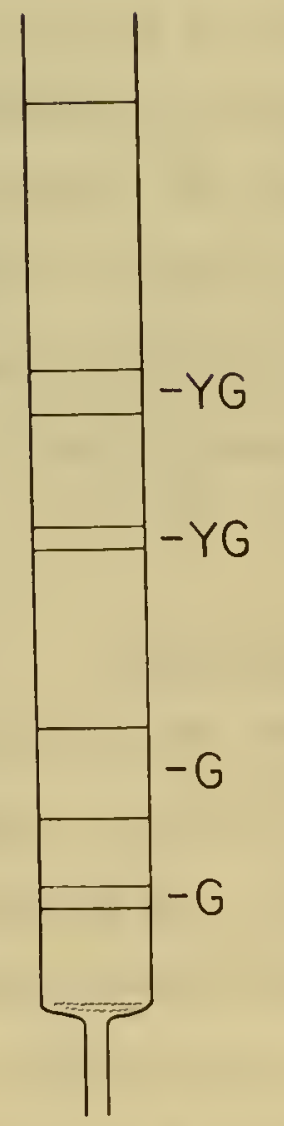

CHLOROPHYLL b

CHLOROPHYLL $b^{\prime}$

CHLOROPHYLL a

CHLOROPHYLL $a^{\prime}$ 
as the wash liquid as has been described before ${ }^{2}$. Attempts to isolate chlorophyll d in quantity usually lead to contamination of the product by the isomers, which are formed in detectable quantities before the pigment can be isolated.

Chromatographic Sequence of the Chlorophylls and Their Isomers

As a guide for the separation and identification of the chlorophylls, the sequence of the chlorophyll pigments in a column of powdered sugar is shown in Figure III, $1_{4}$. This sequence was established by adsorption of the pigments from petroleum ether solutions followed by development with petroleum ether containing 0.5 per cent n-propanol. The chlorophyll c was isolated from brown algae, chlorophylls $\underline{a}$ and $\underline{b}$ from leaves, and chlorophyll d from red algae. The isomers were isolated after heating $\underline{n-p r o p a n o l ~ s o l u t i o n s ~ o f ~} \underline{a}, \underline{b}$ and $\underline{d}$. The protochlorophyll was isolated from the inner seed coats of manroot, Cucurbitacear (Appendix I). It did not yield additional pigments when its solution in propanol was heated.

Isolation of the Methyl and Ethyl Chlorophyllides

The methyl chlorophyllides were formed when chopped, fresh leaves of mallow (Malvaceae) were treated with twice their weight of methanol and allowed to stand for 6 to 24 hoursII,3. The pigments were then extracted and separated in columns of powdered sugar. Some free chlorow phyllides were usually formed, and these were strongly sorbed at the top of the column. The methyl chlorophyllide $\underline{b}$ was sorbed above the chlorophyll b between neoxanthin and violaxanthin。 The methyl chlorophyllide a was sorbed above the chlorophyll a in the lutein plus zeaxanthin zone as shown in Figure $I I I, 150$ 
Figure III,140 Adsorption sequence of the chlorophylls and their principal isomers in a column of powdered sugar washed with petroleum ether containing 0.5 per cent nopropanol.

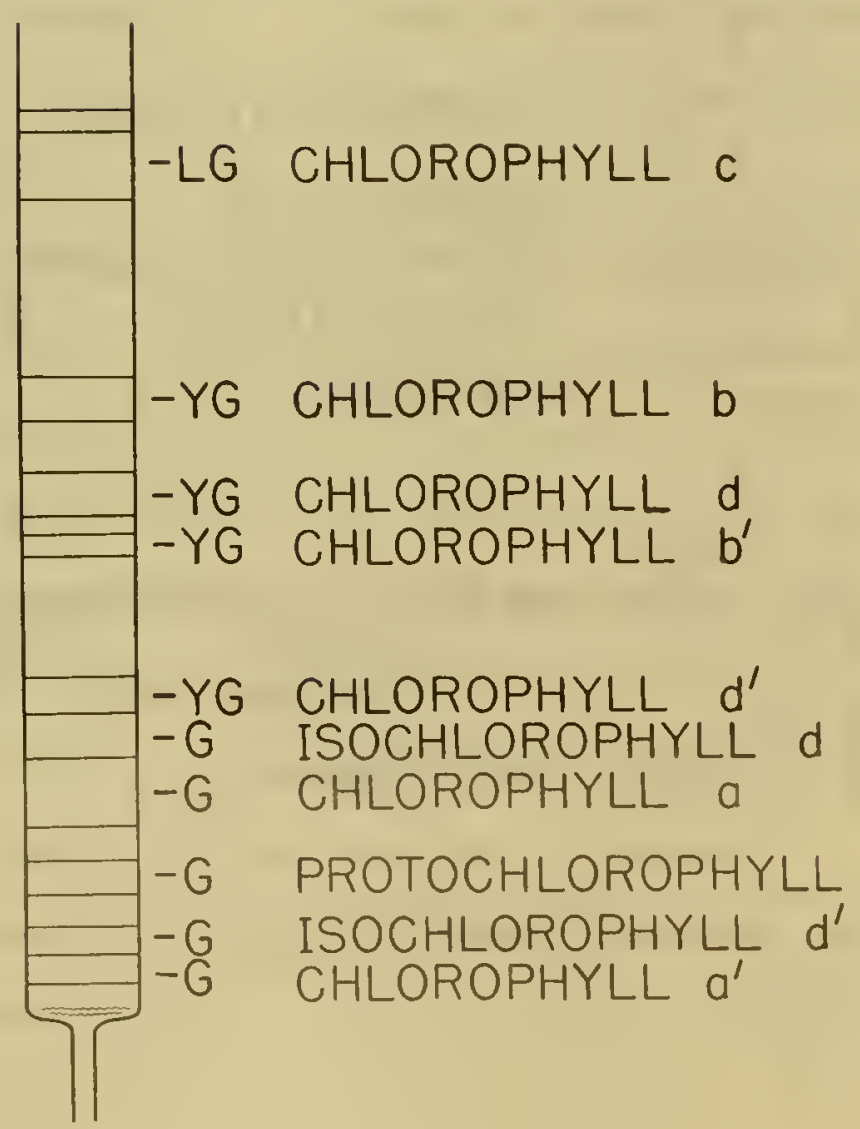


Figure III,15. Methyl chlorophyllides separated by adsorption after treatment of mallow leaves with methanol.

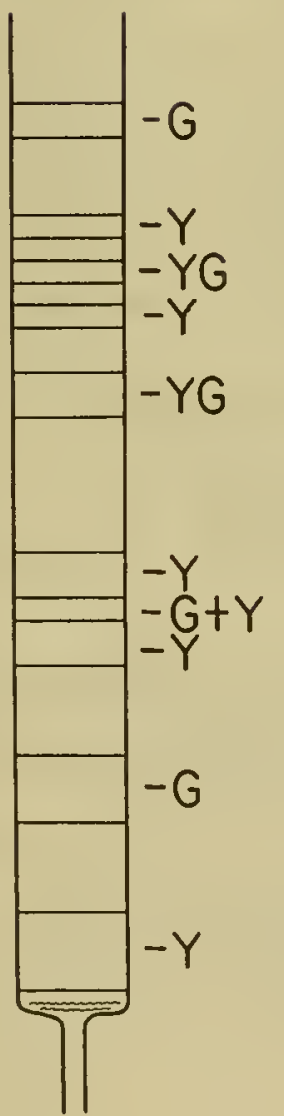

CHLOROPHYLLIDES

NEOXANTHIN METHYL CHLOROPHYLLVIOLAXANTHIN IDE b CHLOROPHYLL $b$

METHYL CHLOROPHYLL-
+ LUTEIN + ZEAXANTHIN CHLOROPHYLL a CAROTENES 
When mallow leaves were permitted to stand with ethanol, the ethyl chlorophyllides were formed. The ethyl chlorophyllide $\underline{b}$ was less sorbed than the methyl chlorophyllide $\underline{b}$, but more sorbed than chlorophyll $\underline{b}$. With the leaf pigments, it formed a zone just below violaxanthin. The ethyl chlorophyllide a was less sorbed than the methyl chlorophyllide a, and with the leaf pigments, it formed a green zone just below the yellow lutein zone.

Isomerization of the Methyl Chlorophyllides

The methyl chlorophyllides, prepared in mallow leaves and isolated in columns of powdered sugar as described above, were dissolved in $\underline{n-}$ propanol, and the solutions were heated at $100^{\circ}$ for an hour. The pigments in the heated solution were transferred to petroleum ether, adsorbed in sugar columns, and washed with petroleum ether containing 0.5 per cent $\underline{n}$-propanol. Methyl chlorophyllide $\underline{b}$ yielded a small quantity of a green pigment that was less sorbed than the initial methyl chlorophyllide $\underline{b}$ and that had about the same sorbability and spectral properties as chlorophyl b itself. Methyl chlorophyllide a also yielded small amounts of a less sorbed green pigment with spectral properties like those of chlorophyll a. All these products gave positive, yellow phase tests when treated with strong alkalies in methanol.

When the heat-formed products were recovered and their solutions in n-propanol were heated to $100^{\circ}$ for an hour, the pigments were partially (about 70-80 per cent) reconverted into the methylesters derived directly from the chlorophylls. Like the isomerization of the chlorophylls, the partial reconversion or interconversion was produced almost instantly by traces of alkalies added to the propanol solutions. 
Enzymatic Oxidation of Chlorophylls in Leaves

When the leaves of many plants are killed with anesthetics or by grinding, so that the oxidative systems are not destroyed, the chlorophylls are partially oxidized yielding additional green pigments 5:II, 3. This effect is partioularly conspicuous when the chopped, young, green leaves of barley are permitted to stand for a day or two with twice their weight of acetone. The pigments, then extracted from the leaves with methanol and petroloum ether and separated by chromatography in a column of powdered sugar, provided a chromatogram like that shown in Figure III,16. An oxidation product of chlorophyll b separated just above the neoxanthin zone. An oxidation product of chlorophyll a separated with and just below the chlorophyll $\underline{b}$. This a oxidation product and the chlorophyll $\underline{b}$ were recovered, adsorbed in another column of powdered sugar and separated by washing with benzene. Under these conditions, the a oxidation product was sorbed above the chlorophyll bo Each oxidation product exhibited spectral absorption properties like those of the chlorophyl from which it was derived. But each oxidation product gave a green phase test whereas the recovered chlorophylls gave yellow phase tests with strong alkalies。

The same oxidation products were isolated after barley leaves had been treated with methanol, with ethanol and with ethyl ether。 These oxidation products were also found among the allomerization products of the chlorophylls. (See next section.)

\section{Allomerization of Chlorophylls}

It has long been known that chlorophylls $a$ and $\underline{b}$ when dissolved in absolute methanol and permitted to stand in air yield the so-called 
Figure III, 16. Oxidized chlorophylls separated by adsorption after treatment of young barley leaves with acetone for 1 day.

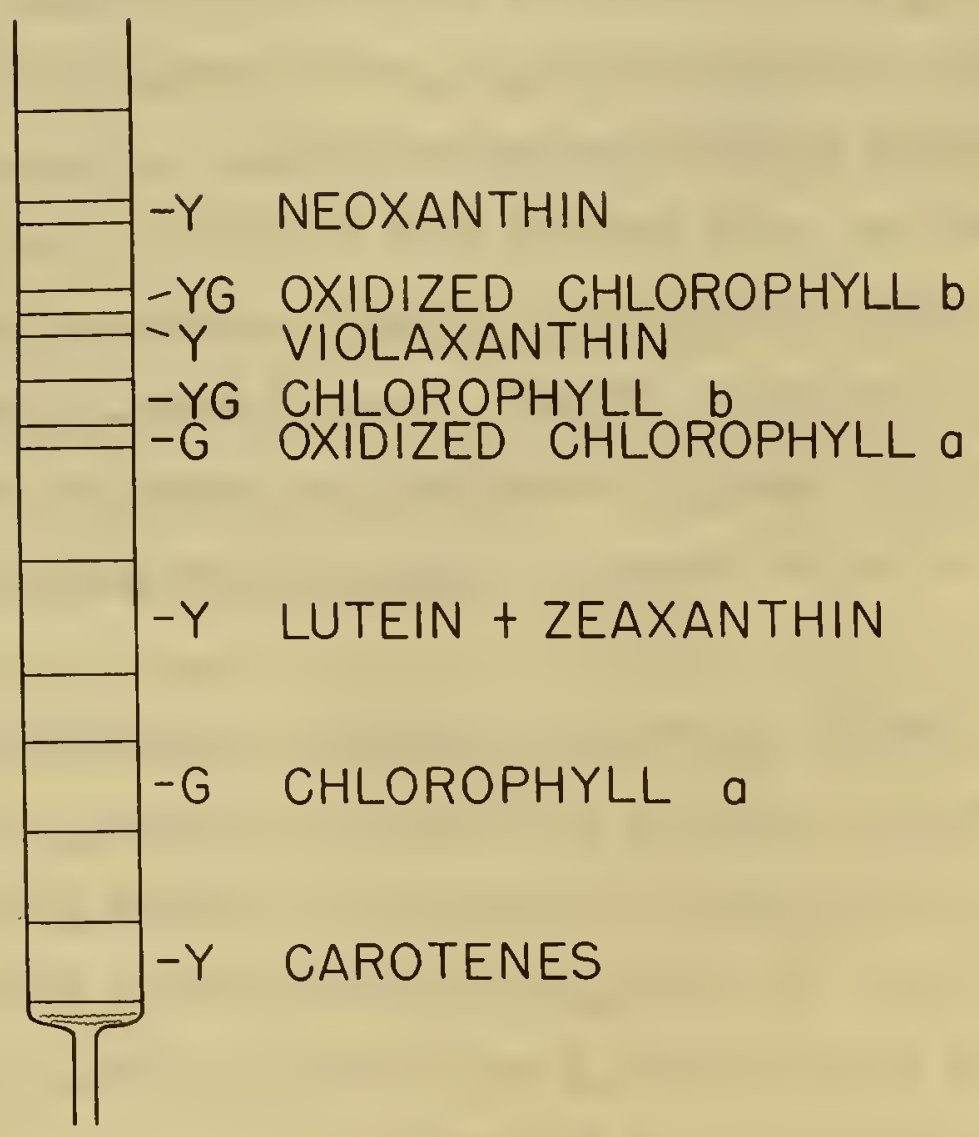


allomerized chlorophylls. These allomerized pigments, that are formed by oxidation of the chlorophylls and simultaneous reaction with methanol, exhibit speotral absorption maxima at wave lengths about $10 \mathrm{~m} \mu$ shorter than those of the parent chlorophylls 3 .

Examination of the allomerized chlorophylls in columns of powdered sugar has now shown that a mixture of pigments is usually produced. The principal allomerization product of chlorophyll a formed a blue-green zone in the sugar columns. It was more sorbed than the a itself and a little less sorbed than lutein. It exhibited absorption maxima at wave lengths about $20 \mathrm{~m} \mu$ shorter than those of chlorophyll $\underline{a}_{0}$ The second most abundant oxidation product was sorbed second above the chlorophyll a and exhibited absorption maxima corresponding to those of the a. This pigment was sorbed with and below chlorophyll b and was identical with the product obtained by the enzymatic oxidation of chlorophyll a in barley leaves (Figure III,16). Traces of several pigments more sorbed than this oxidation product and less sorbed than chlorophyll a were observed in the columns. All these pigments gave green phase tests。

The principal allomerization product of chlorophyll b in methanol was slightly more sorbed in sugar than the unaltered b. This product exhibited spectral absorption maxima at wave lengths about 10 m shorter than those of $\underline{b}$. The second most abundant oxidation product was sorbed second above the chlorophyll b and exhibited absorption maxima oorresponding to those of b. It was identical with the pigment obtained by the enzymatic oxidation of chlorophyll b in barley leaves (Figure III, 16). Traces of additional pigments more sorbed and less sorbed than the two principal oxidation products were also observed in the columns. 
The principal allomerization products of $\underline{a}$ and $\underline{b}$ did not yield additional pigments (isomerization products), separable by chromatography, when n-propanol solutions were heated to $100^{\circ}$ for an hour II, 3 .

\section{Formation of Pheophytins}

When plants that contain strongly acidic juices are killod in various ways or extracted with methanol, the acids convert the chlorophylls into the weakly adsorbed, magnesium-free pheophytins. This deleterious effect may be reduosd by rapid extraction and also by the addition of dimethylaniline to the extraction solvento

With the extracts of acidic leaves adsorbed in columns of sugar, the pheophytin a formed a gray zone below chlorophyll a'. Phoophytin b formed a yellow-gray zone below the lutein zone and well above chlorophyll a.

When solutions of the pheophytins in n-propanol were heated, the a and the b pheophytins yielded less sorbed pigments that were reconvertible to the $\underline{a}$ and the $\underline{b}$ pheophytins ${ }^{1}$. These less sorbed pheophytins correspond to the chlorophyll isomers $\underline{a^{\prime}}$ and $\underline{b}$ '。

Chlorophyll d treated with acid at low temperature yielded pheophytin d that formed a yellow zone in the sugar columns ${ }^{2}$. With acid at room temperature, the d yielded isopheophytin d that formed a gray zone in the columns. With heat or upon standing, pheophytin d yielded a similar less sorbed pigment, pheophytin d', corresponding to chlorophyll d', and isopheophytin d yielded a less sorbed isomer, isopheophytin $d$, corresponding to isochlorophyll d'。 The relative positions of the principal pheophytins in a sugar column washed with petroloum ether containing 0.1 per cent $\underline{n}$-propanol are shown by Figure III, 17。 
Figure III, 17. Adsorption sequence of the pheophytins of the principal ohlorophylls in columns of powdered sugar washed with petroleum ether containing 0.1 per cent n-propanol.

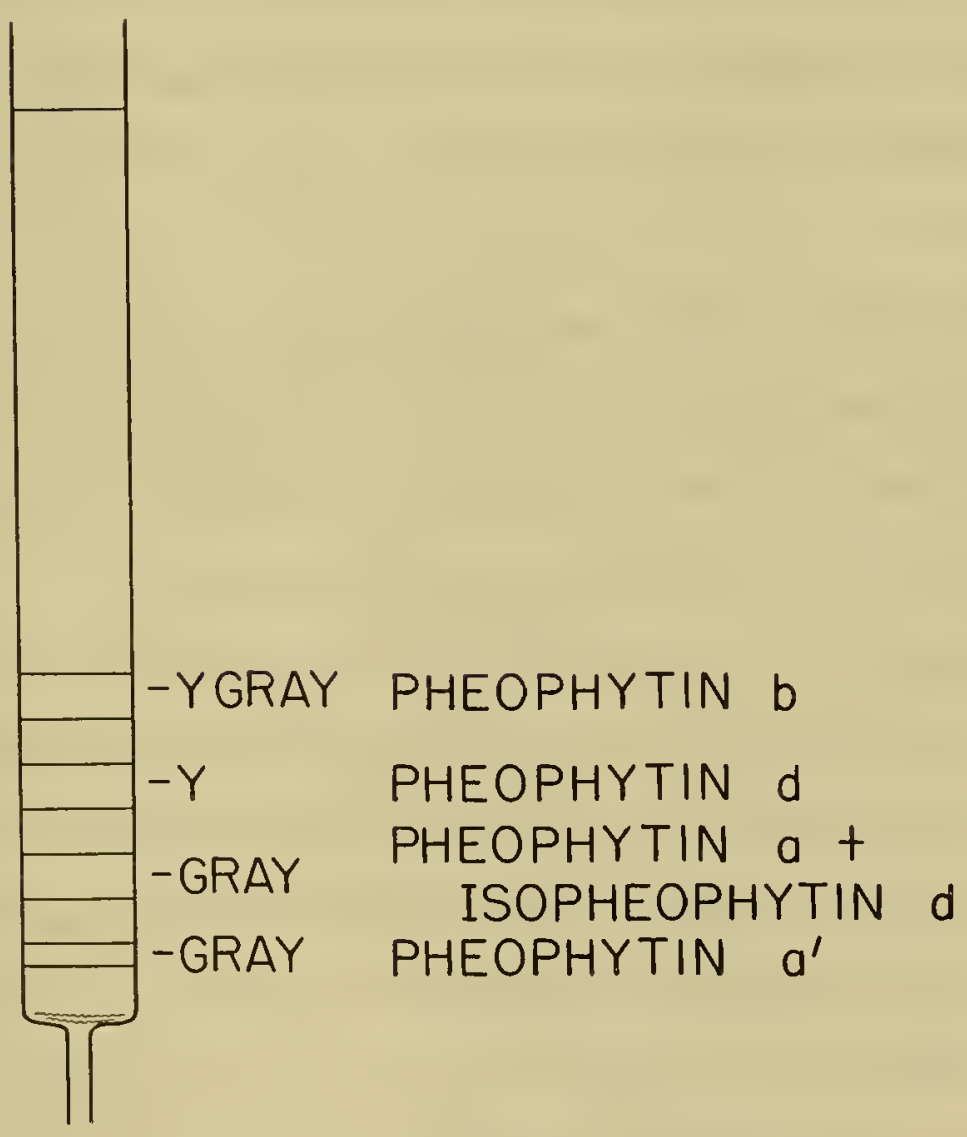




\section{PIGMENTS AND PHOTOSYNTHESIS}

Role of Pigments in Photosynthesis

Green plants, particularly young barley leaves, have been ex3d to a great variety of conditions that are known to affect the osynthetic process. The pigments were then extracted and sepa1 by chromatographic adsorption in sugar columns $I, 6 ; I, 9$. Some e conditions employed were low temperature $\left(-0^{\circ}\right)$, high tempera(30-35 ), carbon dioxide-free air, carbon dioxide-rich (5 per iir, vacuum, oxygen, reducing agents such as hydroquinone, s, sunlight, and infrared and ultraviolet light。 Under all alfferent conditions, the same pigments were always isolated, and these pigments were obtained in about the same proportions.

\section{CONCLUSIONS}

The isolation of the chloroplast pigments by chromatographic adsorption methods has revealed characteristic pigment distributions that facilitate the comparison and definition of the principal plant groups. The occurrence of chlorophyll a, xanthophylls, and carotenes in $a 11$ plants that produce oxygen by photosynthesis indicates a como mon origin for the photosynthetic apparatus. It suggests a fundamental functional role for the pigments that was established long before evolution of the species that are known today.

The occurrence of specific chlorophylls and xanthophylls in species of major taxonomic divisions supports the phylogeny or race history of the principal plant groups. The occurrenoe of chlorophylls $\underline{a}$ and $\underline{b}$, lutein plus zeaxanthin, violaxanthin, nooxanthin, and $\beta$-carotene 
in flowering plants, flowerless plants and green algae indicates a close relationship among these organisms. The siphonalean green algae with siphonaxanthin, siphonein and much $\alpha$-carotene in addition to the pigments of other green algae appear as a distinct modification of the green algae. The Euglenas with chlorophylls $\underline{a}$ and $\underline{b}$ and $\beta-c a r o t e n e$ but with unique xanthophylls are a distinct group remotely related to the other algae. With respect to pigments, the Chrysophta are a diverse group: the Bacillariophyceae or diatoms with chlorophylls a and c) fucoxanthin, diatoxanthin, diadinoxanthin and $\beta$-carotene are diso tinct from the Heterokontae with chlorophyll a, unique xanthophylls and $\beta$-carotene. Actually, the diatoms and the brown algae (Phaeophyta), with the same chlorophylls, a and $\underline{c}$, the same principal xanthophyll, fucoxanthin, and the same $\beta$-carotene, are much more alike than the diatoms and the Heterokontae. The dinoflagellates with chlorophyll but with a unique prinoipal xanthophyll, peridinin, must represent a distinct group remotely allied to diatoms and brown algae。 Red algae,

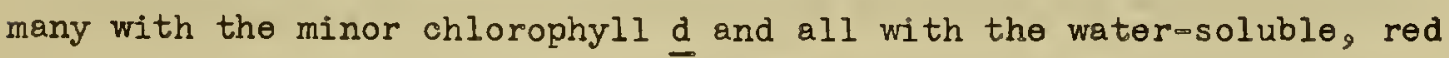
$r \rightarrow$ phycoerythrin, form another distinct class as do the blue-green algae with myxoxanthophyll, myxoxanthin and the blue cophycocyanin.

The chromatographic adsorption methods have revealed that, in solution, the plant pigments undergo various isomerization and alteration reactions yielding a variety of colored products。 Great care must be exercised in the extraction and isolation of the pigments to prevent contamination of the natural pigments with these alteration products.

By contrast with their lability in solution and in injured or anesthetized plant tissues, the chloroplast pigments are remarkably 
stable in the living plants. This result indicates that photosynthesis occurs without conversion of the principal pigments into other oolored substances or into colorless products that are reformed under the action of light and air. From this standpoint, the chloroplast pigment system is an organic antenna that collects the energy of sunlight for photosynthesis without itself undergoing extensive chemical change or alterw ation.

The pigment system consisting of chlorophyll a plus or minus other chlorophylls, xanthophylls, and one or more carotenes is characteristic of autotrophic plants growing under natural conditions. The only principal pigment common to all the organisms examined was chlorophyll a. Yet the fact that this chlorophyll a was not found unaccompanied by carotenoids suggests that the carotenoids play an indispensable role in the formation, maintenance, structure, or function of the photosynthetic apparatus.

At the present stage of our knowledge about the photosynthetic process, it is possible to fancy a variety of mechanisms whereby the energy of sunlight is transformed to chemical potential energy by the production of organic matter and oxygen through the intermediary action of the pigments. But the precise mechanism has yet to be elucidated 6 . 


\section{REFERENCES}

1. H。H.Strain and WoM。Manning, JoBiol。Chem。, 146, 275 (1942)。

2. W。M。 Manning and $H_{0} H_{0}$ Strain, J。Biol。Chemo, 151, 1 (1943)。

3. Ho Fischer and Ao Stern, Die Chemie des Pyrrols。 II。 Band。 Pyrrolfarbstoffe。2。 Hllfte。 Leipzig, (1940)。

4. H。H. Strain, Jo Am。Chem。Soc。, 77, 5195 (1955)。

5. HoH。Strain, W。M。Manning and Go Hardin, JoBiol。Chem。, 148, 655 (1943)。

6. M.Calvin, Photosynthesis。 University of California Radiation Laboratory, UCRL-3848, July 1957. 


\section{PROCEDURES}

\section{Tswett's Empirical Method}

The separation of the chloroplast pigments in adsorption columns established the chromatographic adsorption prooedure. This technique, the formation of a narrow zone of the mixture followed by washing with fresh solvent, represented a distinct advance over the earlier adsorption methods in which a solution of the mixture was permitted to percolate through the porous sorbent $I, 5$.

The methods for the recovery of the chloroplast pigments separated in columns have served for the isolation of various kinds of substances resolved by chromatography. Collection of successive portions of the percolate has served for isolation of the weakly sorbed components. Removal of the individual zones from the column followed by elution of each substance with a suitable solvent has facilitated the recovery of the strongly sorbed components $I, 5$.

The observability of the chloroplast pigments in chromatographic columns provided much information about the chromatographic process. It revealed the dynamic sorption and desorption of the pigments, the distribution of the pigments in the zones, and the effect of the sorbent and the solvent upon the separation of the pigments $1,2,3$.

The experiments with the chloroplast pigments not only demonstrated the effectiveness of the chromatographic technique, but they also led to the separation of mixtures of all kinds of soluble and volatile substanoes. Many of these applications were contingent upon the development of 
sensitive techniques for the detection and investigation of the sepa rated substances.

\section{SOLVENTS AND SORBENTS}

Functions of the Solvent

In the early investigations of chloroplast pigments, the solvent was found to serve three critical functions. It dissolves the pigments in a condition suitable for adsorption. It permits the reversible sorption of the pigments in the chromatographic column, and it facilis tates the selective sorption of the components of the mixture by the sorbent.

The chromatographic experiments with chloroplast pigments showed that the separations are often improved by slight modifications of the solvent. The addition of weakly polar substances such as alcohols and acetone to nonpolar wash liquids provides an adsorption gradient in the column. It accelerates the separation of the sorbed pigments. It often improves the sharpness or definition of the pigment zones, ber cause it reduces the trailing regions. In this way, it restricts the crossocontamination of the zones, and it facilitates the separation of the strongly sorbed pigments as well as the separation of the weakly sorbed pigments in columns of a single sorbent。

With a given sorbent and with a particular pigment mixture, the solvent determines the sorption capacity of the sorbent and the sepaw rability of the mixture. As a rule, sorption is greatest from solutions in nonpolar solvents such as saturated hydrocarbons and least in very polar substances such as organic acids and bases 1,5 . The separability of pigments varies greatly with the solvent and with the addition of various solutes. The addition of substances that are sorbed 
between the components of mixtures usually increases the separability. Variation of the solvent often results in unpredictable variation of the chromatographic sequence and of the separability ${ }^{l}$.

\section{Functions of the Sorbent}

Like the solvent, the sorbent also plays three critical roles. It exhibits selective affinity for the components of the mixture, it permits dynamic, reversible sorption of each component of the mixture, and it equalizes the flow of the solvent through the column thereby providing uniform, symmetrical zones。

The sorption of solutes at an interface between a solution and a solid as utilized for the separation of chloroplast pigments is excoedingly complex. The sorptive properties of the sorbent, ineluding the sorption eapacity, the selectivity or the resolving power, and certain deleterious effects on sorbed substances, vary with the composition and treatment or activation. As shown by the studies with activated magnesia, not only the capacity for adsorption but also the quality of the adsorption vary with the conditions of activation I, 15 . For example, the adsorption capacity of magnesia for carotenes increases with the time and temperature of calcination approaching a high level, but the capacity of the magnesia to alter the carotenes increases even more with continued activation.

The method employed to pack the chromatographic column and the filtration properties of the column depend upon the properties of the sorbent. Powders that are compressible may be pressed into the tubes with plungers but slightly smaller than the tubes themselves. This method is particularly effective with powdered sugar, powdered cellulose, Celite, and mixtures of Celite with various finely powdered 
substances such as magnesia。 (See Lecture Io) It provides columns that filter uniformly and that do not form deleterious channels even if allowed to run dry $\mathbf{I}, 5$ 。

Columns may also be formed from slurries of the sorbent with the solvent. Compressible powders and especially noncompressible powders such as starch may be packed into columns in this way. These columns also filter uniformly, but they frequently form channels, and they shrink and become useless if allowed to run dry.

\section{SORBABILITY OF PIGMENTS}

\section{Molecular Structure and Sorbability}

At the time of Tswett's experiments, the major structural features of the chloroplast pigments had not been discovered. Consequently, como parison of the molecular structure of these pigments with their chromatographic behavior in adsorption columns was delayed for some 25 to 50 years. Meanwhile, there were few applications of chromatographic methods to organic substances of known molecular structure. As a result some of the first relationships among molecular structure, sorbability and sorption sequences were established with carotenoid pigments。

Long before Tswett's chromatographic experiments, the carotenes had been found to be hydrocarbons ${ }^{I}, 8$. Their lack of affinity for Tswett's mild adsorbents could, therefore, be attributed to the absence of polar groups. Many years later when the carotenes were found to be sorbed on the specially activated adsorbents, the molecules of these pigments were found to contain a conjugated system of double bonds, the double bonds occurring alternately with single bondsI,10\&I,11. The color or redness of the carotenes, as indicated by the wave lengths of 
the spectral absorption maxima, and the sorbability on activated sorbents increase with the number and the conjugation of the double bonds. Some of these relationships are indicated by Table IV,I. Lycopene, with 13 double bonds 11 of which occur in a single conjugated system, is more intensely colored, redder and much more sorbed than $\beta$-carotene, with 11 conjugated double bonds. But $\beta$-carotene, with its 11 conjugated double bonds, in redder and more sorbed than $\alpha$-carotene, with 11 double bonds only 10 of which are conjugated with single bonds.

At Tswett's time, the orystalline xanthophyll then isolated from leaves by Willstlter and his associates appeared to be an oxygen derivative of carotene. The greater sorption of the xanthophylls relative to carotene could be attributed to the oxygen atoms. Several decades later when the chemical combination or function of the oxygen atoms was determined, the sorbability of the xanthophylls was related to the presence of particular structural units such as hydroxyl $(\equiv \mathrm{C}-\mathrm{OH})$, keto $(=\mathrm{C}=0)$ and epoxy $\left(=\mathrm{C}^{\prime}-{ }^{\prime} \mathrm{C}=\right)$ groups $\mathrm{I}, 6, \mathrm{I}, 10$.

Among the ranthophylls, the relative sorbability, as reflected by the sorption sequenoe, is related not only to the number and conjugation of the double bonds, to the number of oxygen atoms, and to the function of the oxygen atoms but also to the solvent and the sorbentII,5. Table IV, II shows the molecular structures of four comon xanthophylis, rhodoxanthin, zeaxanthin, lutein, and cryptoxanthin. Table IV,III shows the effeot of variation of the sorbent and of the solvent upon the sorption sequence of these xanthophylis and the three oarotenes of Table IV,I. The brackets in Table IV,III indioate pigments that were not separated from one onother. 
TABLE IV,I。 Structural Formulas and Sorption Sequence of Three Carotenes

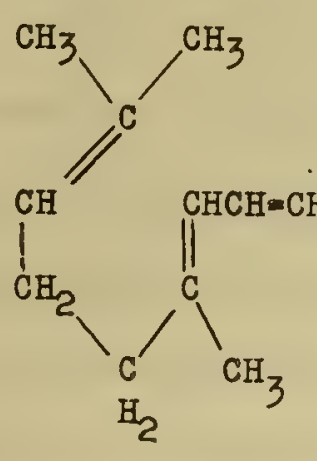

$$
\begin{gathered}
\text { Lycopene } \\
(11 \text { conjug ted }+2 \approx) \\
\text { (most sorbed) }
\end{gathered}
$$
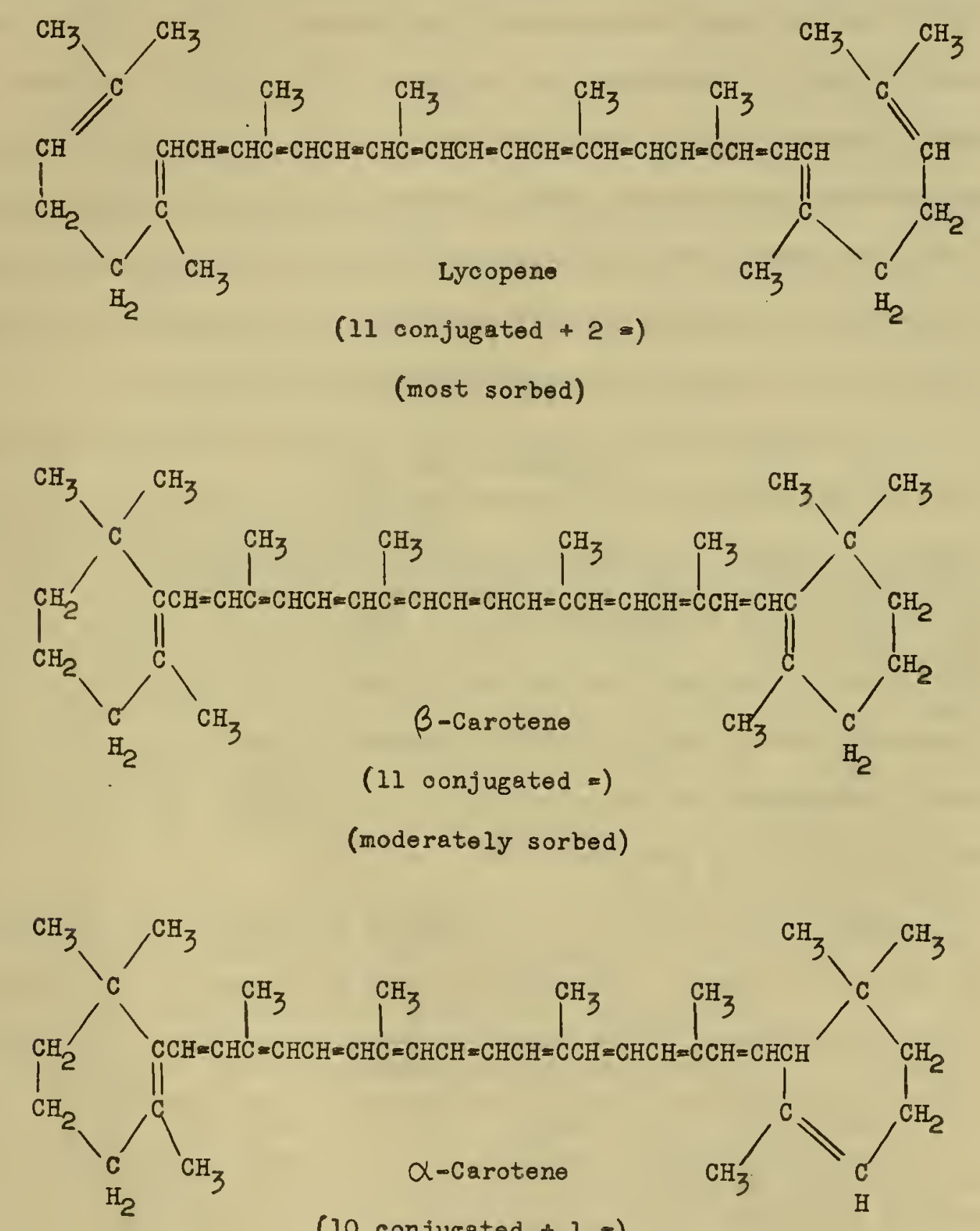

$$
\begin{gathered}
\alpha \text {-Carotene } \\
(10 \text { conjugated }+1=) \\
\text { (least sorbed) }
\end{gathered}
$$

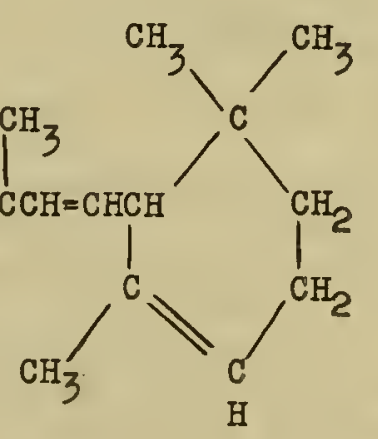


TABLE IV,II。 Structural Formulas of Four Xanthophylls<smiles>CCC1C(C)=CC2=CC1(C)CC2C</smiles>

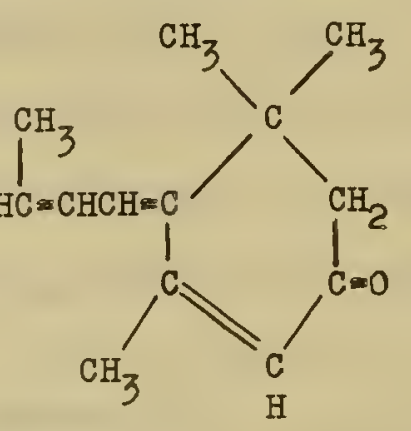

(14 conjugated $=$

including $2 \mathrm{C}=0$ groups)<smiles>CCC1=C(C)CC(O)CC1(C)C</smiles>

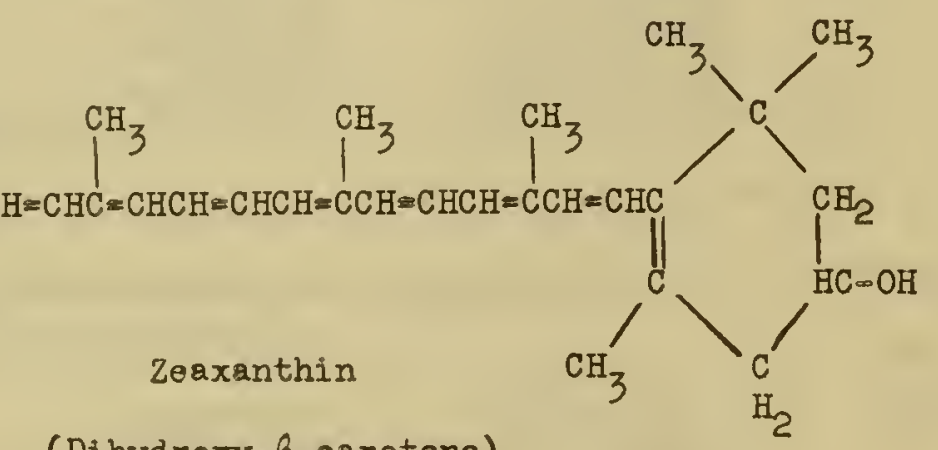

(II oonjugated +12 OH groups)<smiles>CCC(C)C1=C(C)CC(O)CC1(C)C</smiles>

(Dihydroxy- $\beta$-carotene)

(10 conjugated $+1=+2$ OH groups)<smiles>CC1=C(C(C)C)C(C)(C)CC(O)C1</smiles>

Lutein

(Dihyd roxy= $\alpha-$ carotene)

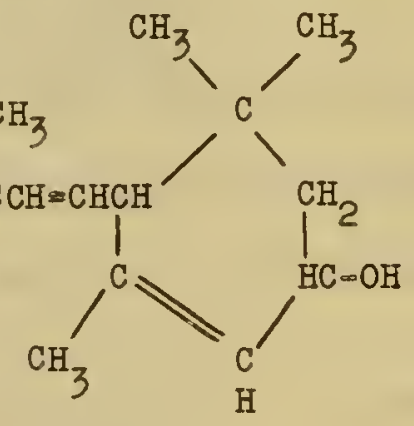


TABLE IV,III. Effect of Sorbents and Solvents upon the Sorption Sequence of Carotenoid Pigments

\begin{tabular}{|c|c|c|c|}
\hline Sorbent & Sugar & Sugar & Sugar \\
\hline Solvents & Petroleum ether & $\begin{array}{l}\text { Petroleum ether } \\
+ \text { n-Propanol }(0.5 \%)\end{array}$ & $\begin{array}{l}\text { Petroleun ether } \\
+ \text { Acetone (4\%) }\end{array}$ \\
\hline Sequences & $\begin{array}{l}\text { Rhodoxanthin } \\
\text { Zeaxanthin } \\
\text { Lutein } \\
\text { Cryptoxanthin } \\
\text { Lyoopene } \\
\text { B-Carotene } \\
\alpha \text {-Carotene }\end{array}$ & $\begin{array}{l}\text { Zeaxanthin } \\
\text { Lutein } \\
\text { Cryptoxanthin } \\
\text { Rhodoxanthin } \\
\text { Lycopene } \\
\text { B-Carotene } \\
\text { - Carotene }\end{array}$ & $\begin{array}{l}\text { Zeaxanthin } \\
\text { Lutein } \\
\text { Cryptoxanthin } \\
\text { Rhodoxanthin } \\
\text { Lycopene } \\
\text { B-Carotene } \\
\text { d-Carotene }\end{array}$ \\
\hline Sorbent & Celite 501 & Celite 501 & Celite 501 \\
\hline Solvents & Petroleum ether & $\begin{array}{l}\text { Petroleum ether } \\
+\underline{\text { noPropanol }}(0.5 \%)\end{array}$ & $\begin{array}{l}\text { Petroleum ether } \\
+ \text { Acetone ( } 4 \%)\end{array}$ \\
\hline Sequences & $\begin{array}{l}\text { Rhodoxanthin } \\
\begin{array}{|l}\text { Zeaxanthin } \\
\text { Lutein } \\
\text { Cryptoxanthin } \\
\text { Lycopene } \\
\text { B-Carotene } \\
\text { a-Carotene }\end{array}\end{array}$ & 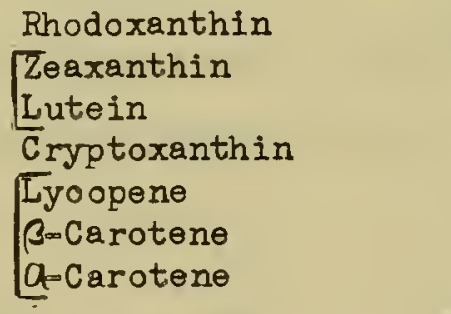 & $\begin{array}{l}\text { Zeaxanthin } \\
\text { Lutein } \\
\text { Phodoxanthin } \\
\text { Cryptoxanthin } \\
\text { Lycopene } \\
\text { - -Carotene } \\
\alpha-\text { Carotene }\end{array}$ \\
\hline Sorbent & Magnesia 2641 & Magnesia 2641 & Magnesia 2641 \\
\hline Solvents & Petroleum ether & $\begin{array}{l}\text { Petroleum ether } \\
+ \text { n-Propanol ( } 4 \%)\end{array}$ & $\begin{array}{l}\text { Petroleum ether } \\
+ \text { Acetone ( } 25 \%)\end{array}$ \\
\hline Sequences & $\begin{array}{l}\text { Rhodoxanthin } \\
\text { Lycopene } \\
\text { Zeaxanthin } \\
\text { Lutein } \\
\text { Cryptoxanthin } \\
\text { B-Carotene } \\
\alpha \text {-Carotene }\end{array}$ & $\begin{array}{l}\text { Rhodoxanthin } \\
\text { Zeaxanthin } \\
\text { Lyeopene } \\
\text { Lutein } \\
\text { Cryptoxanthin } \\
\text { B-Carotene } \\
\text { Q }=\text { Carotene }\end{array}$ & $\begin{array}{l}\text { Phodoxanthin } \\
\text { Lyoopene } \\
\text { Zeaxanthin } \\
\text { Lutein } \\
\text { Cryptoxanthin } \\
\text { B-Carotene } \\
\alpha \text {-Carotene }\end{array}$ \\
\hline
\end{tabular}


Certain regularities in the sorbability of the pigments appear in Table IV,III. Zeaxanthin, a dihydroxy- $\beta$-carotene, and lutein, a dihydroxy- $\alpha$-carotene, are more sorbed than cryptoxanthin, a monohydroxy- $\beta$. carotene. Cryptoxanthin, is, in turn, more sorbed than the $d$-carotene and $\beta$-carotene. Among these five pigments, the sorbability on sugar and on Celite is proportional to the number of the hydroxyl groups. The sorbability on magnesia is proportional to the number of the hydroxyl groups, to the number of double bonds, and to the number of conjugated double bonds.

Irregularities in the adsorption sequence of the pigments reported in Table IV,III are due largely to variation of the sorbability of rhodoxanthin and lycopene relative to the sorbability of the other pigments. The variation of the sorbability of lycopene is due primarily to variation of the sorbent, because lycopene is strongly sorbed on magnesia but weakly sorbed on sugar and Celite irrespective of the solvent。

The variation of the relative sorbability of rhodoxanthin (Table IV, III) is due primarily to variation of the solvent. In columns of the three different sorbents and with petroleum ether as solvent, the rhodoxanthin is the most adsorbed pigment. In columns of Celite, addition of acetone causes the rhodoxanthin to be sorbed below lutein and above cryptoxanthin. And in columns of sugar, addition of nopropanol or of acetone causes the rhodoxanthin to be sorbed below cryptoxanthin but above the carotenes.

The effects of these polar solvents upon the relative sorbability of the pigments may be attributed to two principal reactions; the combination of the sorbent with the polar solvent and the solvation of the 
pigment molecules with the polar solvent. As the sorbent becomes saturated with the polar solvent, its affinity for each pigment may vary from that in the absence of the polar molecules. This variation is a function both of the nature and the concentration of the polar substances added to the solvent.

As shown by their spectral absorption properties, the oarotenoid pigments react with polar organic solvents. In solution in nonpolar hydrocarbons, the carotenoid pigments exhibit well-defined spectral adsorption bands with definite absorption maxima, but in solution in polar organic solvents such as alcohols, the pigments exhibit poorly defined, spectral absorption bands. This effect indicates solvation of the chromophoric systems. It is most conspicuous with carotenoid molecules containing keto groups as has been shown already for rhodoxanthin, Figure II,2, siphonaxanthin, Figure II,5, and fucoxanthin, Figure II,6. These solvated molecules should exhibit relative adsorption affinities quite different from those of nonsolvated or less solvated pigments. The variation of the chromatographic sequence with variation of sorbent and solvent is greatest when there are large differences among the pigments themselves. For example, it is much easier to vary the sequence of chlorophylls, xanthophylls, and carotenes than to vary the sequence of carotenes or of xanthophylls 1,3 .

Variation of the relative sorbability of the pigments shown in Table IV,III is related to the structure of the molecules. In columns of magnesia, for example, lycopene is strongly sorbed along with the zeaxanthin. But in columns of sugar and of Celite, the lycopene is scarcely sorbed and forms a zone with the nonsorbed p-carotene and Q-carotene. As the conjugated, system of Iycopene is similar to that 
of zeaxanthin, magnesia attracts the two isolated double bonds in lycopene about as strongly as it attracts the two hydroxyl groups in zeaxanthin. Zeaxanthin and lutein, which differ from each other only in the number of conjugated double bonds, are readily separable in columns of magnesia but not in columns of sugar or of Celite. As zeaxanthin and lutein are comparable, dihydroxy derivatives of (3-carotene and $\alpha$-carotene, these observations indicate that powdered sugar attracts the hydroxyl groups of lutein and zeaxanthin but not the conjugated systems of double bonds. Magnesia, by contrast, attracts the hydroxyl groups, the conjugated double bonds, and the isolated double bonds. For each combination of sorbent and solvent, the sorbability of an organic molecule is the sumation of the sorbability of the funotional groups.

The conclusions just enumerated have provided several important practical implications. A sorbent for the resolution of mixtures of similar molecules should attract preferentially those groups or struce tural units that differ most. The more complex the molecule, however, the smaller the variation of sorbability caused by a particular group. From this standpoint, chromatographic methods do not permit the segregation of complex organic molecules in relation to particular functional groups as the specific chemical methods do. All these variable oircumstances must be considered when chromatographic sequences are utilized as a guide to the determination of molecular structure.

The observations summarized in Table IV, III and many of those reported in Lectures I, II, and III show that variation of the chromatographic sequence produced by variation of the sorbent and the solvent is frequently an aid in the separation of mixtures. For the separation 
of mixtures of unknown substances, various combinations of sorbents and solvents should be tested. The sequences observed under these different conditions provide a basis for the description of the components of the mixtures。

\section{CHROMATOGRAPHIC SYSTEMS}

\section{Complex of Mixture, Solvent, and Sorbent}

As shown first with chloroplast pigments, chromatographic separations are based upon a very selective and reversible interaction among the mixture, the solvent, and the sorbent, On the sorbent there is sorption of the solvent and of the pigments or solutes. In the solvent there are molecules of the solutes and their reaction or solvation products 。

At any point in the column there is a dynamic interaction among solutes, solvent and sorbent. Each component reacts reversibly with the others as indicated by the following diagramt.

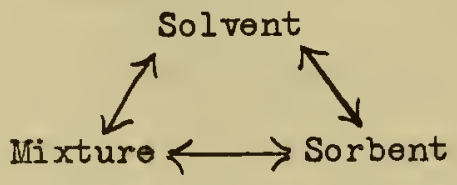

For definition of this kind of chromatographic system, the principal components must be specified. The mixture of the sorbed substances is usually defined with respect to the chemical nature of the constituents or with respect to the physical condition of the mixture as a gas, a vapor, or a solution. The solvent is described with respeot to its chemical composition or with respect to its physical state, usually a liquid or a gas as now employed in the new field of gas chromatography, 
recently developed by Martin and James 5,6 . The sorbent, by contrast, cannot be defined precisely in terms of its chemical composition alone. Its sorptive properties may depend, in part, upon the method of preparation, upon the treatment after preparation, and upon the degree of subdivision. The principal interactions of the chromatographic systems frequently employed in solution chromatography are indicated by Figure IV, 1 .

Variation of Mixture

After the effectiveness of the chromatographic procedure had been demonstrated by the separation of various pigments, the method was adapted to use with many different kinds of substances. These substances have now included all kinds of soluble organic compounds as hydrocarbons and their various derivatives, numerous labile organic compounds such as carbohydrates, fats, and proteins derived from living organisms, and various inorganic compounds including cations, anions, and nonionized compounds 7,8 .

As virtually all substances may be dissolved, nearly all substances can be examined by chromatographic methods. In this respect, solution chromatography is one of the most widely applicable analytical techniques ${ }^{6}$. (See Table IV,IV。)

An important variation of the mixture is the use of gases and vapors rather than the use of solutions. Gaseous substances and the vapors of substances that boil below about $300^{\circ}$ without decomposition may be examined by this so-called gas chromatography 5 . This modification of the technique reduces the dilution of the substances being separated and facilitates their detection by physical methods, such as 


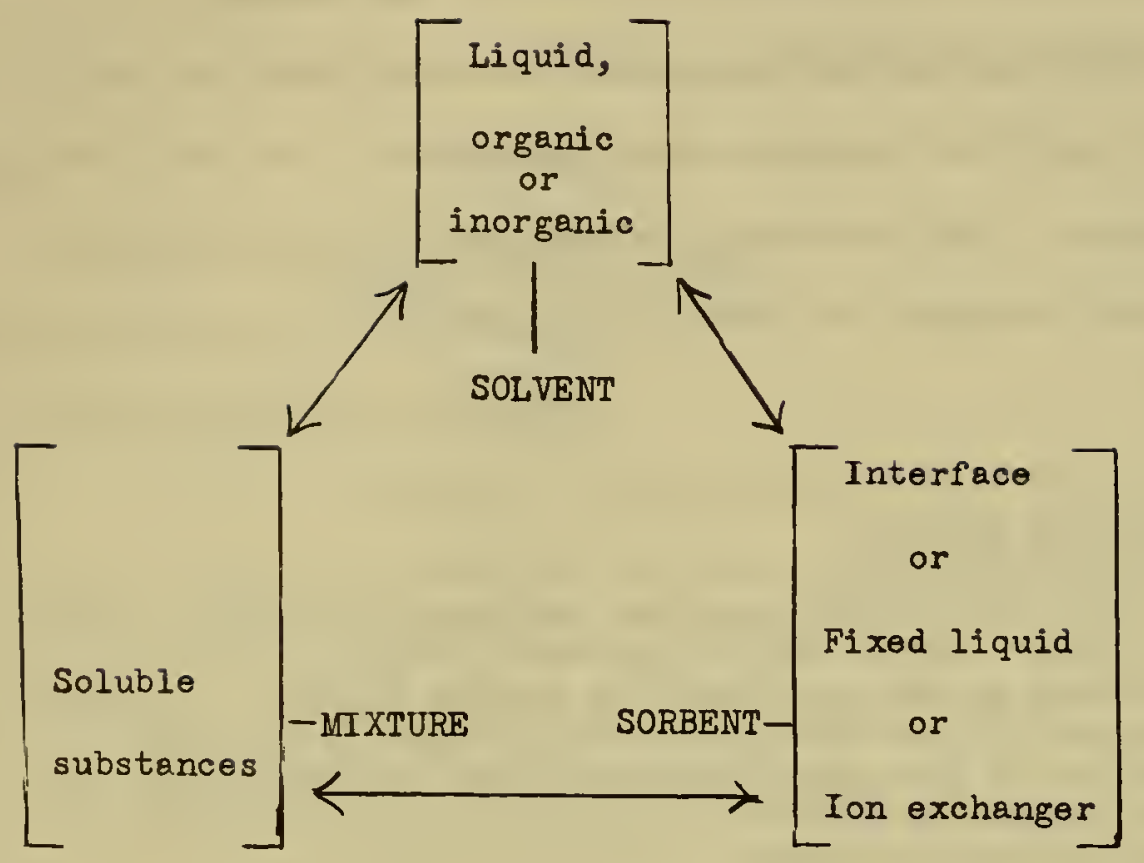

FIGURE IV, 1. Principal interactions in solution chromatography。 
TABLE IV, IV。 Some Common Mixtures, Solvents, and Sorbents

Employed in Solution Chromatography

Mixtures

Organic

Hydrocarbons

Saturated

Unsaturated

Halogenated compounds

Oxygen, nitrogen derivatives

Nitro derivatives, dyes, etc。

Biological products

Sugars, fats,

amino acids,

proteins,

pigments

hormones, etc。

Inorganio

Cations

Anions

Complexes

Chelates

etc。

Solvents

\section{Sorbents}

Liquids

Organic

Hydrocarbons

Chlorinated compounds

Ethers

Ketones

Esters

Terto amines

Sec。 amines

Prin。 amines

Alcohols

Acids

Mixtures

Inorganic

Water

Aqueous

solutions

Fused salts

\section{Interfaces}

Liquidosolid

Li qui doliquid

Ion exchangers

Zoolites

Cation exchange

Anion exchange

Resins

Cation exchange

Anion exchange

Fixed liquids

Polar liquids

Nonpolar liquids

(reversed phase) 
thermal conductivity, that are applicable to all kinds of volatile substancos. The principal interactions in systems employed with gas chromatography are shown by Figure $\mathrm{IV}_{9} 2$ 。

\section{Variation of Solvent}

Liquids employed as solvents for solution chromatography range from the nonpolar hydrocarbons to various polar substances。 They inolude inorganic liquids, various aqueous solutions, and even fused salts. Some of the various kinds of solvents, arranged in approximate order of increasing polarity $I^{5}$, are reported in Table IV, IV. Polarity is however, a relative property: hence the sequence of the solvents in the series varies with the mixture and the sorbent as may be inferred from Table IV, II.

With the development of gas chromatography, the solvents for chromatographic separations were extended to include gases as well as liquids. These aeriform fluids most useful in gas chromatography in clude nitrogen, hydrogen, and the rare gassesmonelium and argon 5,6 .

\section{Variation of Sorbent}

Along with the variation of mixtures and solvents, there has been a corresponding variation of sorbents ${ }^{6}$. (See Table IV,IV。) Many different kinds of powdered solids have been employed as the sorptive agents. Some of these have been activated in various ways. Not only sorption at gasmsolid and liquidosolid interfaces have been utilized but also sorption at liquid-liquid interfaces $I, 19$.

Natural and synthetic zeolites were employed for some of the first separations of various inorganic ions. And with the development of cation and anion exchange resins, ion exchange has become an important 


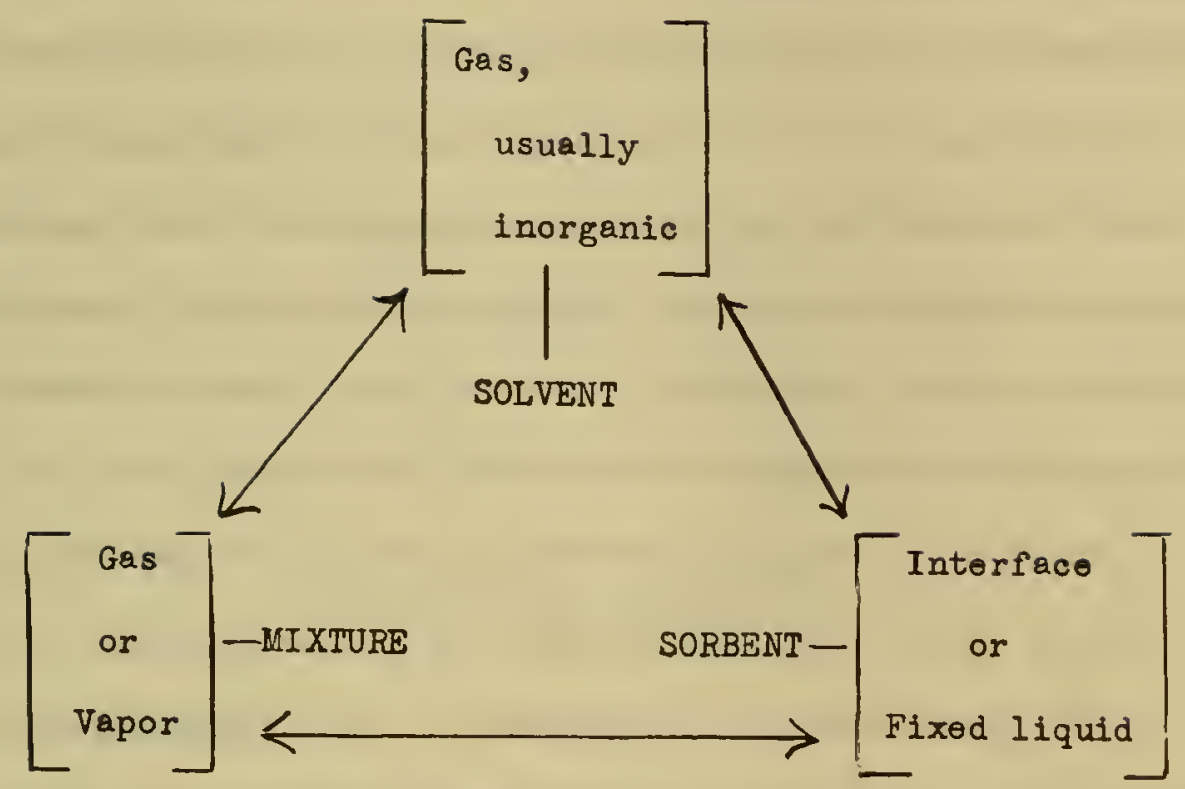

FIGURE IV,2. Principal interactions in gas chromatography. 
sorption phenomenon for the resolution of mixtures of all kinds of organic and inorganic ions.

An important variation of the sorbent first employed with colorless substances was the use of a fixed liquid as the sorptive agent. With these liquids fixed on powdered nonsorptive solids, mixtures are resolved by selective partition between the stabilized, nonmobile liquid and a mobile, immiscible liquid or gas. This procedure is effective both with organic and inorganic substances?.

In spite of a prodigious amount of work on the separation of substances by the various modifications of chromatography, there is not as yet a very sound basis for comparison of the effectiveness of various modifications of the method. For the leaf pigments, adsorption in columns of magnesia provides extensive separation of many carotenoids but produces decomposition of the chlorophylls. Adsorption in columns of sugar provides separation of chlorophylls and many carotenes as shown in Figure II, l. Partition between petroleum ether and aqueous methanol with either solvent fixed in paper provides separations very similar to those observed in columns of powdered sugar $I, 19: I, 20$.

\section{Variations of Chromatographic Systems}

For the resolution of a particular mixture, various combinations of sorbents and solvents may be employed as shown by the observations with chloroplast pigments and as may be inferred from Table IV, IV. Thus far, there are few guiding principles for the selection of solvents and sorbents. Progress is usually based upon analogy and upon empirical tests。 
The chromatographic systems have also been varied with respect to the geometrical pattern of the sorbent. With paper, partioularly, it has been possible to carry out radial migration and two-way migration which improve the definition and separation of the zones.

With suitable combinations of sorbent and solvent, extremely small quantities or traces of substances may be separated from mixtures. These separations may be made even when the nature of the substances is unknown and when the presence of the trace components is unsuspected 8 .

\section{SEPARATION AND DETECTION}

\section{Selection of Systems}

The selection of chromatographic systems depends upon a large number of variable conditions and upon the objectives of the operator. For a particular separation, various combinations of solvent and sorbent may be employed. Separations may be made on a macro or a micro scale. They may be employed for comparative tests, for descriptive purposes, or for qualitative and quantitative estimations. For many of these objeco tives, special methods must be utilized for the detection and estimation of the separated substances, and these must be selected in relation to the chromatographic system and vice versa。

Detection, Estimation, and Comparison of Separated Substances

Many techniques have now been developed for the location and estimation of substances separated in chromatographic systems. As demono strated with pigments, the separated substances may be located in effluent from the sorptive system, in the system itself, or in extracts from successive portions of the system. 
The detection and estimation methods may be based upon any appropriate property of the separated substances. These properties fall into four principal groups; namely,

\author{
Nuclear properties \\ Physical properties \\ Chemical properties \\ Biological properties.
}

Substances separated by chromatography may be described and compared by their migration relative to other substances as has long been done with the chloroplast pigments. They may also be compared and described by their migration relative to the migration of the solvent, which provides the $R$ or the $R_{F}$ value 9 . In practice, these values are a property of the chromatographic system and of various conditions such as the temperature, the activation of the sorbent, and the presence of impurities in the wash liquid. There will be, therefore, about as many $R$ or $R_{F}$ values for each substance as there are chromatographic systems for its sorption; hence only the values for equivalent or identical systems may be compared.

With all the variable conditions controlled, and with suitable detection and estimation methods, chromatography is one of the most effective techniques for the resolution of mixtures and for the comparison, description and estimation of the components 6 .

\title{
SUMMARIES
}

Keys to the Literature

The investigations concerning the principles and applications of 
chromatography have increased so rapidly that it is extremely difficult to follow them. Fortunately, much of this work has been summarized from several points of view. Reviews of current investigations and the relationship of the chromatographic methods to related differential migration methods of analysis have been presented in Analytical Chemistry $4,6,10,11$, 12,13. The principles involved in chromatographic separations have been summarized by Cassidy 9 , and the diverse applications of chromatographic

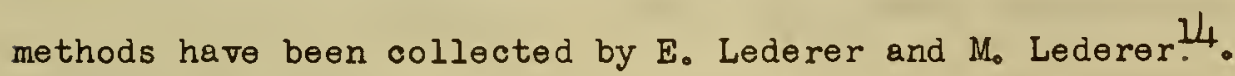




\section{REFERENCES}

1。 HoH。Strain, Ind, Eng。Chem。, 42, 1307 (1950)。

2. H。H。Strain, Ind。Eng。Chem。Anal。Ed。, 18, 605 (1946)。

3. H。H。Strain, Jo Phys。Chem。, 46, 1151 (1942)。

4. H。H。Strain, Anal。Chemo, 23, 25 (1951)。

5. A。 Jo Po Martin and Ao To James, Biochem。 Jo, 63, 138 (1956)。

6. H。H.Strain, Anal。Chemo, 30, (1958)。 In press.

7. A。 Jo Po Martin and R。 L。 M。Synge, Biochem。 Jo, 35, 1358 (1941)。

8. Ho $H_{0}$ Strain, In, Trace analysiso $p_{0} l_{0}$ Edso, JoH. Yoo and $H_{0} J_{0}$ Koch, Jro, John Wiley \& Sons, Inc., New York, 1957.

9. H. G. Cassidy, Fundamentals of chromatagraphy. Interscience Publishers, New York, 1957.

10. HoH。Strain and To Ro Sato, Anal。Chem。, 28, 687 (1956).

11. H。H० Strain, T。 Ro Sato and Jo Engelke, Anal。Chem。, 26, 90 (1954)。

12. H。H.Strain and GoW.Murphy, Anal。Chemo, 2h, 50 (1952).

13. Ho HoStrain, Anal。Chem。, 22, 4 l (1950)。

14. E。 Lederer and Mo Lederer, Chromatography。 2nd。 ed。, D。 Van Nostrand Co., Inc., New York, 1957. 
ELECTROCHROMATOGRAPHY AND ANALOGOUS

DIFFERENTIAL MIGRATTON METHODS OF ANALYSIS

CHROMATOGRAPHY AND DIFFERENTIAL MIGRATION

\section{Mechanism for the Chromatographic Separations}

The studies of the chloroplast pigments provided numerous clues to the mechanism of the chromatographic separations. They led to the elaboration of these techniques, to the invention of analogous separatory methods, and to the correlation of various analytical procedures that depend upon the phenomenon of differential migration.

In the chromatographic columns, the pigments are transported by the wash liquid. The nonsorbed molecules, those remaining in the liquid, are carried along with the solvent until they become adsorbed. While bound by the sorbent, they are fixed and are not conveyed by the wash liquid. In the dynamic system in the column (see Figure IV, I), the migration of each pigment molecule is proportional to the time that It remains in solution relative to the time that it is in the column ${ }^{1}$. The migration of each pigment zone depends upon the avarage distribution of the moleoules between the solvent and the sorbent. It is proportional to the fraction in the solution and inversely proportional to the fraction on the sorbent. But with surface-active sorbents, the nonsorbed fraction of the pigments decreases with decreasing conoentration. As a consequence, the migration of the zones decreases with decreasing. concentration; the leading boundaries of the zones remain sharp: the trailing boundaries become diffusel. 
Differential Migration from a Narrow-Zone

Chromatography, as shown by the studies with chloroplast pigments, is a differential migration method of analysis. The separation of the zones depends upon their relative rates of migration, upon the initial width of the zone of the mixture, and upon the distance of the migration. For effective separations, the initial zone of the mixture should be narrow, the zones should migrate at different rates, and the region for the migration should be much longer than the initial width of the zone of mixture IV, 6 。

For the migration of the chromatographic zones, a driving force is necessary. This driving force is the flow of the wash liquid. It is a nonselective driving force, because it carries each nonsorbed molecule along at the same rate。

The sorbent provides a selective resistive force. It retards the migration of the solutes as they come into contact with fresh pore tions of the sorptive phase. This retardation is proportional to the degree of sorption ${ }^{I V}, 12$.

\section{Differential Migration Methods of Analysis}

By analogy with chromatography, any system that produces differo ential migration of molecules or ions may serve as a separatory technique. The primary requirement is a driving force. This driving force, the attendant resistive force, or both these forces must prow duce the differential migration ${ }^{I V}, 6$ 。

These views led to the use of direct current (DC) electrical potential as a driving force to produce differential migration of lons from a narrow zone of the mixture in an electrically conducting 
background solution ${ }^{2}$. This electrical force has been used in several arrangements providing one-way and transverse migrations. From their close relationship to chromatographic techniques, these methods have become known as one-way electroohromatography, two-way electrochromatography, and continuous electrochromatography 3,4. Different modifioations of these methods were devised independently by several workers with various points of view. As a result, some of these methods are now known by various semidescriptive synonyms such as zone eleotrophoresis, eleotropherography, paper electrophoresis, and ionography $4,5,6$.

A few effective separatory procedures that are remotely related to chromatography also belong in this category of differential migration analysis. The consideration of chromatography as a differential migration method of analysis has thus provided effective concepts for the development and correlation of many analytical techniques IV, $6: I V, 10$.

\section{ELECTROCHROMATOGRAPHY}

\section{Differential Electrioal Migration}

Long employed to measure the electrical mobility of lons and to indicate the complexity of mixtures, differential electrical migration has only recently been widely employed as a separatory technique 6 . With a solution extending continuously between two electrodes, as indicated by Figure V,l, electrolysis alters the proportions of the ions at the eleotrodes and provides an indication of the mobilities of the ions. With a wide zone of the mixture in a background electrolytic solution extending to each electrode, electrolysis produces a partial separation of the ions so that the overlapping zones provide an indication 
Figure V, 1. Schematic arrangement for the partial separation of ions by differential electrical migration from the electrode compartments $I V, 10$.

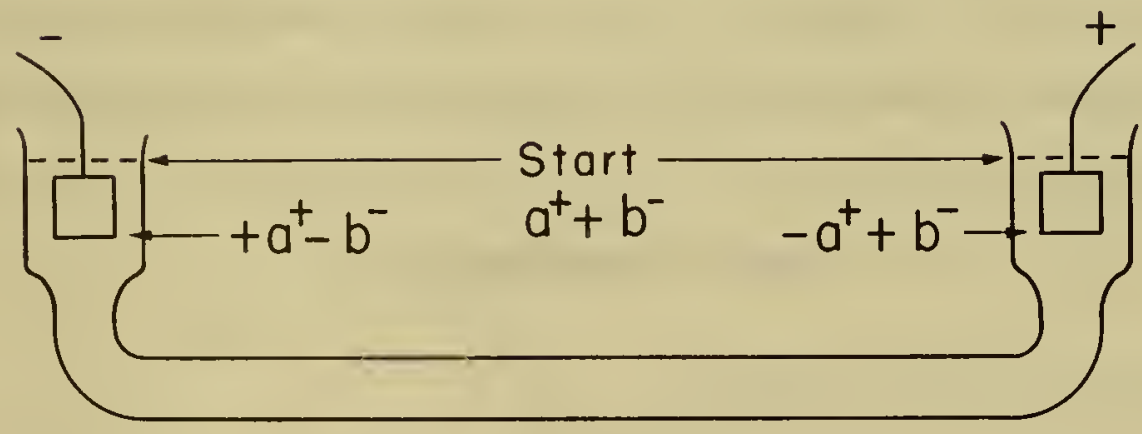


of the number of the constituents in the mixture IV, 10, as illustrated by Figure V,2. With a narrow zone of the mixture, electrolysis separates the components of the mixture and provides a series of discrete zones analogous to those in a chromatographic system IV, 10 , as shown in Figure $V, 3$.

Electrical migration is often accompanied by convection and by variation of the density of the solution. For the production of welldefined zones with sharp boundaries, it is necessary to control this convection and mixing, as by the use of porous or permeable stabilizing media6. It is also essential to carry out the migration under conditions such that the separated ions may be easily detected and isolated.

\section{Systems for Differential Eleotrical Migration}

Several kinds of equipment have now been employed for analysis by differential electrical migration in stabilized media 4,5,6. The apparatus usually consists of five principal parts, namely, electrodes for cathode and anode, vessels for the electrodes and for reserve background electrolytic solution, a long migration system of the stabilized background solution joining the electrode vessels, a support for the migration system, and frequently an arrangement for cooling the migration medium. Some of these modifications are elaborated in Table V, I。

Electrode vessels are usually adapted to meet the requirements of the migration system. They may be of small capaoity when background solutions with much, partially dissociated electrolyte aro employed。 But for solutions containing little, strongly dissociated electrolyte, large vessels with large electrodes are more suitable7. 
Figure $V$,2。 Schematic arrangement for the partial separation of ions by differential electrical migration from a wide zone of the mixture placed in an electrically conducting background solution IV, 10 。

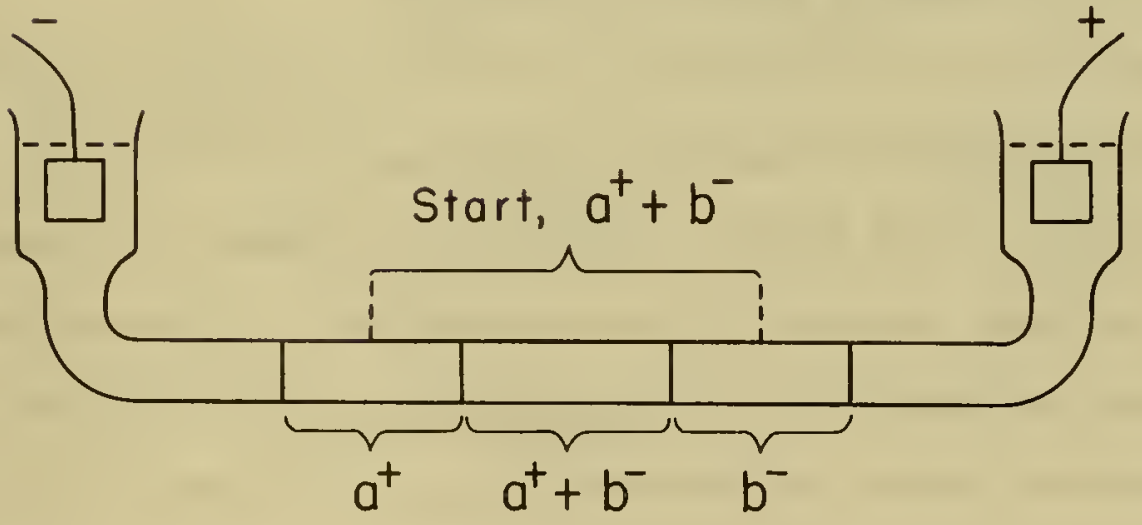


Figure V,3. Schematic arrangement for the electrochromatographic separation of ions by differential electrical migration from a narrow zone of the mixture placed in an electrically conducting background solution ${ }^{\mathrm{IV}}, 10$ 。

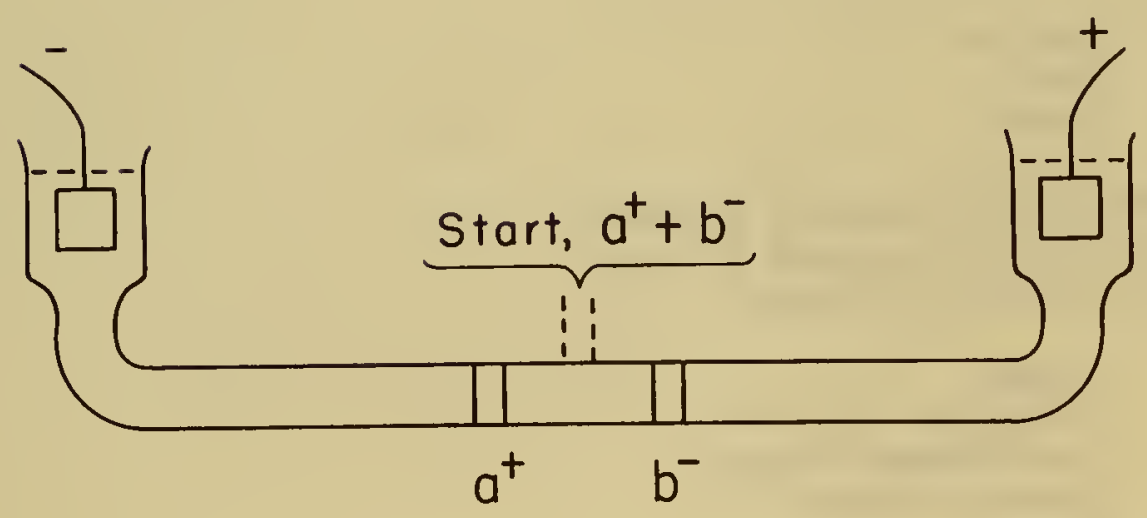


TABLE V,I。 Principal Parts of Apparatus for Analysis by Differential Eleotrical Migration

Eleotrodes

Carbon (graphite) (cathode and anode)

Platinum (wire) (cathodo and anode)

Stainless steel (oathode)

Nichrome (wire) (cathode)

Electrode Vessels

Glass

Plastic (Lucite or polyethylene)

Polystyrene foam

Migration Region

Paper plus background solution

\section{Strips}

Pads

Shoots

Cotton plus background solution

String plus background solution

Packed tubes or troughs

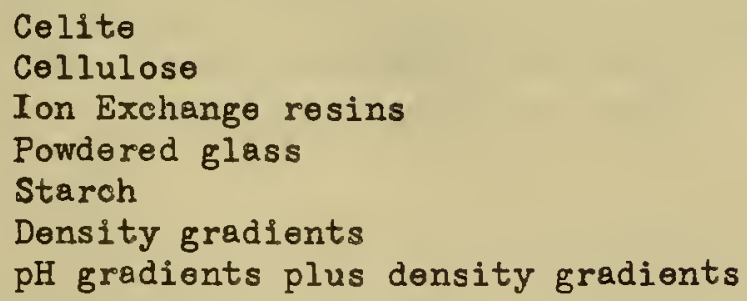

Background Solutions (ca. 0.1 M)

Aoids

Bases

Salts

Chelating agents

Complex-forming substances

$\mathrm{pH}$ buffers

Supports

Glass points in cooled atmosphere 


\section{TABLE V, I, cont'd。}

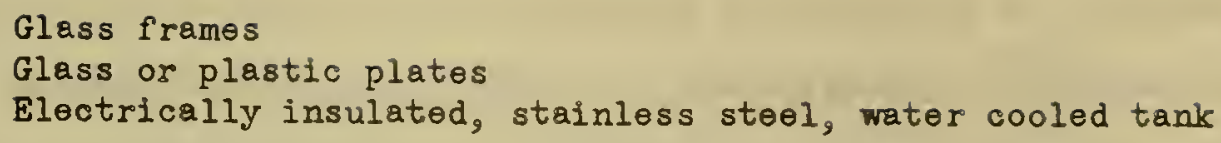

\section{Cooling Devices}

Refrigerated atmosphere (box or cold room)

Cooled, electrically nonconducting, water immiscible liquid surrounding migration medium

Electrically insulated, water cooled, stainless steol support 
The electrode vessels with their reserve electrolytic solution may sometimes be eliminated by placing the electrodes on the migration medium itself 8,9 . (See Figure $v, 40$ ) Under these oircumstances, the background solution should contain reserve, undissociated electrolyte as, for example, weak acids or weak bases. Even under these circumstances, regions of low electrolyte concentration and of high resistance often develop at the electrodes, and the potential difference per unit length of the migration system decreases 9 .

The migration medium is usually the background electrolytic solution stabilized by various porous substances 4,6 . These stabilizing substances fall into four principal categories, powdered solids, fibrous solids such as paper, gels, and density gradients formed with nonelectrolytes. (See Table $V_{,} I_{0}$ ) of the various stabilization media, paper has found the most extensive application5. It may be employed as strips ${ }^{10}$, sheөts ${ }^{11}$, or pads ${ }^{12}$. (See Figures $V, 4$ and $v, 5$. ) It is remarkably uniform; it is of suitable density and thickness; and it permits the detection and recovery of the separated substances 5.

Powdered solids and density gradients are usually employed as stabilizing media in vertical glass tubes with the electrodes in side tubes 13. Powdered solids and gels are frequently used in horizontal troughs connecting the electrode vessels 4 .

A great variety of background solutions has been employed 4,6 . Virtually all of these have been aqueous solutions of acids, bases, or salts. Many of these solutes serve as complexing and solubilizing agents and as pH buffers as well as electrolytes. The concentration of the background solutions has been varied over a great range but is 
Figure $V$, 40 Simple apparatus for the one-way electrochromatographio separation of a mixture placed in a paper strip, $\mathbf{P}_{9}$ moistened with a background eleotrolytic solution and sandwiched between glass or plastic plates. Electrodes attached to the paperio.

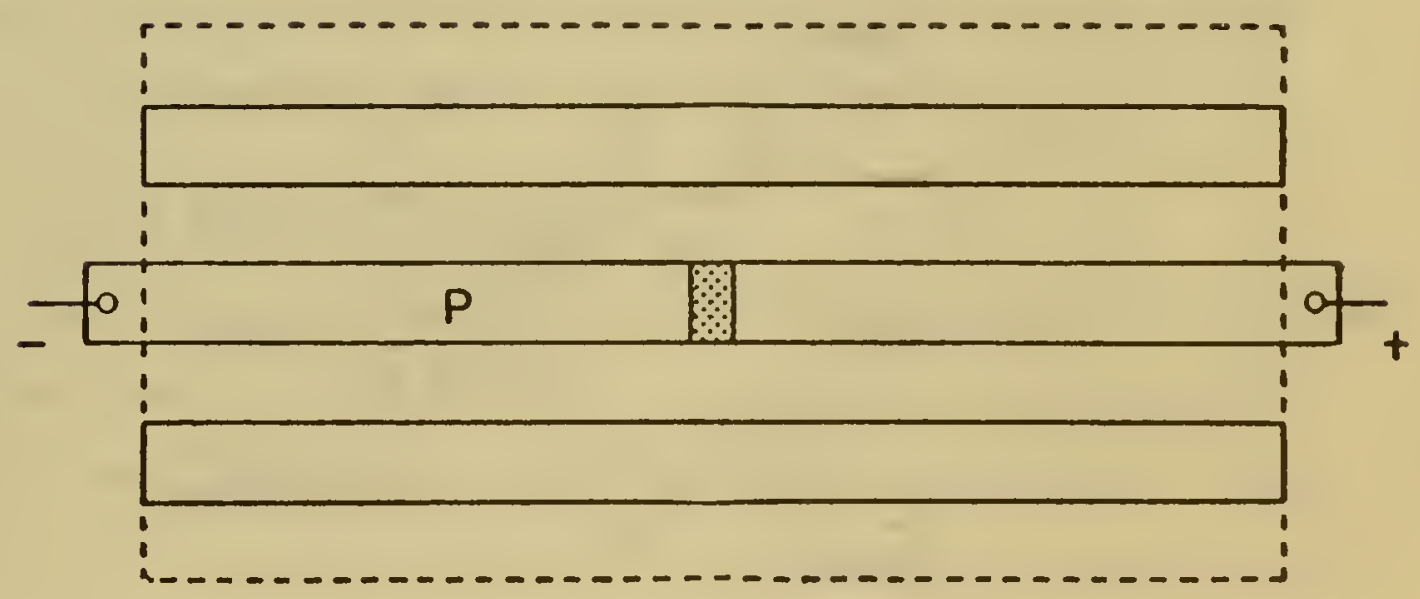


Figure V,5. One-way electrochromatographic separation of rare earth ions, with radioactive tracers, in paper molstened with lactic acid solutions ( 5 volts per $\mathrm{cm}$. for 24 hours) and with tartaric acid plus amonium tartrate ( 5 volts per om. for 48 hour's)。 Zones wore located by photography。 Separations in dilute lactic acid were the result of selective sorption by the papero Separations in the presence of tartrate were the result of complex formation 19 .

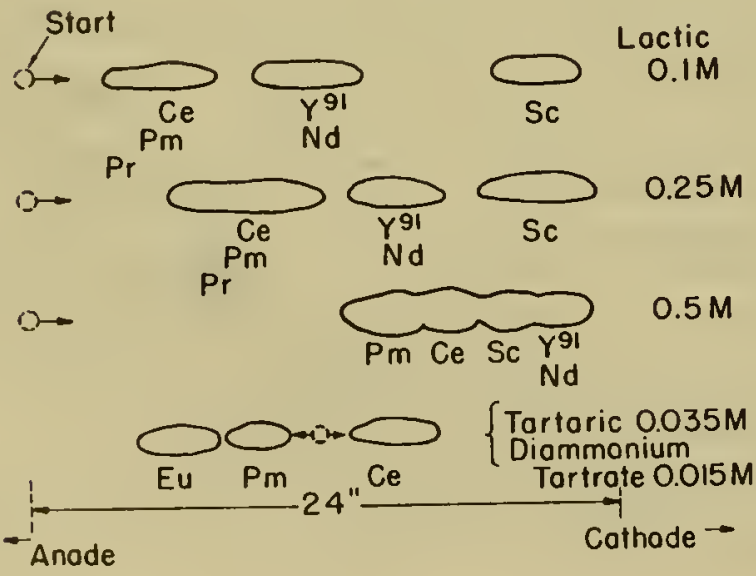


usually between 0.01 and $0.1 \mathrm{M}$. Various complexing agents have been added to the background solution in order to improve the separability of many substances. For example, polybasic acids form anionio complexes with polyvalent cations but not with monovalent cations thereby facilitating the separation of these complexed cations from the nonoomplexed monovalent cations9 (Figure $\mathrm{V}, 6$ )。

Many different supports have been employed for the electrochromatographic apparatus 4,6 , particularly for the migration systems (Table $\mathrm{V}, \mathrm{I})$. Molst paper strips have been suspended horizontally on glass points in a closed cooled atmosphere. They have been suspended over a glass rod as an inverted $V_{0}$ They have been suspended in a cooled, nonconducting organic liquid such as chlorobenzene $4,5,6$. The moist paper has also been placed between glass or plastic plates, between watero cooled glass vessels $I, 20$, or between polyethylene sheets on a watercooled stainless steel tank ${ }^{7}$.

\section{Detection of Separated Substances}

Substances separated by electrochromatography are easily detected, isolated, and estimated by means of the methods previously employed with chromatography, particularly with paper chromatography 5 . (See Lecture IV.) The avallability of these detection and estimation techo niques contributed, in large measure, to the rapid application of paper electrochromatography IV, 6 。

The great majority of the detection methods are based upon ohemical reactions that yield colored products $I V, 6$. Nuclear methods, including radioactive tracer techniques and neutron activation before and after migration, have been employed with substances containing 
Figure V,6. One-way electrochromatographic separation of barium, strontium, ealcium, lithium, sodium, potassium, cesium, and rubidium lons in a paper strip moistened with diammonium oitrate solution, $0.05 \mathrm{M}_{2}$ at 5 volts per cm. for 3 hours。 The paper ( $5.1 \mathrm{~cm}$. wide) was cut transverse to the direction of migration ( $1 \mathrm{~cm}$. sections), and the Ions were eluted and determined by flame spectrometry?

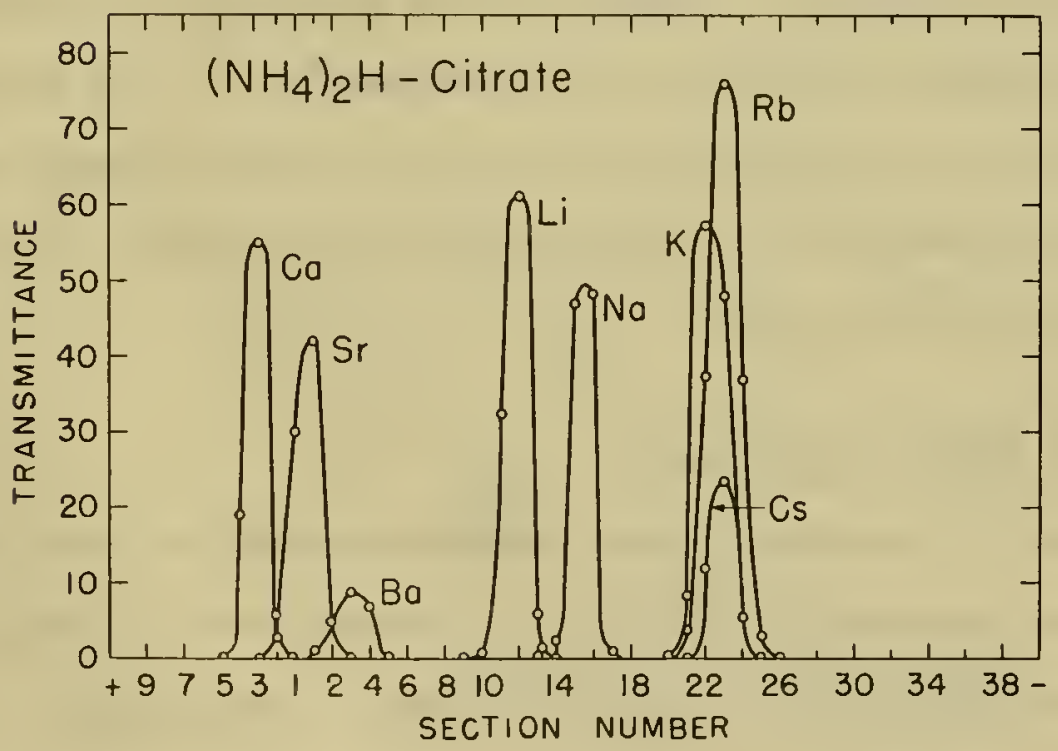


elements of suitable cross section and half-life 7 . Physical and bioo logical detection methods have been widely employed, the latter especially with antibiotics and growth hormones. As in chromatography, the eleotrochromatographic sequences also serve for the description and identification of various substances 14 . Some of the detection methods are illustrated by the flgures showing various modifications and applications of the electrochromatographic techniques。(Se日 Figo ures $v, 5$ to $V, 100$ )

Conditions Required for Electrochromatographic Separations

Many circumstances affect the separation of mixtures by differe ential electrical migration, hence the experimental conditions must be controlled and described. These variable conditions are the composio tion of the background solution ${ }^{12}$, the temperature, the DC potential, the concentration of the mixture and of extraneous ions in the mixture ${ }^{12}$, and the sorbability of the migrating lons by the stabilization medium 15 . The composition of the background solution is usually specified with respect to the nature and concentration of the electrolyte and the $\mathrm{pH}$. For estimation of the ionic velocity, the temperature and the potential must be carefully controlled, but for comparative separations careful control is unnecessary. The DC potential may vary from 5 or 10 volts per centimeter to as much as 100 volts. At the high potential, the separations take place very rapidly, and the zones of the separated substanoes remain very small16。

The ionic concentration of the mixture itself or of the mixture plus extraneous electrolytes should not be much greater than the ionio concentration of the background electrolytic solution. At high 
Figure V,7. One-way electrochromatographic separation of phosphate, $\mathrm{H}_{3} \mathrm{PO}_{4}$, phosphite, $\mathrm{H}_{3} \mathrm{PO}_{3}$, and hypophosphite, $\mathrm{H}_{3} \mathrm{PO}_{2}$, in paper moistened with $0.1 \mathrm{M}$ lactio acid solution, at about 5 volts per cmo for 24 hours. The paper was dried, exposed to neutrons, and the radioactive zones were located by scanning with a Geiger-Mllier counter 7 .

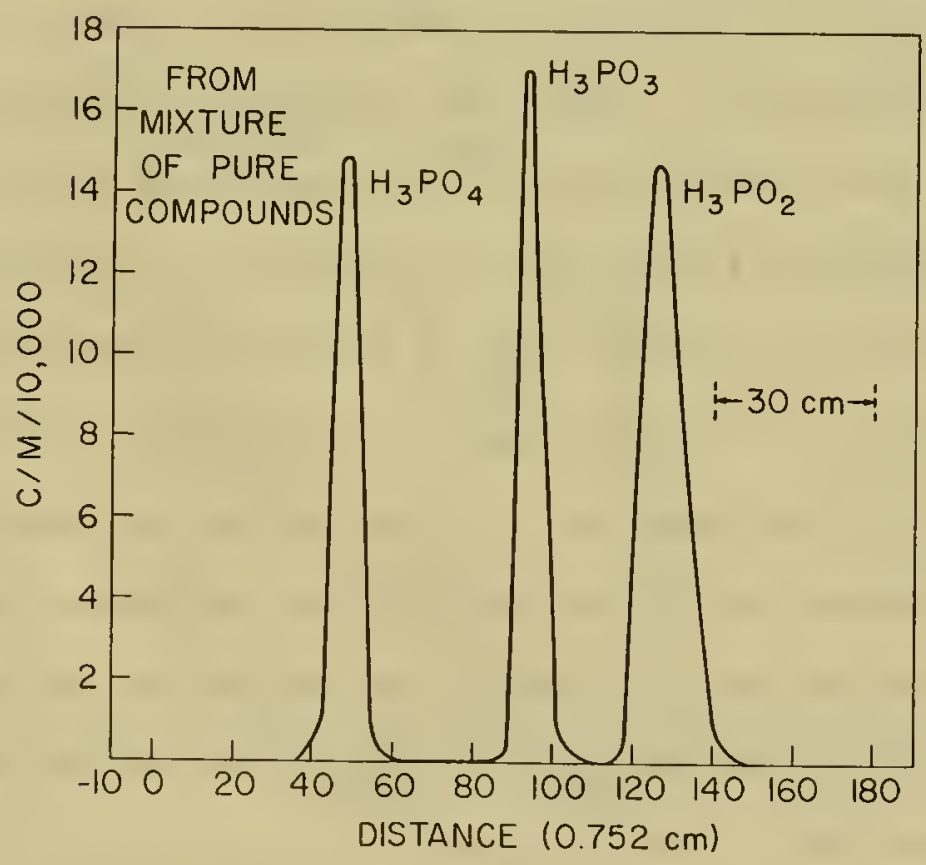


Figure V,8. Two-way electrochromatographic separation of cadmi um, lead, oupric, bismuth, and mercurio ions. One-way migration in $0.1 \mathrm{M}$ lactic acid (left) followed by transverse migration after treatment with ammonia (right). Ions located with hydrogen sulfidell.
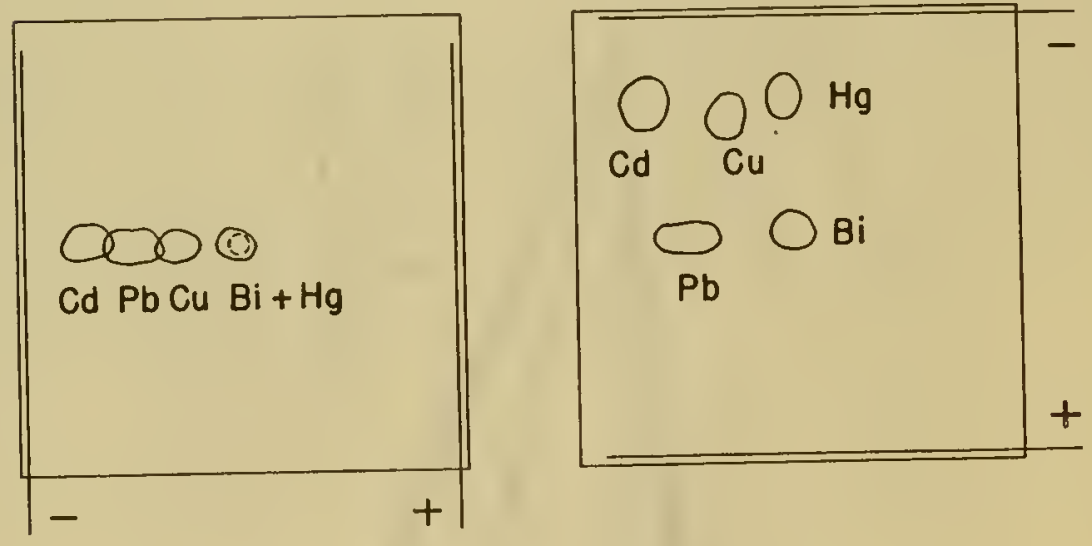
Figure V,9. Separation of lead, silver and mercurous ions, contained in a spot of solution, by electrical migration transverse to simultaneous flow of the background solution, $0.1 \mathrm{M}$ lactic acid, at 250 volts per $15 \mathrm{~cm}^{10}$ 。

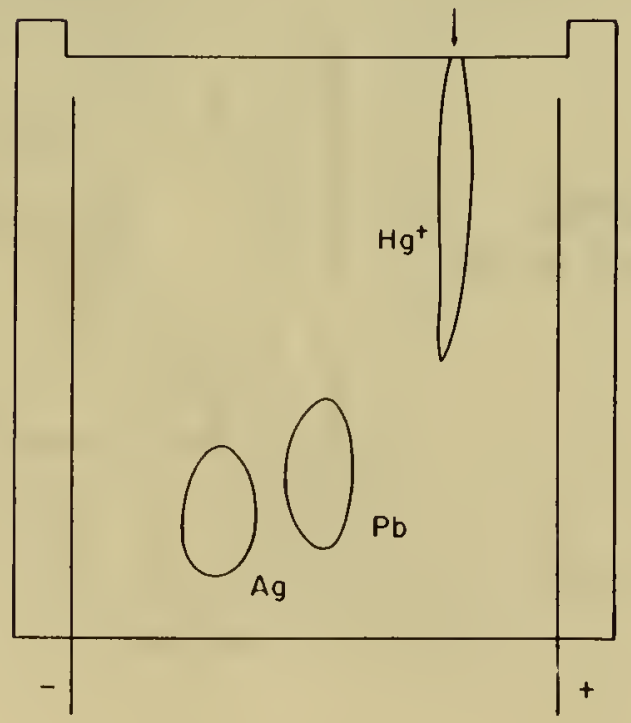


Figure V,10. Continuous electrochromatographic separation of silver, cadmium, bi smuth and aluminum ions, contained in a nar row stream of the solution, by eloctrical migration transverse to simultaneous flow of the background solution, $0.05 \mathrm{M}$ monoammonium malonate。 DC potential, 162 volts, applied to platinum wire electrodes laced through the holes in the paper. Aluminum lons located with 8-hydroxyquinoline in ultraviolet light; silver, cadmium and bismuth ions located with yellow ammonium sulfidell.

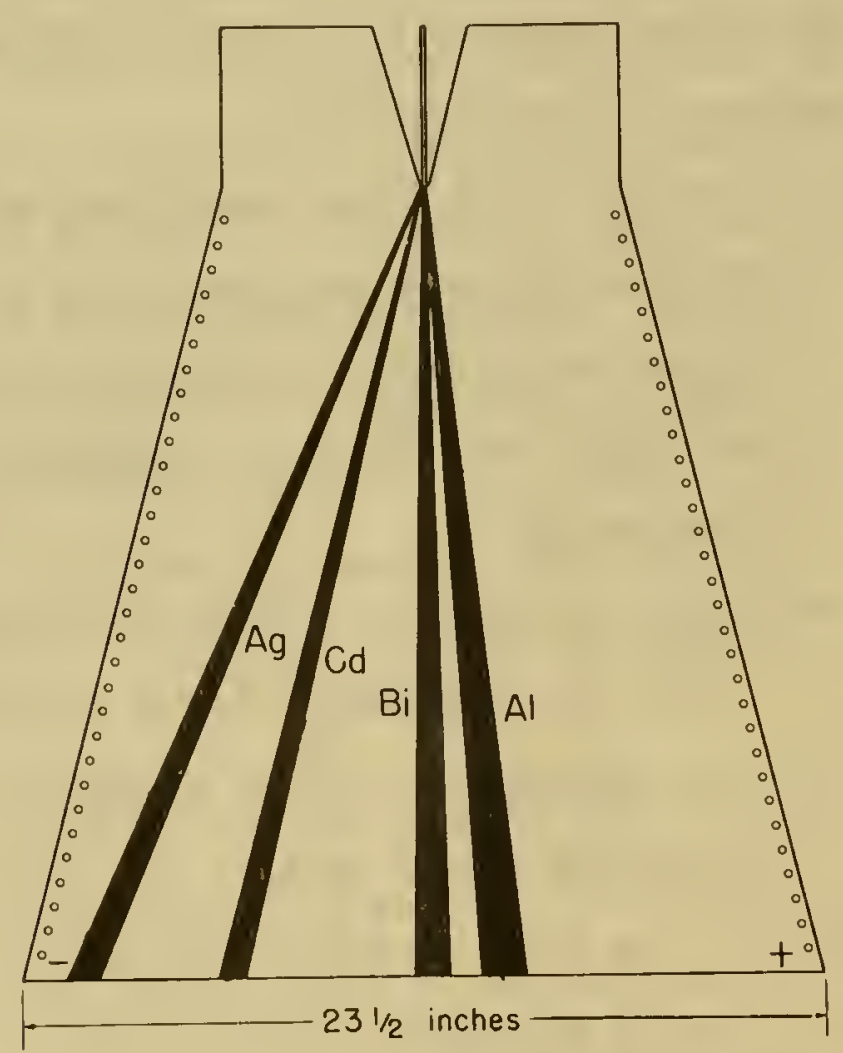


concentration, the mixture forms a zone that migrates slowly with a fastermigrating, diffuse leading region. At low concentration of the mixture, the ions yield uniform zones, and the rate of migration is independent of concentration down to the smallest quantities that oan be detected by the most sensitive tracer methods 12 .

Ions that are sorbed by the stabilizing medium migrate slower than if there were no sorption 15. Under these conditions, the zones remain well-defined at the leading boundary but become diffuse at the trailing boundary like the zones in a chromatographic column. This sorption provides a resistive force that is often sufficiently selective to determine the separability of mixtures and the sequence of the separated components. (See Figure V,50)

Ions that are not sorbed by the stabilizing medium migrate slower in the stabilized solution than they do in the background soluo tion alone. This retardation may be attributed to the fact that the ions follow a more circuitous path in the stabilized solution than in the nonstabilized solution 17 .

With many stabilized media, the electrical potential produces electroosmotic flow of the background solution through the stabilizing agent. This flow of the solution and the corresponding transport of the zones of the migrating ions is usually much smaller than the electrical migration of the ions. It may be determined by adding a $z$ one of a nonionized, easily detectable substance such as hydrogen peroxide to the medium before the migration. Dependent upon the stabilizing agent and the nature and $\mathrm{pH}$ of the background electrolytic solution, the electroosmotic flow may be toward the anode or toward the cathode ${ }^{18}$. 
As a rule the electroosmotic flow is greater when electrode vessels are employed than when the electrodes are applied directly to the migration medium 8 .

\section{Substances Separated by Electrochromatography}

Many different kinds of substances have now been examined by electrochromatography。 All kinds of inorganic cations and anions have been studied under a great variety of conditions $4,5,6,7$.

For the separation of the rare earth cations, the method is very seleotive when the ions are sorbed on the paper stabilization medium or when they form complexes with tartrate ions ${ }^{19}$ (See Figure $V, 50$ ) For the separation of alkaline earth oations, the electrical migration is more selective in the presence of amonium citrate (see Figure $\mathrm{V}, 6$ ) than in citric acid solution. Although lithium, sodiun, and potassium ions are readily separable, potassium, oesium, and rubidium ions are inseparable 9 as indicated in Figure $V, 6$ 。

Various inorganic anions such as the oxy acids of phosphorus separate readily in a particular sequence 7 . (See Figure V,70) The mobility of phosphate is a function of $\mathrm{pH}^{20}$. The oxy acids of sulfur also separate easily。

In all these separations there is no systematic relationship between the oxidation state of an element and the electrochromatographic sequence. There is also little relationship between the separability of ions by electromigration and by the usual chemical methods.

Many ionized organic substances have been separated by electrical migration. These include various acids and bases, especially the amino acids。 Many nonionized organic substances such as aldehydes, ketones, 
and carbohydrates are readily separable in solutions containing ionized, complex-forming reagents such as borate and sulfite $4,5,6$.

Electrochromatography is especially useful for the separation of proteins, particularly the proteins of serum. For this purpose, electrochromatography has become an indispensable clinical tool. With conditions selected so that there is little or no sorption, there is also little alteration or denaturation of the protein $4,5,6$.

\section{TWO-WAY ELECTROCHROMATOGRAPHY}

\section{Eleotrical Migration in One Solution Followed by Transverse Migration}

\section{in Another Solution}

Separations that are inoomplete after eleotrical migration in one solution may be completed by a second migration transverse to the first. In this two-way electrochromatography, which is the electrical counterpart of two-way chromatography, the solvent for the second, transverse migration must be different from the solvent for the first migration. This variation may be achieved by alteration of the $\mathrm{pH}$ or by the addition of complex-forming or chelating reagents to the solutions. As in two-way chromatography, the separations by two-way electrochromatography are carried out most conveniently in sheets of filter paper, particularly in soft thick paper5,11. (See Figure $V, 80$ )

Two-way electrochromatography has served for the separation of inorganio ions and also for the separation of organic substances such as amino acids. A typical separation of inorganic cations is illustrated by Figure $\mathrm{V}, 8$. 


\section{CHROMATOGRAPHY PLUS TRANSVERSE ELECTROCHROMATOGRAPHY}

\section{Flow of Solvent Transverse to Electrical Migration}

Mixtures contained in a spot of solution have been separated by various combinations of flow of background solution plus transverse electrioal migration5. Flow of the solution provides the driving force for one component of the two-way migration, and electrical pos tential provides the driving force for the other component. As the two driving forces are different, the same solution may be employed for both migrations.

The chromatographic migration, with flow of the solution, and the electrical migration may be utilized in several sequences. Flow of the solution may precede the electrical migration: it may follow the eleotrical migration; and it may occur simultaneously with the electrical migration. An illustration of the separation of lead, silver, and mercurous ions by simultaneous flow of the background solution and eleotrical migration 10 is provided by Figure $V$,9. The paths traversed by the ions will depend upon the sequence in which the transverse migrations are carried out. The resultant separations will not be significantly different IV, 11 .

With respect to applicability and sensitivity, these transverse chromatographic and electrochromatographic methods are comparable to one-way eleotrochromatography. With respect to resolving power, they are similar to two-way chromatography and two-way electrochromatography。 


\section{CONTINUOUS ELECTROCHROMATOGRAPHY}

\section{Resolution of a Stream of the Mixture}

With flow of the background solution transverse to DC electrical potential, a narrow stream of a solution of the mixture may be added continuously to the migration system. Under these conditions, the components of the mixture follow separate paths and emerge at separate points at the base of the migration system where they may be oollected individually and continuously $4,5,6,10$ 。

Various modifications of the continuous electrochromatographic apparatus have been devised. These include tanks packed with powdered solids, square paper sheets suspended in a closed atmosphere to prevent evaporation, soft paper pads compressed between glass plates, and soft paper sheets supported upon tilted squares of solidified polystyrene foam $4,5,6,21,22$. Tapered paper sheets have also been found to provide uniform filtration and effective separation of various ions 21 .

Continuous electrochromatography is effective with various organic ions ranging from proteins to amino acids. It is useful with all kinds of inorganic ions and with a great variety of substances as the background electrolytic solution. It produces separations at the lowest concentrations that can be detected 22 . A typical continuous separation of silver, cadmiun, bismuth, and aluminum lons is provided by Figure $V, 10$, which shows the paths followed by the ions in the migration medium, a tapered sheet of paper。

The separations produced by continuous electrochromatography depend primarily upon the selective electrioal migration. They also depend upon the selective sorption of the components of the mixture IV, 6 . 


\section{VARIOUS DIFFERENTIAL MIGRATION METHODS}

\section{Comparison of Migration Methods}

A number of separatory methods may now be classified as differ= ential migration methods of analysis IV, 6 IV, $10 ; I V, 11 ; I V, 12$. These methods are applicable to various kinds of substances which, with respect to their physical state, are usually gases or solutes。 Most of the methods serve primarily for the resolution of mixtures. A few, as time-of-flight mass spectrometry and gas chromatography, are very effective for the detection of the constituents of mixtures. Some, as electromagnetic mass spectrometry, serve for the separation of mixtures and for the detection of the components.

The principal differential migration methods of analysis are compared in Table V,II. The principal driving forces, the substances that may be examined, and the most effective uses, such as separation or detection, are included in this table.

Some of the methods have been improved by the use of gradients that increase the sharpness of the zones. Solution or elution gradients are widely employed in chromatography. Density gradients have served as stabilizing systems in electrochromatography and in centrifugation. Likewise, pH gradients have proved extremely useful for increasing the sharpness of the zones in electrochromatography IV, $6, I V, 10$.

TOOLS FOR PROGRESS

\section{Analysis and Progress}

The remarkable scientific progress that has been made since Priestley"s observations on gases, on respiration, and on photosynthesis 
TABLE V,II。 Differential Migration Methods of Analysis

\begin{tabular}{|c|c|c|c|}
\hline Method & Driving force & Applicable to & Use \\
\hline Solution chromatography & Flow of solution & Solutes & Separation \\
\hline Gas chromatography & Flow of gas & Gases, vapors & $\begin{array}{l}\text { Separation, } \\
\text { detection }\end{array}$ \\
\hline Electrochromatography & Electrical field & Ions & Separation \\
\hline $\begin{array}{l}\text { Electrogravitational } \\
\text { migration }\end{array}$ & $\begin{array}{l}\text { Electrical field } \\
\text { + gravity }\end{array}$ & Ions & Separation \\
\hline Fractional distillation & Temperature gradient & Lìquids & Separation \\
\hline Fractional sublimation & Temperature gradient & Volatile solids & Separation \\
\hline $\begin{array}{l}\text { Thermogravitational } \\
\text { diffusion }\end{array}$ & $\begin{array}{l}\text { Temperature gradient } \\
+ \text { gravity }\end{array}$ & $\begin{array}{l}\text { Gases, vapors, } \\
\text { solutes }\end{array}$ & Separation \\
\hline Diffusion & $\begin{array}{l}\text { Concentration gradi- } \\
\text { ent }\end{array}$ & Solutes, gases & Separation \\
\hline Multiple partition & Chemioal potential & Solutes & Separation \\
\hline Sedimentation & Centrifugal force & $\begin{array}{l}\text { Solutes, col- } \\
\text { loids }\end{array}$ & Separation \\
\hline Mass spectrometry & $\begin{array}{l}\text { Electriogl + mago } \\
\text { netic fields }\end{array}$ & Gases, vapors & $\begin{array}{l}\text { Separation, } \\
\text { detection }\end{array}$ \\
\hline Mass spectrometry & $\begin{array}{l}\text { Electrical field, } \\
\text { only }\end{array}$ & Gases, vapors & Detection \\
\hline $\begin{array}{l}\text { Continuous electroo } \\
\text { ohromatography }\end{array}$ & $\begin{array}{l}\text { Flow of solution } \\
+ \text { electrical field }\end{array}$ & Solutes & Separation \\
\hline
\end{tabular}


is intimately linked to the development of analytical techniques。 These techniques now serve as refined tools for the further exploration of various natural phenomena involving chemical substances and their reactions. As the usefulness of the tools is exploited, new and more effective techniques must be devised. In these ways, analysis is continuing to provide the new observations that are essential to an understanding of the changes of chemical substances in all kinds of material transformations. 


\section{REFERENCES}

1. H. Ho Strain, In, Frontiers in chemistry。 Vol。VIII, p。29。 Eds。 R。E。Burk and O。Grumitt, Interscience Publishers, Inc。, New York, 1950。

2. H。H。Strain, J。Am。Chem。Soo, 6l, 1292 (1939)。

3. HoH。 Strain and To Ro Sato, Chem。Eng。News, 32,1190 (1954)。

4. Mo Lederer, An introduction to paper electrophoresis and relatod methods. 2nd Impression. Elsevier Publishing Co., New York, 1957.

5. R。 J. Block, E。 L。 Durrum and G。 Zweig。 A manual of paper chromatography and paper electrophoresis. Academic Press Inc。, New York, 1955.

6。 H。J०McDonald, R० Jo Lappe, E。 Po Marbach, R。H。 Spitzer and M。C。 Urbin, Ionography。 Electrophoresis in stabilized media。Year Book Publishers, Chicago, Ill。, 1955.

7. Po A。 Sellers, T。 Ro Sato and $H_{0} H_{0}$ Strain, Jo Inorg。 \& Nuclear Chem。, 5, 31 (1957)。

8. S。 E。 Wood and H。H。Strain, Anal。Chem。, 26, 1869 (1954)。

9. G。H。 Evans and Ho HoStrain, Anal。Chem。 28, 1560 (1956)。

10. HoH. Strain and J。C.Sullivan, Anal。Chem。, 23, 816 (1951)。

11. H。H.Strain, Anal。Chem。, 24,356 (1952)。

12. T。R。 Sato, W。 E。 Kisieleski, W。 P。Norris and H。H。Strain, Anal。 Chem。, 25, 438 (1953)。

13. R。 Cramer, $K_{0}-D_{0}$ L Lerner and $A_{0}$ Polson, Science Tools, LKB Instrument Journal, 4,17 (1957)。

14. T。 R。 Sato, Wo PoNorris and H。H。Strain, Anal。Chemo, 26, 267 (1954)。

15. T。R。 Sato, Wo PoNorris and H。H。Strain, Anal。Chemo, 27, 521 (1955)。

16. D。Gross, Nature, 180, 596 (1957)。 
17. H。 G. Kunkel and A。 Tiselius, JoGen。 Physiol,, 35, 89 (195:)。

18. JoL。 Engelke, Ho Ho Strain and S。E.Wood, Angl。Chem。, 26, 1864 (1954)。

19. To R。 Sato, Ho Diamond, $W_{0} P_{0}$ Norris and $H_{0} H_{0}$ Strain, Jo Am。Chem。 Soco, 74, 6154 (1952)。

20. Jo Engelke and Ho H. Strain, Anal。Chom。, 26, 1872 (1954)。

21. Ho Ho Strain, Anal。Chem。, 30, 228 (1958)。

22. To Ro Sato, Wo Po Norris and Ho Ho Strain, Analo Chemo, 2ly, 776 (1952)。 


\section{APPENDIX I}

Flowering Plants Whose Leaves Yielded the Pigments Illustrated by Figure $I I, I$ 。

(The natural habitat is recorded as well as the location, in parentheses, of the speciments examined. Variations of the pigment system, particularly the presence or absence of $\alpha$-carotene, are noted in the tabulation. Traces of taraxanthin were found in the Cycadaceae).

\section{SPERMATOPHYTA}

\section{GYMNOSPERMAE}

\section{ARAUCARI ACEAE}

Agathis robusta, Queensland Kauri, Austrailia (Oahu) (much $\alpha$-carotene)

Araucaria excelsa, Norfolk-Island-Pine, Norfolk Island and Australia (Oahu) (much $\alpha$-carotene)

Araucaria imbricata, Monkey Puzzle Tree, Chile, (Burlingame) (some $\alpha$-carotene)

\section{CUPRESSACEAE}

Cupressus macrocarpa, Monterey Cypress, California Coast (Stanford) (some $\alpha$-carotene)

Cupressus sempervirens, Italian Cypress, Southern Europe (Stanford) (some $\alpha$-carotene)

Libocedrus decurrens, Incense Cedar, California (Stanford) (much $\alpha_{- \text {caroten } \theta \text { ) }}$

Thuya orientalis, Northern China (Stanford) (some $\alpha$-carotene) (pigments of red-brown winter foliage included much rhodoxanthin)。 


\section{SPERMATOPHYTA (cont。)}

\section{GYMNOSPERMAE}

\section{CYCADACEAE}

Geratozamin mexicana, Mexico (Chicago) (much $\alpha$-carotene and a trace taraxanthin)。

Cycas circinalis, Fern Palm, Tropical Asia (Chicago) (Oahu) (some $\alpha$-carotene and trace taraxanthin).

Cycas revoluta, Sago $\mathrm{Palm}$, Java (Berkeley, Oahu) (much $\alpha$-carotene and trace taraxanthin)

Dioon edula, Mexico (Chicago) (much $\alpha$-carotene and trace

Encephalartos Hildenbrandtii, East Africa (Chicago) (much $\alpha_{0}$ carotene and trace taraxanthin)

Strangeria paradoxa, Port Natal (Chicago) (much $\alpha$-carotene and trace taraxanthin)

Zamia floridana, Florida (Chicago) (much $\alpha$-carotene and trace taraxanthin)

Zamia media, Central America (Chicago) (much $\alpha$-carotene 'and trace taraxanthin)

Zamia mexicana, Mexico (Chicago) (much $\alpha$-carotene and trace taraxanthin)

Zamia portoricensis, Puerto Rico (Chicago) (much $\alpha$-carotene and trace taraxanthin)

Zamia pumila, Central America (Chicago) (much $\alpha$-carotene and trace taraxanthin)

\section{GINKGOACEAE}

Ginkgo biloba, China (Palto Alto) (male, staminate tree) (much $\alpha$-carotene)

\section{GNETACEAE (EPHEDRACEAE)}

Ephedra distachya, South Eastern Europe and Western Asia (Mather, Sierra Nevada) (no $\alpha$-carotene) 


\section{SPERMATOPHYTA $($ cont.)}

\section{GYMNOSPERMAE}

\section{PINACEAE}

$$
\begin{aligned}
& \text { Pinus contorta, } \begin{array}{c}
\text { var. Murrayana, Sierra Nevada (Stanford) } \\
\text { (some } \alpha \text {-carotene) }
\end{array} \\
& \text { Pinus Sabiniana, } \begin{array}{c}
\text { Digger Pine, California (Stanford) (some } \\
\alpha-\text { carotene) }
\end{array} \\
& \text { Cedrus atlantica, Atlantic Cedar, North Africa (Stanford) } \\
& \begin{array}{l}
\text { Aododar Cedar, Himalayas (Stanford) (some } \\
\text { the same pigments as the leaves) }
\end{array}
\end{aligned}
$$

\section{TAXACEAE}

Taxus baccata, English Yow, Europe, North Africa, Contral Asia (Stanford) (some $\alpha$-carotene)

Torreya californica, California (Palo Alto) (some $\alpha$-carotene)

\section{TAXODI ACEAE} Cryptomeria japonica, (tree), Japan (Berkeley) (some $\alpha$-caro-

Cryptomeria japonica, var。 elegans, Japan (Stanford) (trace $\alpha$-carotene) (red winter foliage yielded much rhodoxanthin)

Metasequoia glyptostroboides, China (Berkeley) (much $\alpha$-caro$\operatorname{ten} \theta)$

Sequoia sempervirens, Coastal Redwood, Coastal California (Stanford) (some $\alpha$-carotene)

Sequoiadendron giganteum (Sequoia gigantea), Big Treo, Sierra Nevada (Stanford) (some o-carotene) 


\section{SPERMATOPHYTA (conto)}

\section{ANGIOSPERMAE}

\section{AMARYLLIDACEAE}

$$
\begin{aligned}
& \text { Agave americana, } \begin{array}{l}
\text { Century Plant, Mexico (Stanford) (no } \alpha-c a r o- \\
\text { tene) (seed pods and stems also yielded the } \\
\text { same pigments as the leaves) }
\end{array} \\
& \text { Crinum asiaticum, } \begin{array}{c}
\text { Spider Lily, Phillipine Islands (Oahu) (no } \\
\alpha \text {-carotene) }
\end{array}
\end{aligned}
$$

\section{ANCARDI ACEAE}

Mangifera indica, Mango, India and Malaya (Oahu) (some $\alpha$-carotene)

Pistacia chinensis, China (Stanford) (trace $\alpha$-carotene)

Pistacia terebinthus, Mediterranean (Stanford) (trace $\alpha$-carotene)

Pistacia vera, Mediterranean (Stanford) (trace $\alpha$-carotene)

Rhus diversiloba, Poison Oak, California (Stanford) (trace $\alpha-$ carotene)

Schinus Molle, California Pepper Tree, South America (Stanford) (no $\alpha$-carotene)

Schinus terebinthifolius, Brazil, (Oahu) (trace $\alpha$-arotene)

\section{APOCYNACEAE}

Nerium Oleander, Mediterranean Region (Palo Alto) (some $\alpha$-carotene)

Ochrosia elliptica, New Caledonia (Oahu) (some $\alpha$-carotene)

Plumeria acutifolia, Tropical America (Oahu) (some $\alpha$-carotene)

Vinca minor, Myrtle, Europe (Stanford) (no $\alpha$-oarotene)

\section{ARACEAE}

Alocasia macrorhiza, India, Malaya (Oahu) (trace $\alpha$-carotene) 


\section{SPERMATOPHYTA (cont。) \\ $\Longrightarrow$}

ANGIOSPERMAE

ARACEAE (conto)

Arum italicum, Southern Europe (Palo Alto) (no $\alpha$-caroteno) (green fruits yielded the same pigments as the leaves)

Pistia Stratiotes, American Tropics (Oahu) (trace

Syngonium, spog (Oahu) (much $\alpha$-carotene, much neoxanthin and littlo violaxanthin)

Zantedeschia aethiopica, Calla Lily, South Africa (Palo Alto) (no $\alpha$-carotene)

\section{ARALIACEAE}

Brassia octinophylla, Octopus Tree, Australia (Oahu) (no $\alpha$ carotene)

Cheirodendron platyphyllum, (Panax platyphyllum), Hawaiian Islands (Oahu) (trace $\alpha-\operatorname{caroten} \theta)$

Nothopanax Guilfoylei, (Panax Guilfoylei) Pacific Islands (Oahu) (much owcarotene)

ARISTOLOCHIACEAE

Aristolochia elegans, Brazil (Oahu) (some $\alpha$-carotene)

\section{BATIDACEAE}

Batis maritima, Jamaica (Oahu) (trace $\alpha$-carotene)

\section{BIGNONIACEAE}

Catalpa bignonioides, American'(Stanford) (trace $\alpha$-carotene)

Kigelia africana, Sausage Treo, Tropical Africa (Oahu) (trace a-carotene)

Spathodea campanulata, African Tulip Tree, Tropical Africa

(Oahu) (some $\alpha$-carotene) 


\section{SPERMATOPHYTA (cont。)}

\section{ANGIOSPERMAE}

\section{BI XACEAE}

Bixa Orellana, South America (Oahu) (some $\alpha$-carotene)

\section{BOMBACACEAE}

Adansonia digitata, $\begin{aligned} & \text { Baobab Tree, Tropical Africa (Oahu) } \\ & \text { (some } \alpha \text { carotene) }\end{aligned}$

\section{BROMSELIACEAE}

Ananas satisvus, Pineapple, South America (Oahu) (some $\alpha=$ Tillandsia useneoides, Spanish Moss, Virginia to Brazil (Houston, Texas: Hawaiian Islands) (no $\alpha$-carotene)

\section{CACTACEAE}

Hylocereus undatus, Night-blooming Cereus, Mexico, Central America (Oahu) (some $\alpha-\operatorname{carotene})$

\section{CAMPANULACEAE}

Rollandis calycina, Hawaiian Islands (Oahu) (some $\alpha$-carotene)

\section{CANNACEAE}

Canna spo, Asia and Amerioa (San Rafael) (trace $\alpha-$ carotene)

\section{CAPRIFOLIACEAE}

Sambucus glauca, Biue Elderberry, Western United States (Stanford) (some $\alpha$-carotene)

\section{CARICACEAE}

Carica papaya, Papaya, American Tropios (Oahu) (trace $\alpha$-caroo tene and trace violaxanthin) (staminate and pistillate plants yielded the same pigments) 


\section{SPERMATOPHYTA $($ cont.)}

\section{ANGTOSPERMAE}

\section{CASUARI NACEAE}

Casuarian equisetifolia, Northern Australia (Stanford) (no $\alpha$ -

\section{CHENOPODIACEAE}

Salicornia ambigua, Coastal United States (San Francisco Bay marsh) (no $\alpha$-carotene)

\section{COMBRETACEAE}

Terminalia Catappa, Tropical Asia (Oahu) (some $\alpha$-carotene)

\section{COMMELINACEAE}

Rhoeo discolor, Mexico (Oahu) (trace $\alpha$-carotene)

\section{COMPOSITAE}

Achillea lamulosa, Mexico (Stanford) (trace $\alpha$-carotene)

Achillea Millefolium, Iceland (Stanford) (trace $\alpha$-carotene)

Argyroxiphium macrocephalum, Silver Sword, Hawaiian Islands (Oahu) (no $\alpha$-carotene)

Arnica amplexicaulis, Western United States (Summit of Sierra Nevada) (no $\alpha$-caroten $\theta$ )

Bidens sp., Hawaiian Islands (Oahu) (no $\alpha$-carotene)

Cirsium lanceolatum, Bull Thistle, Europe (Stanford) (no $\alpha-$

Coreopsis lanceolata, North America (Palo Alto) (no $\alpha$-carotene)

Cotula coronopifolia, Brass Buttons, S. Africa (San Francisoo Bay marsh) (no $\alpha$-carotene)

Gnaphalium chilense, Western United States (Newark) (no $\alpha$-carotene) 
COMPOSITAE (conto)

Grindelia robusta, Coastal California (Stanford) (no $\alpha$-carotene)

Helianthus annuus, Sunflower, North America (Stanford) (slight trace $\alpha$-carotene)

Parthenium argentatum, Guayule, Mexico (Stanford) (no $\alpha$-carotene)

Solidago multiradiata var。 scopulorum, Western United States (Sumit of Sierra Nevada) (no $\alpha$ carotene, much violaxanthin)

Taraxacum officinale, Dandelion, Europe (Stanford) (taraxanthin not found in the leaves although abundant in the flowers)

CONVOLVULACEAE

Ipomea batatas, Sweet Potato, Tropics (Oahu) (no $\alpha$ carotene)

\section{CORNACEAE}

Aucuba japonica, Japan (San Rafael) (some $\alpha$-carotene) (male and female plants yielded the same pigments)

\section{CRASSULACEAE} Bryophyllum pinnatum (calycinum), $\begin{aligned} & \text { East Indies (Stanford) (no } \alpha- \\ & \text { carotene) }\end{aligned}$

Kalanchoe spo, Kalanchoe, Cultigen (Stanfor $\alpha)$ (trace $\alpha$-carotene)

Sedum roseum, Circumpolar Regions South to New York (Sumnit. of Sierra Nevada) (trace $\alpha-c a r o t e n e)$

\section{CUCURBITACEAE}

Echinocystis fabacea,

Common Manroot, California (Stanford) (no $\alpha-\operatorname{caroten} \theta$ ) (fruit hulis and stems yielded the same pigments as the leaves inner seed coats contained much protochlorophyll) 


\section{ANGIOSPERMAE}

\section{DIPSACEAE}

Dipsacus fullonum, Fuller's Teasel, Europe (Stanford) (no $\propto$ carotene)

\section{EPACRIDACEAE}

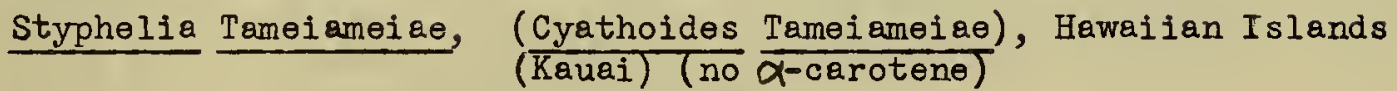

\section{ERICACEAE} Cassiope Mertensiana, $\begin{gathered}\text { California (Summit of Sierra Nevada) (no } \\ \alpha \text {-carotene) }\end{gathered}$

Vaccinium calycinum, var. meyerianum, Hawaiian Islands (Oahu) (no $\alpha$-carotene)

Vaccinium ovatum, California Huckleberry, Coastal California (Marin County) (trace $\alpha$-carotene)

\section{EUPHORBI ACEAE}

Aleurites moluccana, Malaya (Oahu) (some $\alpha$-carotene)

Codiaeum variegatum, Croton, Malaya (Oahu) (some $\alpha$-carotene)

Euphorbia antiquorum, India (Oahu) (some $\alpha$-carotene)

Euphorbia pulcherrima, Poinsettia, Mexico (Oahu) (no $\alpha$-carotene)

Ricinus communis, Castor Bean (San Rafael) (no $\alpha$-carotene)

\section{FAGACEAE}

Quercus Suber, Cork Oak, Southern Europe and North Africa (Stanford) (trace $\alpha$-carotene and much neoxanthin)

\section{GARRYACEAE}

Garrya elliptica, Coastal Northern California (Stanford) (no $\alpha-$ carotene) 
SPERMATOPHYTA $($ conto)

ANGIOSPERMAE

GESNERI ACEAE

Saintpaulia ionantha, African Violet, Tropical Africa (Palo Alto) (trace $\alpha$-carotene)

GOODENIACEAE

Scaevola Gaudichaudiana, Hawaiian Islands (Oahu) (no $\alpha$-carotene)

\section{GRAMI NEAE}

Arundo Donax, Giant Reed, Mediterranean Region (Palo Alto, Oahu) (some $\alpha$-carotene)

Cortaderia argentia, Pampas Grass, South America (Oahu) (traco $\alpha$-carotene)

Hordeum murinum, Foxtail, Europe (Palo Alto) (trace $\alpha$-carotene)

Hordeum vulgare, Barley, Cultigen (Stanford) (trace $\alpha$-carotene)

Saccharum officinarum, Sugar Cane, Eastern Tropical Asia (Oahu) (no $\alpha$-carotene)

Sotaria palmifolia, Palm Grass, Tropics (Oahu) (trace $\alpha$-carotene)

GUTTIFERAE

Clusia rosea, West Indies (Oahu) (some $\alpha$-carotene)

Hypericum anagalloides, Pacific Coast of North America (Summit of Sierra Nevada) (no $\alpha$-carotene)

\section{HAEMODORACEAE}

Sansevieria zeylanica, Bow String Hemp, Ceylon (Oahu) (some $\alpha_{-}$ carotene)

\section{HALORRHAGI DACEAE}

Gunnera petaloides, Hawaiian Islands (Oahu) (f'aint trace $\alpha$-caro- 


\section{SPERMATOPHYTA (conto)}

\section{ANGIOSPERMAE}

\section{HYDROCHARI TACEAE}

Halophila ovata, Tropical Asia, Australia (Oahu) (no $\alpha$-carotene)

\section{RIDACEAE}

Gladiolus sp。, Gladiolus, Cultigen (Palo Alto) (no $\alpha$-carotene)

Iris germanice, Iris, Cultigen (Palo Alto) (no $\alpha$-carotene)

\section{JUGLANDACEAE}

Juglans regia, English Walnut, South Easterm Europe, Himalayas (Palo Alto) (trace $\alpha$-carotene)

\section{LAURACEAE}

Cinnamonum zeylanicum, India or Malaya (Oahu) (much $\alpha$-orotene)

Hernandia peltata, Jack-in-the-Box, Tropics (Oahu) (some $\alpha$-carotene)

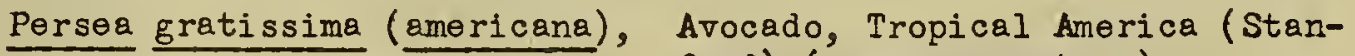
ford) (some $\alpha$-carotene)

Umbellularia californica, California Laurel, Western United States (Stanford) (trace $\alpha$-carotene)

\section{LECYTHIDACEAE}

Barringtonia speciosa, Fish Poison Tree, Pacific Islands (Oahu) (much $\alpha$-carotene)

\section{LEGUMINOSAE}

Acacia Koa, Hawailan Islands (Oahu) (no $\alpha$-carotene)

Calliandra haematonia, Tropics (Oahu) (much o-carotene)

Cassia Fistula, Golden Shower Tree, Tropical Asia (Oahu) (some arcarotene) 


\section{SPERMATOPHYTA (cont。)}

\section{ANGIOSPERMAE}

\section{LEGUMINOSAE (cont。)}

Cercis occidentalis, Redbud, California (Stanford) (trace $\alpha$-carotene)

Cytisus scoparius, Spanish Broom, Central and Southern Europe, (Stanford) (no $\alpha$-carotene) (stems yielded the same pigments found in the leaflets)

Enterolobium cyclocarpum, Elephant's Ear, West Indies, Central America (Oahu) (some $\alpha$-carotene)

Erythrina variegata, var, orientalis, Tiger's Claw, Tropical Asia (Oahu) (some $\alpha$-carotene)

Medicago hispida, Bur Clover, Europe (Stanford) (no $\alpha$-carotene) Pickeringia montana, Chaparral Pea, California (Stanford) (no $\alpha_{-}$ carotene)

Poinciana regia, (Delonix regia), Royal Poinciana, Madagascar (Oahu) (trace $\alpha-\operatorname{caroten} \theta)$

Prosopis juliflora, Tropical America (Oahu) (trace $\alpha$-carotene) Robinia Pseudo-Acacia, Locust, America (Palo Alto) (trace $\alpha$-caro$\operatorname{ten} \theta)$

Wallaceodendron celebicum, Banuvo, Philippine Islands (Oahu) (trace $\alpha$-carotene)

\section{LEMNACEAE}

Wolffiella spo, (Stockton) (no $\alpha$-carotene)

\section{LILIACEAE}

Agapanthus umbellatus, Lily-of-the-Nile, South Africa (Palo Alto) (no $\alpha$-carotene)

Allium Cepa, Onion, Western Asia (Stanford) (no $\alpha$-carotene)

Aspidistra lurida, China (San Rafael) (much $\alpha-c a r o t e n \theta)$

Chlorogalum pomeridianum, Soap Plant, Western United States (Stanford) (no $\alpha$-carotene) 


\section{SPERMATOPHYTA $($ cont。)}

\section{ANGIOSPERMAE}

\section{LILIACEAE (cont。)}

Cordyline terminalis, (Tretsia fruticosa), "Ti", Tropical Asia Australia, Pacific Islands (Oahu) (much $\alpha$ carotene)

Phormium tenax, New Zealand Flax, New Zealand (Palo Alto) (no $\alpha$ $\operatorname{corotene)}$

Similax sandwicensis, Hawailan Islands (Kauai) (trace $\alpha$-carotene)

Yucca brevifolia, Joshua Tree, South Western United States (Stanford) (no $\alpha$-carotene)

\section{LINACEAE}

Linum usitatissimum, Flax, Asia (Stanford) (no $\alpha$-carotene)

\section{LOASACEAE}

Sibbaldia procumbens, Subarctic (Summit of Sierra Nevada) (no $\alpha-$ carotene)

\section{LOGANI ACEAE}

Buddleia japonica, Japan (Stanford) (no $\alpha$-carotene)

Strychnos nux-tomica, Strychnine Tree, India or Burma (Oahu) (much $\alpha$-carotene)

\section{LYTHRACEAE}

Lawsonia inermis, Africa and India (Oahu) (some $\alpha$-carotene)

\section{MAGNOLIACEA}

Magnolia grandiflora, Magnolia, Southern United States (Palo Alto) (much $\alpha$-carotene)

Magnolia Soulangeana, Deciduous Magnolia, Cultigen (Stanford) (much $\alpha$-carotene 


\section{SPERMATOPHYTA (conto)}

\section{ANGIOSPERMAE}

\section{MALVACEAE}

Althaea rosea, Hollyhock, China (Stanford) (no $\alpha$-carotene)

Gossypium tomentosum, Wild Cotton, Hawaiian Islands (Orhu) (trace $\alpha$-carotene)

Hibiscus rosa-sinensis, China (Oahu) (trace $\alpha$-carotene)

Hibiscus schizopetalus, Coral Hibiscus, Tropical Africa (Oahu) (much $\alpha$-carotene)

Hibiscus tiliaceus, "Hau", Old World Tropics (Oahu) (trace $\alpha-$ $\operatorname{caroten\theta })$

Malva parviflora, Mallow, Europe (Stanford) (no $\alpha$-carotene)

MORACEAE

Artooarpus integrifolia, Jack Fruit, India (Oahu) (some $\alpha$-carotene)

\section{MUSACEAE}

Heliconia spo, False Bird of Paradise, Tropical America (Oahu) (much $\alpha$-carotene)

Musa Ensete, Abysinian Banana, Abysinia (trace $\alpha$-carotene)

Musa sapientum, Banana, Tropical Asia (Oahu) (much $\alpha$-carotene)

Phaeomeria speciosa, Torch Ginor, Mauritius Island (Oahu) (much $\alpha$-carotene)

Ravenala madagascariensis, Traveler's Tree, Madagascar (Oahu) (some $\alpha$-carotene)

Strelitzia Reginae, Bird-of-Paradise, South Africa (Oahu) (trace $\alpha$-carotene)

\section{MYRTACEAE}

Couroupita guianensis, Cannon Ball Tree, Guinea (Oahu) (some $\alpha$ carotene) 


\section{SPERMATOPHYTA (conto)}

\section{ANGIOSPERMAE}

MYRTACEAE (cont.)

Eucalyptus globulus, Australia (Stanford) (no $\alpha$-carotene)

Metrosideros macropus, Hawailan Islands (Kauai) (trace $\alpha$-carotene)

Metrosideros polymorpha, Polynesia (Oahu) (trace $\alpha$-carotene)

Melaleuca decussata, Australia (Palo Alto) (no $\alpha$-carotene)

Melaleucka spo, Cultigen (Palo Alto) (trace $\alpha$-carotene)

Pimenta acris, Bay Rum, West Indies (Oahu) (some $\alpha$-carotene)

Pimenta officinalis, Allspice, West Indies (Oahu) (much $\alpha$-carotene)

Psidium Gusjava, Tropical America (Oahu) (much $\alpha$-carotene)

\section{NAJADACEAE}

Phyllospadix sp., Pacific Coast of North America (Half Moon Bay) (trace $\alpha$-carotene)

\section{NYCTAGINACEAE}

Mirabilis Jalapa, Four-o' clock, Mexico (Oahu) (some $\alpha$-carotene)

OLEACEAE

Osmanthus sandwicensis, Hawaiian Islands (Oahu) (some $\alpha$-carotene)

\section{ONAGRACEAE}

Epilobium obcordatum, California (Summit of Sierra Nevada) (trace $\alpha$-carotene)

Fuchsia Magellanica, Cultigen (Palo Alto) (no $\alpha$-carotene)

Fuchsia speciosa, Fuchsia, Cultigen (Palo Alto) (no $\alpha$-carotene) 


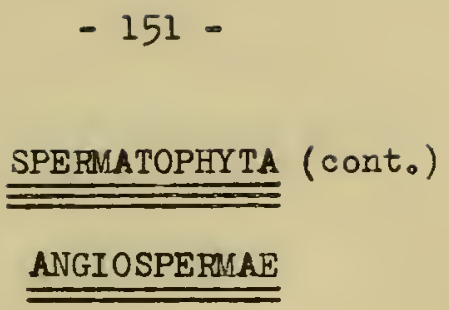

\section{ORCHI DACEAE}

Epipactis gigantea, Orchid, Sierra Nevada (Palo Alto) (trace $\alpha$ carotene)

Vandopsis spo, (Oahu) (trace $\alpha$-carotene)

\section{PALMAE}

Actinophloeus Macarthuri, New Guinea (Oahu) (some $\alpha$-carotene)

Cocos nucifera, Coconut, Tropics (Oahu) (some $\alpha$-carotene)

Erythea edulis, $\begin{gathered}\text { Guadalupe Palm, Guadalupe Islands (Stanford) (trace } \\ \alpha \text {-carotene) }\end{gathered}$

Eupritchardia remota, Nihoa Island, Hawailan Islands (Oahu) (trace $\alpha$-carotene

Hyophorbe amaricaulis, Bottle Palm, Mauritius Island (Oahu) (trace $\alpha$-carotene)

Phoenis canariensis, Canary Island Palm, Canary Islands (Stanford) (no $\alpha$-carotene) Rhapis flabelliformis, $\begin{gathered}\text { Bamboo Palm, China and Japan (Oahu) (much } \\ \alpha \text {-carotene) }\end{gathered}$

\section{PANDANACEAE} Freycinetia arborea, Screw Pine, Hawaiian Islands (Oahu) (some $\alpha$ yielded the same pigments)

Pandanus Rockii, (in fruit), Palmyra Island (Oahu) (much $\alpha$-carotene)

\section{PAPAVERACEAE}

Dendromecon rigida, California (Stanford) (trace d-carotene)

Eschscholtzia californica, California Poppy, California (Stanford) (no $\alpha$-carotene)

Papaver Rhoeas, Shirley Poppy, Europe and Asia (Palo Alto) (no $\alpha$ carotene) 


\section{SPERMATOPHYTA (conto)}

\section{ANGIOSPERMAE}

\section{PASSIFLORACEAE}

\section{Passiflora mollissima, Passion Flower, Andes (Kauai) (no $\alpha$ - carotene)}

\section{PIPERACEAE}

Peperomia reflexa, Pacific Islands (Oahu) (some $\alpha$-carotene)

Piper methysticum, Hawaiian Islands (Oahu) (much $\alpha$-carotene)

\section{PITTOSPORACEAE}

Pittosporum eugenioides, New Zealand (Stanford) (no O-carotene)

\section{POLYGONACEAE}
Antigonon leptopus, Mexican Creeper, Mexico (Oahu) (trace $\alpha_{-}$ carotene)
Coccoloba uvifera, Shore Grape, Tropical America (Oahu) (much $\alpha$ - carotene)

PONTEDERIACEAE

Eichhornia crassipes, Water Hyacinth, Tropical America (Oahu)

\section{PORTULACACEAE}

Montia perfoliata, Miner's Lettuce, Western United States (Stanford) (no $\alpha$-carotene)

\section{PROTEACEAE}

Grevillea robusta, Silk Oak, New South Wales (Stanford; Hawaii) (no $\alpha$-carotene)

RANUNCULACEAE

Ranunculus occidentalis, Western Buttercup, Pacific Coast

(Stanford) (no $\alpha$-corotene) 


\section{SPERMATOPHYTA $($ cont。)}

\section{ANGIOSPERMAE}

\section{RHI ZOPHORACEAE}

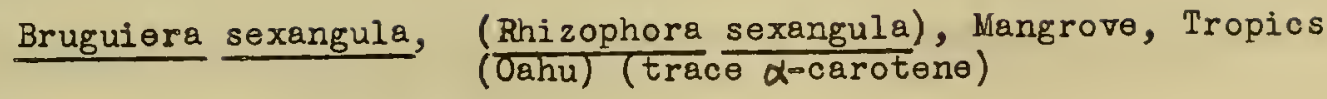

Rhizophora Mangle, Mangrove, Tropics (Oahu) (trace $\alpha$-carotene)

\section{ROSACEAE}

Eribotrya japonica, Loquat, Japan (Stanford) (trace $\alpha$-carotene)

Fragaria californica, California Strawberry, California (Stanford) (no $\alpha$-carotene)

Lyonothamnus floribundus, Catalina Ironwood, California Coastal

Islands (Stanford) (no $\alpha$-carotene)

Photinia arbutifolia, Toyon, California (Stanford) (no $\alpha$-carotene)

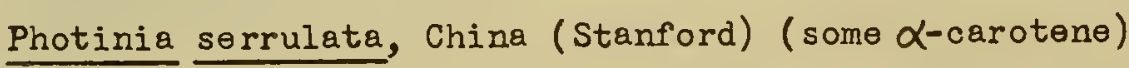

Prunus cerasifera, var. Pissartii, Flowering Plum, Cultigen (Stanford) (trace $\alpha$-carotene) (red leaves and green leaves)

RUTACEAE

Citrus sinensis, Navel Orange, China (Stanford) (much $\alpha$-carotene)

RUBI ACEAE

Coffea arabica, Coffee, Africa (Oahu) (much $\alpha$-carotene)

Ixora parviflora, India (Oahu) (much $\alpha$-carotene)

Morinda citrifolia, India or Malaya (Oahu) (some $\alpha$-carotene)

Nertera depressa, South America, New Zealand (Oahu) (trace $\alpha$-carotene)

\section{SALICACEAE}

Salix babylonica, Weeping Willow, China (Palo Alto) (no $\alpha$-carotene) (bark and leaves) 


\section{SPERMATOPHYTA (conto)}

\section{ANGIOSPERMAE}

SALICACEAE (conto)

Populus alba, Poplar, Asia (Palo Alto) (no $\alpha$-caroteno) (green leaves and yellow autumn leaves)

\section{SAPINDACEAE}

Aesculus californica, California Buckeye, California (Stanford) (some $\alpha$-carotene)

Sapindus oahuensis, Hawaiian Islands (Oahu) (some $\alpha$-carotene)

\section{SANTALACEAE}

Santalum Freycinetianum, var. littorale, Sandalwood, Oahu (Oahu) (no $\alpha$-carotene)

\section{SAXIFRAGACEAE}

Broussaisia arguta, Hawaiian Islands (Oahu) (some $\alpha$-carotene) Carpenteria californica, Sierra Nevada Foothills (Stanford) (no $\alpha$-carotene)

Hydrangea hortensis, $\begin{aligned} & \text { Hydrangea, Japan and China (Stanford) (some } \\ & \alpha \text {-carotene) }\end{aligned}$

\section{SC ROPHULART ACEAE}

Pedicularis groenlandica, Summit of Sierras to British Columbia to Labrador (Summit of Sierra Nevada) (trace $\alpha$-carotene)

Veronica speciosa, New Zealand (Palo Alto) (no $\alpha$-carotene)

\section{VERBENACEAE}

Tectona grandis, Teakwood, India (Oahu) (some $\alpha$-carotene)

\section{SIMARUBACEAE}

Ailanthus altissina, Tree-of-Heaven, China (Stanford) (no $\alpha$-caro$\operatorname{ten} \theta$ ) 


\section{SPERMATOPHYTA $($ cont.)}

\section{ANGIOSPERMAE}

\section{SOLANACEAE}

Brugmansia arborea, Angel's Trumpet, South America (Oahu) (no $\alpha-$ carotene)

Solanum tuberosum, Potato, South America (Stanford) (no $\alpha$-carotene)

STERCULIACEAE

Brachychiton diversifolium, Australia (Stanford) (no $\alpha$-carotene)

Fremontia californica, California (Stanford) (no $\alpha$-carotene) (zeaxanthin equal to or greater than the lutein)

Heritiera littoralis, Looking Glass Tree, Tropical Asia and Pacific (Oahu) (much $\alpha$-carotene)

Pterospermum acerifolium, India (Oahu) (some $\alpha$-carotene)

\section{TACCACEAE}

Tacca leontopetaloides, Southerst Asia (Oahu) (some $\alpha$-carotene)

\section{TAMARICACEAE}

Tamarix parviflora, Southern Europe (Stanford) (no $\alpha$-oarotene)

TERNSTROEMIACEAE

Camellia japonioa, Cultigen (Palo Alto) (much $\alpha$-carotene)

\section{TYPHACEAE}

Typha latifolia, Cat Tail, North Temperate Zone (Stanford) (no $\alpha$-carotene)

\section{URTICACEAE}

Ficus retusa, Chinese Banyan, Asia (Oahu) (some $\alpha$-carotene)

Pipturus albidus, Hawailan Islands (Oahu) (some $\alpha$-carotene)

Touchardia latifolia, Hawailan Islands (Oahu) (trace $\alpha$-carotene) 
SPERMATOPHYTA (cont.)

\section{ANGIOSPERMAE}

\section{VERBENACEAE}

Clerodendrum indicum, Southeast Asia (Oahu) (traco $\alpha$-carotene)

\section{INGIBERACEAE}

Hedychium flavum, Yellow Giner, India (Oahu) (much $\alpha$-carotene) 
APPENDIX II

Ferns, Horsetails, Club Mosses and Quillwort That Yielded the Same Plgments Observed in the Leaves of Flowering Plants as Illustrated by Figure II, J.

\section{PTERIDOPHYTA}

DICKINSONTACEAE

Cibotium Chamissoi, $\begin{aligned} & \text { Hawaiian Tree Fern, Hawailan Islands (Hawaii) } \\ & \text { (no } \alpha \text {-carotene) }\end{aligned}$

\section{EQUI SETACEAE}

Equisetum arvense, Common Horsetail, North Temperate Zone (Marin County) (much $\alpha$-carotene)

Equisetum telmateia, Giant Horsetail, North Temperate Zone (Berkeley) (much $\alpha$-carotene)

\section{GLEICHENI ACEAE}

Gleichenia dichotoma, False Staghorn Fern, Tropics (Hawail and Kauai) (trace $\alpha$-carotene)

HYMENOPHYLIACEAE

Hymenophyllum recurveum, $\begin{aligned} & \text { Filmy Fern, Hawailan Islands (Oahu) } \\ & \text { (some } \alpha \text {-carotene) }\end{aligned}$
$\underline{\text { Trichomanes Bauerianum, }} \begin{aligned} & \text { Filmy Ferm, Polynesia (Oahu) (trace } \alpha- \\ & \text { carotene) }\end{aligned}$

\section{ISOETACEAE}

Isoetes Bolanderi, Bolander's Quillwort, Sierra Nevada. (Sumit of Sierra Nevada) (no $\alpha$-carotene) 


\section{PTERIDOPHYTA $($ cont.)}

\section{LYCOPODIACEAE}

Selaginella arbuscula, Club Moss, Pacific Islands (Oahu) (trace $\alpha$-carotene)

Lycopodium cernum, Club Moss, Tropics (Hawaii) (trace $\alpha$-carotene)

Selaginella Wallacei, Club Moss, Western U.S.A. (Berkeley) (no $\alpha$-carotene)

\section{OPHIOGLOSSACEAE}

Botrychium silaifolium, Leathery Grape Fern, Northern North America (Summit Sierra Nevada) (no $\alpha$-carotene)

\section{POLYPODIACEAE}

Acrostichum spo, (Hawaii) (some $\alpha$-carotene)

Adiantum Jordani, California Maidenhair, Coastal California (Stanford) ( $\operatorname{som} \theta \alpha$-carotene)

Asplenium lobulatum, Hawaiian Islands (Kauai) (some $\alpha$-carotene) Coniogramme pilosa, (ㅁ fraxinea) China, Japan (Kauai) (some $\alpha_{-}$ carotene)

Elaphoglos sum conforme, Subtropics (Oahu) (some $\alpha$-carotene)

Elaphoglossum retioulatum, Hawaiian Islands (Hawaii) (some $\alpha$-carotene)

Nephrolepis exaltata, Sword Fern, Tropics (Hawaii) (trace $\alpha$-carotene)

Pellaea ternifolia, Cliff Brake, Texas to Chile (Hawaii) (trace $\alpha-$ $\operatorname{coroten} \theta$ )

Pityrogramma calomelanos, Gold Fern, Tropical America (Kauai) (no $\alpha-\operatorname{corotene})$

Pityrograma triangularis, Gold Fern, Western U.S.A. (Stanford) (some $\alpha$-carotene)

Platycerium bifurcatum, Elkhorn Fern, Temperate Australia (Oahu) (some $\alpha$-carotene)

Polypodium californicum, California Polypody, Coastal California

(Stanford) (trace $\alpha$-carotene) 


\section{PTERIDOPHYTA (cont。)}

POL YPODIACEAE (cont。)

Polypodium lineare, Tropics (Hawaii) (some $\alpha$-carotene)

Polypodium phymatoides, New Guinea (Oahu) (much $\alpha$-carotene)

Polystichum munitum, Western Sword Fern, Western North America (Stanford) (some $d$-carotene)

Pteridium aquilinum, Bracken, Worldwide (Kauai) (Stanford) (trace $\alpha \rightarrow$ carotene)

Pteridium complanatum, Hawail (trace $\alpha$-carotene)

Pteris excelsa, Tropical Asia and Polynesia (Hawail) (trace $\alpha_{0}$ carotene)

Sadleria spo, (pallida?), (Hawaii) (some $\alpha$-carotene)

Sphenomeris chusana, (Odontosoria chinensis) (Stenoloma chinensis) (trace $\alpha$-carotene)

Woodwardia fimbriata, (W. Chamissoi), Chain Fern, Western North America (Stanford) (some $\alpha$-carotene)

\section{PSILOTACEAE}

Psilotum complanatum, Hawailan Islands (Hawaii) (some $\alpha$-carotene)

Psilotum nudum, Hawailan Islands (Hawaii) (some $\alpha$-carotene)

\section{SALVINIACEAE}

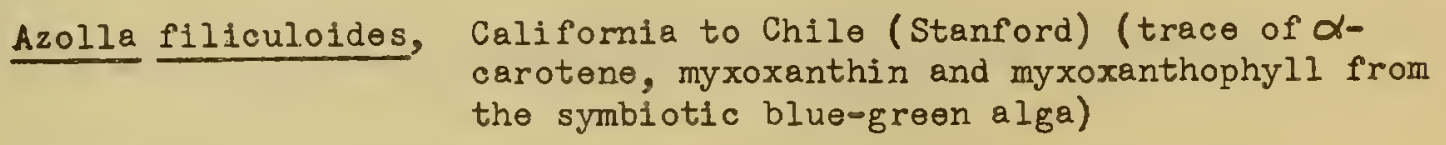




\section{APPENDIX III}

Mosses (Musci), Liverworts (Hepaticae), a Lichen (Lichenes) and a Stonewort (Charophyceae) That Yielded the Same Pigments Observed in the Leaves of Flowering Plants as Illustrated by Figure II, I.

\section{BRYOPHYTA}

\section{MUSCI}

Aquatic Moss, (Lake Lagunita, Stanford) (trace $\alpha$-carotene)

Aquatic Moss, (Nicholasville $\left.\mathrm{Ky}_{\bullet}\right)$ (trace $\alpha$-carotene)

Terrestial Moss (Stanford) (no $\alpha$-carotene)

Aulacomnium pelustre, (Summit of Sierra Nevada) (trace $\alpha$-carotene)

Hygrohypnum Smithii, (Sumit of Sierra Nevada) (trace -carotene)

Hygrohypnum spo, (Summit of Sierra Nevada) (trace $\alpha$-carotene)

Philonotis fontana, (Summit of Sierra Nevada) (trace $\propto$ carotene)

Pohlia longicolla, (Summit of Sierra Nevada) (no $\alpha$-carotene)

Sphagnum sp., (Sumit of Sierra Nevada) (trace $\alpha$-carotene)

\section{HEPATICAE}

Anthoceros sp., (yellow spored species) (Stanford) (some $\alpha$-carotene)

Asterella californica, (Stanford) (trace $\alpha$-carotene)

Conocephalum conicum, (Berkeley and Stanford) (some $\alpha$-carotene)

Marchantia polymorpha, (Summit of Sierra Nevada) (no $\alpha$-carotene) 


\section{THALLOPHYTA}

\section{LICHENES}

Ramelina reticulata, Lichen (Stanford) (no $\alpha$-carotene) (pigments from green algae in the lichen, see Appendix IV)

\section{CHLOROPHYTA}

\section{CHAROPHYCEAE}

Chara fragilis, Stonewort (Lake Lagunita, Stanford) (no $\alpha$-carotene, traces lycopene and $\gamma$-carotene) (see also Charophycere in Appendix IV) 


\section{APPENDIX IV}

Green Algae (Except Siphonales) That Yielded the Same Pigments Found in Leaves and Illustrated in Figure II, I.

(Variations of the $\alpha$-carotene-content are indicated in the tabulation. Many of the organisms yielded traces of xanthophyll adsorbed between neoxanthin and violaxanthin).

\section{CHLOROPHYTA}

\section{(CHAROPHYCEAE)}

CHARALES

\section{CHARACEAE}

Chara fragilis, Lake Lagunita, Stanford (no $\alpha$-carotene, traces lycopene and $\gamma$-carotene) (See Appendix III).

\section{(CHLOROPHYCEAE)}

CHLOROCOCCALES

\section{CHLOROCOCCACEAE}

Chlorocoocum sp., Cultured (some $\alpha$-carotene)

\section{COELASTRACEAE}

Coelastrum proboscideum, cultured (trace $\alpha$-carotene)

\section{OÖCYSTACEAE}

Ankistrodesmus falcatus, Cultured (trace $\alpha$-carotene)

Chlorella pyrenoldosa, Cultured (trace $\alpha$-oarotene)

\section{PROTOSIPHONACEAE}

Protosiphon botryoides, Cultured (trace $\alpha$-carotene) 


\section{CHLOROPHYTA (cont.)}

\section{(CHLOROPHYCEAE)}

\section{CHLOROCOCCALES}

\section{SCENEDESMACEAE}

Scenedesmus bifulgatus, Cultured (trace $\alpha$-carotene)

Scendesmus brasiliensis, Cultured (some $\alpha$-carotene)

\section{CLADOPHORALES}

\section{CLADOPHORACEAE}

Chaetomorpha aerea, Asilomar Beach, Monterey (trace $\alpha$-carotene)

Chaetomorpha antennina, Oahu (much $\alpha$-carotene)

Cladophora crispata, Berkeley (trace $\alpha$-carotene)

Cladophora fascicularis, Oahu (trace $\alpha$-carotene)

Cladophora glomerata, San Francisquito Creek, Stanford also Oahu (trace $\alpha$-carotene)

Cladophora graminea, Half Moon Bay (trace $\alpha$-carotene)

Cladophora membranacea, Oahu (trace $\alpha$-carotene)

Cladophora trichotoma, Asilomar Beach, Monterey (trace $\alpha$-carotene)

Cladophora sp., Intertidal Zone, Oahu (trace $\alpha$-carotene)

Rhizoclonium implexum, Hopkins Marine Station, Pacific Grove (no $\alpha$-carotene)

Spongomorpha coalita, Monterey (trace $\alpha$-carotene)

\section{DASYCLADALES}

DASYCLADACEAE

Acetabularia clavata, Oahu (no $\alpha$-caroteno) 


\section{CHLOROPHYTA (cont.)}

\section{DASYCLADALES}

\section{DASYCLADACEAE (cont.)}

Acetabularia crenulatum, Mermaid's Wine Glass, Miami, Florida (no $\alpha$-carotene)

Acetabularia Mobii, Oahu (no $\alpha$-carotene)

Bornetella sphaerica, Oahu (no $\alpha$-carotene)

Neomeris annulata, Oahu (no $\alpha$-carotene)

\section{SIPHONOCLADALES}

\section{ANADYOMENACEAE}

Microdictyon Setchellianum, Oahu (no $\alpha$-carotene)

BOODLEACEAE

Boodlea kaeneana, Oahu (some $\alpha$-carotene)

Struvea sp., Oahu (trace $\alpha$-carotene)

\section{VALONIACEAE}

Dictyosphaeria cavernosa, Oahu (trace $\alpha$-carotene

Dictyosphaeria favulosa, Puerto Rico (trace $\alpha$-carotene)

Dictyosphaeria Versluysii, Oahu (trace $\alpha$ - $\operatorname{coroten} \theta$ )

Valonia fastigiata, Oahu (trace $\alpha$-carotene)

\section{TETRASPORALES}

\section{COCCOMYXACEAE}

Coccomyxa Viridis, Cultured (trace $\alpha$-carotene)

Coccomyxa simplex, Cultured (trace $\alpha$-carotene) 


\section{CHLOROPHYTA (cont.)}

\section{ULOTRICHALES}

CHAETOPHORACEAE

Chaotophora incrassata, Creok in Monterey County (trace $\alpha$ carotene)

Draparnaldia glomerata, Stanford (trace $\alpha$-carotene)

Draparnaldia spo, Stanford (trace $\alpha$-carotene)

Stigeoclonium spo, Stanford (trace $\alpha$-carotene)

\section{PROTOCOCCACEAE}

Protococcus sp., Cultured (trace $\alpha$-carotene)

\section{ULOTRICHACEAE}

Hormidium flaccidum, Cultured (trace $\alpha$-carotene)

Hormidium spo, Stanford (trace $\alpha$ carotene)

Stichococcus subtilis, Stanford (trace $\alpha$-carotene)

Ulothrix spo, Saratoga Spa, New York (trace $\alpha$-carotene)

\section{ULVALES}

\section{ULVACEAE}

Enteromorpha (intestinalis?) Oahu (no $\alpha$-caroten $\theta)$

Enteromorpha tubulosas Palo Alto Yacht Harbor (trace $\alpha$-carotene)

Enteromorpha spo, Oahu (some $\alpha$-carotene)

Monostroma spo, Cultured (trace $\alpha$ carotene)

Ulva fasciata, Oahu (some $\alpha$-carotene)

Ulva linza, Asilomar Beach, Monterey (trace $\alpha$-carotene)

Ulva reticulata, Oahu (some $\alpha$-carotene)

Ulva spo, oahu (no $\alpha$-carotene) 


\section{CHLOROPHYTA $($ cont.)}

\section{VOLVOCALES}

\section{CHLAMYDOMONADACEAE}

Chlanydomonas agloeformis, Cultured (much $\alpha$-caroteno)

\section{POLYBLEPHARIDACEAE}

Dunaliella salina, Cultured (trace $\alpha$-carotene)

\section{ZYGNEMATALES}

\section{ZYGNEMATACEAE}

Mesotanium aldariorum, Cultured (some $\alpha$-carotene)

Spirogyra sp., Stanford (trace $\alpha$-carotene)

Spirogyra sp., Stanford (trace $\alpha$-carotene) 
APPENDIX V

Siphonalean Green Algao (Siphonales) That Yielded the Same Pigments Found in Leaves Plus Siphonaxanthin and Siphonein as Shown in Figure II, 3.

(In all these plants except Dichotomosiphon, the $\alpha$-carotene was several times more abundant that the $\beta$-carotene)

CHLOROPHYTA

(CHLOROPHYCEAE)

SIPHONALES

\section{BRYOPSIDACEAE}

Bryopsis spo, Oahu

Bryopsis sp., Oahu

Bryopsis corticulans, Pacific Grove

Bryopsis hypnoldes, Half Moon Bay

\section{CAULERPACEAE}

Caulerpa lentillifera, Oahu

Caulerpa prolifera, Puerto Rico

Caulerpa racemosa, Oahu, Puerto Rico

Caulerpa racemosa, var。 macrophysa, Oahu

Caulerpa racemosa, var。peltata, Oahu

Caulerpa racemosa, var. turbinata, Oahu

Caulerpa serrulata, var. typica, Oahu

Caulerpa sertularioides, Oahu 


\section{CHLOROPHYTA (cont.)}

\section{(CHLOROPHYCEAE)}

\section{SIPHONALES}

\section{CODI ACEAE}

Codium coronatum, Oahu

Codium fragile, Monterey

Codium Muelleri, Oahu

Halimeda Opuntia, Puerto Rico

Halimedia Tuna, Oahu

Penicillus capitatus, Puerto Rico

Udotea Flabellum, Puerto Rico

\section{DICHOTOMOSIPHONACEAE}

Dichotomosiphon tuberosus, Lake Michigan

\section{HALICYSTIDACEAE}

Derbesia Lamourouxii, Naples, Italy

Derbesia vaucheriaeformis, Beaufort, North Carolina

Halicystis ovalis, Pacific Grove

\section{UNCLASSIFIED}

Unidentified, Palo Alto Yacht Harbor 
APPENDIX VI

"Golden" Algae That Yielded the Pigments Illustrated by Figure III,3.

\author{
CHRYSOPHYTA \\ $=$ \\ (XANTHOPHYCEAE, HETEROKONTAE) \\ HETEROCOCCALES
}

PLEUROCHLORIDACEAE

Polyedriella helvetica, Cultured

Vischeria stellata, Cultured

HETEROSIPHONALES

VAUCHERTACEAE

Vaucheria geminata, Stanford

Vaucheria hamata, On mud at Felt Lake, Stanford

Vaucheria sessilis, var. clavata, San Francisquito Creak, Stanford

Veucheria spo, Stanford

Vaucheria spo, Oregon

\title{
HETEROTRTCHALES
}

MONOCILIACEAE

Monocilia (Heterocoocus chodatii), Cultured

TRI BONEMATACEAE

Heterothrix debilis, Cultured

Tribonema bombycinum, Stanford

Tribonema minus, Stanford

Tribonema spo, Cultured 
APPENDIX VII

Brown Algae That Yielded the Pigments Illustrated in Figure III,7.

\section{PHEOPHYTA}

(PHEOPHYCEAE)

CHORDARI ALES

\section{CHORDARI ACEAE}

Haplogloia Andersonii, Half Moon Bay

CORYNOPHLOCACEAE

Petrospongium rugosum, Pebble Beach

DICTYOTALES

DICTYOTACEAE

Dictyota sp., Dahu

Padina sp., (Paronia?), Oahu

\section{ECTOCARPALES}

\section{ASPEROCOCCACEAE}

Colpomenia sinuosa, Oahu

\section{HETEROCHORDART ACEAE}

Heterochordaria abietina, Half Moon Bay 
PHEOPHYTA (cont.)

\section{FUCALES}

FUCACEAE

Fuous furcatus, Half Moon Bay

Hesperophycus Harveyanus, Half Moon Bay

Pelvetiopsis Iimitata, Half Moon Bay

Turbinaria ornata, Oahu

\section{SARGASSACEAE}

Cystoseria Osmundacea, Half Moon Bay

Sargassum echinocarpum, Oahu (From intertidal zone and from water 100 feet deep.)

Sergassum polyphyllum, Oahu

\section{LAMINARIALES}

\section{ALARACEAE}

Egregia Menziesii, Half Moon Bay

Pterygophora californica, Half Moon Bay

\section{LAMINARI ACEAE}

Laminaria Andersoni1, Half Moon Bay

Macrocystis integrifolia, Half Moon Bay

Postelsia palmaeformis, Half Moon Bay 


\section{APPENDIX VIII}

Red Algae That Yielded the Pigments Illustrated in Figure III,9.

(Variations of the pigment system, particularly the presence or absence of chlorophyll $d$, zeaxanthin and $\alpha$-carotene, are noted in the tabulation). (Principal pigments: chlorophyll a, lutein or zeaxanthin, $\alpha$-carotene or $\beta$-carotene and $r$-phycoerythrin).

\section{RHODOPHYTA}

\section{(RHODOPHYCEAE)}

BANGIALES

\section{BANGIACEAE}

Porphyra naiadum, Half Moon Bay (no $\alpha$-carotene, some zeaxanthin, no ohlorophyll d)

Porphyra perforata, Half Moon Bay (some $\alpha$-carotene, some zeaxanthin, no chlorophyll d)

PROTOFLORIDEAE

Porphyridium cruentum, Stanford (no $\alpha$-carotene, mostly zeaxanthin, no ohlorophyll d)

\section{CERAMIALES}

\section{CERAMTACEAE}

Callithamnion califormianum, Half Moon Bay (more $\alpha$-carotene than

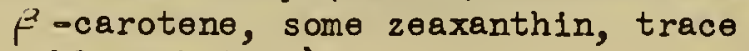
chlorophyli d)

Callithamion Pikeanum, Half Moon Bay (some $\alpha$-carotene, some zeaxanthin, no chlorophyll d)

Centroceras clavatum, Half Moon Bay, Oahu (some $\alpha$-carotene, trace zeaxanthin, trace chlorophyll d) 
RHODOPHYTA (conto)

\section{CERAMI ALES}

CERAMI ACEAE (cont。)

Ceramium Eatonianum, Half Moon Bay (some $\alpha$-carotene, trace zeaxanthin, no chlorophyll d)

Griffithsia pacifica, Half Moon Bay (more $\alpha$-carotene than $\beta$-carotene, some zeaxanthin, some chlorophyll d)

Microcladia borealis, Half Moon Bay (trace $\alpha$-carotene, some zeaxanthin, no chlorophyll d)

Microcladia Coulteri, Half Moon Bay (some $\alpha$-carotene, some zeaxanthin, no chlorophyll d)

Ptilota densa, Half Moon Bay, (more $\alpha$-carotene than $\beta$-carotene, some zeaxanthin, no ohlorophyll d)

Spermothamnion Snyderae, Half Moon Bay (more $\alpha$-carotene than $\beta$ carotene, some zeaxanthin, some chlorophyll d)

\section{DELESSERI ACEAE}

Botryoglossum Farlowianum, Half Moon Bay (mostly $\alpha$-carotene, trace zeaxanthin, no chlorophyll d)

Cryptopleura lobulifera, Half Moon Bay, (mostly o-carotene, trace zeaxanthin, trace chlorophyll d)

Cryptopleura Violacea, Half Moon Bay (mostly $\alpha$-carotene, trace zeaxanthin, trace chlorophyll d)

Hymenena flabelligera, Half Moon Bay (mostly $\alpha$-carotene, some zeaxanthin, trace chlorophyll d)

Hymenena Kylinii, Half Moon Bay (mostly obcarotene, some zeaxanthin, trace chlorophyll d)

Hymenena multiloba, Half Moon Bay (mostly $\alpha$-carotene, trace zeaxanthin, trace chlorophyll d)

Nienburgia Andersoniana, Half Moon Bay (mostly $\alpha$-carotene, some zeaxanthin, traco chlorophyll d)

Polyneura latissima, Half Moon Bay (mostly $\alpha$-carotene, some zeaxanthin, no chlorophyll d) 
RHODOPHYTA $($ cont.)

CERAMIALES

RHODOMELACEAE

Laurencia sp. Oahu (no $\alpha$-carotene, as much zeaxanthin as lutein, trace chlorophyll d)

Laurencia nidifica, Oahu (no $\alpha$-carotene, mostly zeaxanthin, no chlorophyll d)

Laurencia pacifica, Pebble Beach (no $\alpha$-carotene, much more zeaxanthin than lutein, trace chlorophyll d)

Laurencia spectabilis, Half Moon Bay (trace $\alpha$-carotene, much more zeaxanthin than lutein, no chlorophyll d)

Lophosiphonia Villum, Half Moon Bay! ( some $\alpha$-carotene, much more zeaxanthin than lutein, no chlorophyll d)

Odonthalia flocoosa, Half Moon Bay (trace $\alpha$-carotene, much more zeaxanthin than lutein, no chlorophyll d)

Polysiphonia aquamara, Oahu (no $\alpha$-carotene, mostly zeaxanthin, no chlorophyll d)

Polysiphonia californica, Falf Moon Bay (no $\alpha$-carotene, much more zeaxanthin than lutein, no chlorophyll d)

Polysiphonia Collinsii, Half Moon Bay (no $\alpha$-carotene, zeaxanthin but no lutein, no chlorophyll d)

Pterosiphonia Baileyi, Half Moon Bay (no $\alpha$-carotene, some zeaxanthin, no chlorophyll d)

Pterosiphonia bipinnata, Half Moon Bay (no $\alpha$-carotene, more zeaxanthin than lutein, trace chlorophyll d)

Pterosiphonia dendroidea, Half Moon Bay (some $\alpha$-carotene, as much zeaxanthin as lutein, trace chlorophyll d)

Rhodomela Larix, Half Moon Bay (no $\alpha$-carotene, more zeaxanthin than lutein, trace chlorophyll d)

Ricardia saccata, Pebble Beach (no $\alpha$-carotene, mostly zeaxanthin, trace chlorophyll d) 


\section{RHODOPHYTA (conto)}

\section{CERAMIALES}

\section{CALL YMENI ACEAE}

Callophyllis marginifructa,

Half Moon Bay (much more $\alpha$-carotene than $\beta$-carotene, trace zeaxanthin, no chlorophyll d)

\section{CRYPTONEMIALES}

\section{CORALLINACEAE}

Bossea corymbifera, Half Moon Bay (some $\alpha$-oarotene, some zeaxanthin, trace chlorophyll d)

Bossea Orbigniana, Half Moon Bay (some $\alpha$-carotene, some zeaxanthin, trace ohlorophyll d)

Bossea plumosa, Half Moon Bay (some $\alpha-c a r o t e n \theta$, some zeaxanthin, trace ohlorophyll d)

Calliarthron cheilosporioides, Half Moon Bay (no $\alpha$-carotene, much zeaxanthin, no ohlorophyll d)

Calliarthron Setchelliae, Half Moon Bay (no $\alpha$-carotene, muoh zeaxanthin, no chlorophyll d)

Corallina chilensis, Half Moon Bay (trace $\alpha$ carotene, some zeaxanthin, some chlorophyll d)

Corallina gracilis, Half Moon Bay (some $\alpha$-carotene, some zeaxanthin, some chlorophyll d)

Lithophyllum neofarlowii, Half Moon Bay (some $\alpha$-carotene, some zeaxanthin, no chlorophyll d)

\section{DUMONTIACEAE}

Cryptosiphonia Woodii, Half Moon Bay (much $\alpha$-carotene, some zeaxanthin, trace chlorophyll d)

Farlowia compressa, Half Moon Bay (more $\alpha$-carotene than $\beta-c a r o t e n \theta$, some zeaxanthin, no chlorophyll d)

Farlowia mollis, Half Moon Bay (much $\alpha$ carotene, some zeaxanthin, no chlorophyll d) 


\section{RHODOPHYTA (conto)}

\section{CRYPTONEMI ALES}

\section{ENDOCLADIACEAE}

Endocladia muricata, Half Moon Bay (trace $\alpha$-carotene, some zeaxanthin, no chlorophyll d)

\section{GRATELOUPIACEAE}

Grateloupia californica, Half Moon Bay (much $\alpha$-carotene, some zeaxanthin, no chlorophyll d)

Grateloupia filicina, Oahu (some $\alpha$-carotene, some zeaxanthin, no chlorophyll d)

Grateloupia Setchellil, Half Moon Bay (mostly $\alpha$-carotene, some zeaxanthin, no chlorophyll d)

Prionitis Andersonii, Half Moon Bay (much $\alpha$-carotene, some zeaxanthin, trace chlorophyll d)

Prionitis australis, Half Moon Bay (mostly $\alpha$-carotene, some zeaxanthin, some chlorophyll d)

Prionitis lanceolata, Half Moon Bay (much $\alpha$-carotene, some zeaxanthin, trace chlorophyll d)

\section{GELIDI ALES}

\section{GELIDIACEAE}

Gelidium Coulteri, Half Moon Bay (some $\alpha$-carotene, some zeaxanthin, trace chlorophyll d)

\section{GI GARTINALES}

\section{GIGARTINACEAE}

Erythrophyllum delesserioides, Half Moon Bay (much $\alpha$-carotene, some zeaxanthin, no chlorophyll d) 
 \\ RHODOPHYTA (conto)}

GIGARTINALES

GIGARTINACEAE (conto)

Gigartina Agardhi, Half Moon Bay (some $\alpha$-carotene, trace zeaxanthin, some chlorophyll d)

Gigartina californica, Half Moon Bay (as much $\alpha$-carotene as $\beta$ carotene, trace zeaxanthin, no chlorophyll d)

Gigartina canaliculata, Half Moon Bay (some $\alpha$-carotene, some zeaxanthin, no chlorophyll d)

Gigartina corymbifera, Half Moon Bay (much $\alpha$-carotene, some zeaxanthin, no chlorophyll d)

Gigartina papillata, Half Moon Bay (some $\alpha$-carotene, some zeaxanthin, trace chlorophyll d)

Gigartina spinosa, Half Moon Bay (much more $\alpha-c a r o t e n e$ than $\beta$ carotene, some zeaxanthin, no ohlorophyll d)

Iridophycus flaccidum, Half Moon Bay (much $\alpha$-carotene, some zerxanthin, no chlorophyll d)

Irodophyous heterooarpum, Half Moon Bay (some $\alpha$-carotene, some zeaxanthin, trace chlorophyll d)

Rhodoglossum americanum, Half Moon Bay (more $\alpha$-carotene than $\beta$ carotene, some zeaxanthin, no chlorophyll d)

\section{GRACILARIACEAE}

Gracilaria Sjoestedtii,

Half Moon Bay, Pebble Beach (no $\alpha$-carotene, more zeaxanthin than lutein, trace chlorophyll d)

\section{PLOCAMIACEAE}

Plocamium pacifioum, Half Moon Bay (mostly $\alpha$ ocarotene, trace zeazanthin, trace chlorophyll d)

Plocamium violaceum, Half Moon Bay (mostly $\alpha$-carotene, some zeaxanthin, no chlorophyll d) 


\section{$\underline{\underline{\text { RHODOPHYTA }}}$ (cont.)}

GIGARTINALES

\section{SOLERIACEAE}

Agardhiella Coulteri, Half Moon Bay (trace $\alpha$-carotene, trace zeaxanthin, no chlorophyll d)

\section{NEMALIONES}

\section{CHAETANGIACEAE}

Gloiophloea confusa, Half Moon Bay (more $\alpha$-arotene than $\beta$-carotene, some zeaxanthin, no chlorophyll d)

\section{CHANTRANSIACEAE}

Rhodochorton Rothii, Half Moon Bay, Pebble Beach (much $\alpha$-carotene, some zeaxanthin, much chlorophyll $\mathrm{d}$, one third of the chlorophyll)

\section{HELMINTHOCLADI ACEAE}

Cumagloia Andersonit, Pebble Beach (some $\alpha$-carotene, trace zearanthin, trace chlorophyll d)

Galaxaura sp., Oahu (some $\alpha$-carotene, trace zeaxanthin, no chlorophyll d)

\section{RHODYMENIALES}

\section{CHAMPIACEAE} Gastroolonium Coulteri, $\begin{aligned} & \text { Half Moon Bay (some } \alpha \text {-carotene, some } \\ & \text { zeaxanthin, no chlorophyll d) }\end{aligned}$

RHODYMENI ACEAE

Botryocladia Skottsbergii, Oahu (mostly $\alpha$-carotene, trace zeaxanthin, no chlorophyll d) 


\section{RHODOPHYTA (cont.)}

\section{RHODYMENIALES}

RHODYMENI ACEAE

Fauchia media, Half Moon Bay (mostly $\alpha$-carotene, trace zeaxanthin, no chlorophyll d)

Halosaccion glandiforme, Half Moon Bay (trace $\alpha$-carotene, zeaxanthin, violaxanthin, and chlorophyll d) 


\section{APPENDIX IX}

Blue-Green Algae That Yielded the Pigments Illustrated by Figure III, 10 。

(All these species contained the waterosoluble, blue cophycocyanin in addition to the carotenoid pigments and chlorophyll a. The carotenes were primarily $\beta$-carotene)。

CYANOPHYTA

( $\overline{\text { MYXOPHYCEAE) }}$

CHROOCOCCALES

\section{CHROOCOCCACEAE}

Chroococcus spo, Cultured

\section{HORMOGONALES}

NOSTOCACEAE

Anabena spo, Cultured

Hormothamnion enteromorphoides, Oahu

Nostoc muscorum, Cultured

\section{OSCILLATORTACEAE}

Hydrocoleum spo, Oahu

Phormidium autumnale, Cultured 



